BIBLIOTECA INSTITUTO DE QUIMICA Universidade de São Paulo t. 19.821

Universidade de São Paulo

Instituto de Química

\title{
Estudo do Comportamento Reológico de Sistemas LiquidoCristalinos Liotrópicos Colestéricos à base de Cloreto de Decilamônio
}

Edgard Gonçalves Fernandes Jr.

Dissertação de Mestrado

Orientadora: Profa. Dra. Maria Regina Alcantara

São Paulo

29 de novembro de 2001 


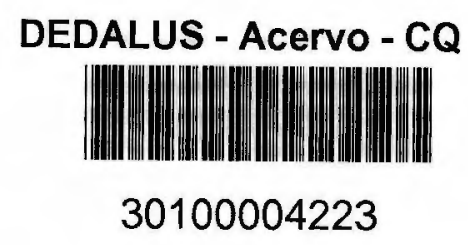

Ficha Catalográfica

Elaborada pela Divisão de Biblioteca e Documentação do Conjunto das Químicas da USP.

\section{Fernandes Júnior, Edgard Gonçalves}

F363e Estudo do comportamento reológico de sistemas liquidocristalinos liotrópicos colestéricos à base de cloreto de decilamônio / Edgard Gonçalves Fernandes Júnior. -- São Paulo, 2001. $122 \mathrm{p}$.

Dissertação (mestrado) - Instituto de Química da Universidade de São Paulo. Departamento de Química Fundamental.

Orientador: Alcantara, Maria Regina

1. Química coloidal 2. Reologia : Mecânica : Física I. T. II. Alcantara, Maria Regina, orientador. 


\section{"Estudo do Comportamento Reológico de Sistemas Liquidocristalinos Liotrópicos Colestéricos à Base de Cloreto de Decilamônio"}

\section{EDGARD GONÇALVES FERNANDES JUNIOR}

Dissertação de Mestrado submetida ao Instituto de Química da Universidade de São Paulo como parte dos requisitos necessários à obtenção do 8 rau de Mestre em Ciências - Área: Físico-Química.

Aprovado por:

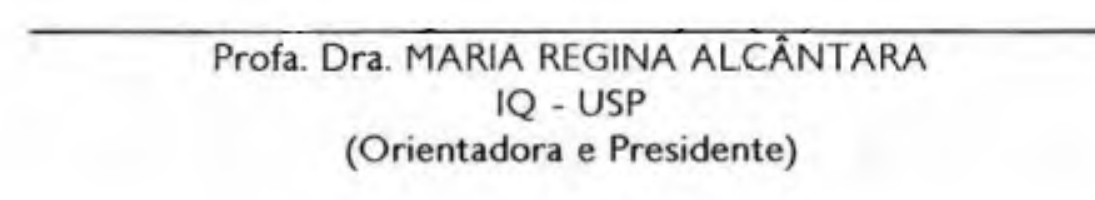

\begin{tabular}{c}
\hline $\begin{array}{c}\text { Prof. Dr. FRANK HERBERT QUINA } \\
\text { IQ - USP }\end{array}$ \\
\hline Profa. Dra. ROSÂNGELA ITRI \\
IF - USP
\end{tabular}

SÃO PAULO

29 DE NOVEMBRO 2001. 
Ao meu pai, Edgard G. Fernandes, por todo apoio e força. À minha mãe, Maria Tereza de C. B. Fernandes, por todo carinho e amor. E principalmente a Renata Rapuano, pelo companheirismo e amor. Sem vocês eu não teria chegado até aqui. 


\section{AGRADECIMENTOS}

À Dra. Maria Regina Alcântara, pela orientação maravilhosa durante todo o trabalho e por ter me ensinado a como ser um pesquisador.

Ao Prof. Dr. Hugo Gallardo pela síntese do cloreto de decilamônio.

Ao Luis Carlos F. Dias, pela amizade e pelo auxilio no início de todo esse trabalho.

A todos os que passaram e ainda estão no grupo, André, Maurício, Renata e Leonardo, que de alguma forma ajudaram nesse projeto.

À Marcela Gerardo Ribeiro, pela amizade e força durante todo essa etapa.

Ao Paulo Firmino Moreira Jr., pelo apoio e auxílio com os computadores.

Aos funcionários e técnicos do IQUSP, e em especial ao Nivaldo e Paulinho, pelos vários favores prestados.

À FAPESP e o CNPq pelo apoio financeiro. 
$\begin{array}{ll}\text { Resumo } & 02\end{array}$

$\begin{array}{ll}\text { Abstract } & 05\end{array}$

I - Introdução $\quad 08$

II - Cristal Líquido $\quad 12$

II.1 -Cristal Líquido Termotrópico 12

II.1.1 - Classificação dos Cristais Líquidos Termotrópicos 13

$\begin{array}{ll}\text { II.1.1.1 - Nemático } & 13\end{array}$

$\begin{array}{ll}\text { II.1.1.2 - Esmético } & 13\end{array}$

$\begin{array}{ll}\text { II.1.1.3 - Colestérico } & 14\end{array}$

II.2 - Novos Cristais Líquidos 15

II.2.1 - Cristal Líquido Polimérico 16

II.2.2 - Cristal Líquido Disperso em Polímero $\quad 18$

II.2.3 - Cristal Liquido Ferroelétrico $\quad 21$

II.2.4 - Cristal Líquido Discótico $\quad 24$

II.2.5 - Cristal Liquido tipo Banana 26

II. 3 - Cristal Líquido Liotrópico $\quad 27$

II.3.1 - Cristal Líquido Liotrópico Nemático $\quad 28$

II.3.2 - Cristal Liquido Liotrópico Colestérico 29

III - Reologia

III. 1 - Métodos Rotacionais

III. 2 - Métodos Oscilatórios 41

III.2.1 - Creep e Recuperação 43

III.2.2 - Regime Dinâmico de Cisalhamento de Pequena Amplitude 48

IV - Parte Experimental $\quad 51$

IV.1 - Ensaios Rotacionais 51

IV.1.1 - Caracterização do Fluido em Função da Taxa de Cisalhamento 51

IV.1.2 - Caracterização do Fluido em Função do Tempo de Cisalhamento 53

IV.1.3 - Determinação da Energia de Ativação de Fluxo 55

IV.2 - Ensaios Oscilatórios $\quad 58$

IV.2.1 - Determinação da Região de Viscoelasticidade Linear 61

IV.2.2 - Creep e Recuperação $\quad 61$

IV.2.3 - Determinação dos Módulos G' e G" em Função da Freqüência 62

V - Resultados e Discussões $\quad 63$

V.1 Ensaios Rotacionais $\quad 63$

V.1.1 - Caracterização do Fluido em Função da Taxa de Cisalhamento 63

V.1.2 - Caracterização do Fluido em Função do Tempo de Cisalhamento $\quad 73$

V.1.3 - Determinação da Energia de Ativação de Fluxo 86

$\begin{array}{ll}\text { V.2 - Ensaios Oscilatórios } & 90\end{array}$

V.2.1 - Determinação da Região de Viscoelasticidade Linear 90

V.2.2 - Creep e Recuperação 93

V.2.3 - Determinação dos Módulos G' e G' em Função da Freqüência 103

VI - Conclusões $\quad 111$

VII - Referências Bibliográficas $\quad 114$

VIII - Curriculum vitae $\quad 121$ 


\section{Resumo}

Esta dissertação apresenta os resultados obtidos na caracterização reológica, utilizando ensaios rotacionais e oscilatórios, de sistemas de cristais líquidos liotrópicos nemáticos e colestéricos à base de cloreto de decilamônio (CDA). Os sistemas colestéricos foram obtidos pela adição às matrizes nemáticas de indutores quirais hidrofóbico (Colesterol) ou hidrofilico (D-(+)Manose) que conferem à estrutura liquidocristalina um arranjo helicoidal. Procuramos analisar os efeitos da concentração do indutor no comportamento reológico, bem como da sua natureza e da quantidade de solvente presentes nestes sistemas mesomórficos.

Os ensaios rotacionais foram realizados utilizando-se taxas de cisalhamento constante e variadas. Os resultados obtidos mostraram que ocorre uma mudança no comportamento reológico dependente da natureza do indutor quiral. Fases com indutor hidrofóbico têm sua viscosidade diminuída com a adição de colesterol, enquanto as fases com D-(+)-Manose têm sua viscosidade aumentada.

Também foram observadas mudanças no comportamento reológico segundo a quantidade de solvente presente na mesofase.

Para sistemas com colesterol e com maior quantidade de água em sua composição, a viscosidade aumenta ao longo do tempo até atingir um valor máximo, seguido de uma diminuição. Este comportamento deve indicar que nestes sistemas, as fases devem primeiro sofrer uma deformação atingindo um máximo de tensão, a partir da qual começa a ocorrer uma melhor acomodação da sua estrutura, provocando a diminuição da viscosidade.

Nos sistemas com indutor hidrofóbico e com menor quantidade de solvente, a viscosidade diminui até atingir um valor mínimo. Pode-se observar 
que quanto maior for a concentração de indutor, maior é o tempo necessário para se atingir este mínimo. A partir deste ponto há um aumento da viscosidade até um valor constante. Isto sugere a ocorrência de uma quebra da estrutura do sistema, seguida por sua reorientação por fluxo.

Em sistemas em que o indutor é D-(+)-Manose, o comportamento reológico observado é semelhante tanto em fases com maior ou menor quantidade de solvente, ou seja, aumento da viscosidade até um valor máximo, seguido pela sua diminuição. A diferença observada é que em sistemas com maior quantidade de solvente, o máximo é atingido mais cedo. $\mathrm{O}$ aumento da viscosidade deve caracterizar uma deformação da estrutura que após atingir uma tensão máxima, começa a se orientar em uma direção preferencial, causando a diminuição da viscosidade sem quebra do edificio colestérico.

A determinação da entalpia livre de ativação de fluxo $\left(\Delta \mathrm{H}^{*}\right)$ mostra que para os sistemas em que o colesterol foi usado como indutor, a energia diminui com o aumento da concentração de indutor, quando D-(+)-Manose é utilizado, a energia aumenta. No caso do indutor hidrofóbico, a força quiral auxiliaria na orientação por fluxo das micelas, pois ao se movimentar uma micela, as outras seriam arrastadas pelas forças elásticas, diminuindo a entalpia de ativação de fluxo. Quando o indutor utilizado é hidrofilico, a entalpia de ativação aumenta, possivelmente devido à natureza do indutor, que possui uma interação maior com o solvente, agindo como uma barreira para a movimentação e orientação das micelas por fluxo.

Os ensaios oscilatórios, por sua vez, mostram que a capacidade de armazenamento e devolução de energia, determinada pelo valor do módulo de armazenamento $\left(G^{\prime}\right)$ é maior que capacidade de dissipação desta por calor ou difusão das partículas, obtida pelo módulo de perda (G”). Ambos os módulos apresentam uma dependência em relação quantidade de indutor, natureza de 
indutor e quantidade de água disponível, porém não foi possível se determinar nenhuma relação direta entre esses fatores.

Esse sistema liotrópico pode ser descrito pelo modelo de Burger, contanto que seja levado em consideração que a componente elástica do elemento de Maxwell possua uma dependência temporal. Esse efeito provavelmente é devido à própria inércia do sistema. 


\section{Abstract}

This dissertation shows the results obtained on the rheological characterization, using rotation and oscillatory essays, for nematics and cholesterics lyotropic liquid crystals based on decylammonium chloride (CDA). The cholesteric systems were obtained adding chiral inductors, hydrophobic (Cholesterol) or hydrophilic (D-(+)-Mannose) to nematic matrixes, inducing a helical arrangement on the liquid crystalline structure. The effect of the inductor concentration besides of its nature and the amount of solvent in these mesomorphic systems were correlated to the rheological properties obtained.

The rotation essays were done using constant and varied shear rates. The obtained results showed a change in the rheological behavior dependent of the chiral inductor nature. Phases with hydrophobic inductor presented viscosity decreased with the increase of cholesterol concentration, while the increase of D-(+)-Mannose concentration leads to the viscosity increase.

Changes in the rheological behavior were also observed according to the amount of solvent present on the phase.

For systems with cholesterol and larger amount of water, the viscosity increases along the time until reaching a maximum value, followed by a decrease. This behavior should indicate that in these systems, the phases should suffer some kind of deformation until reaching a maximum of tension. After that, an accommodation process of the structure causes the viscosity decrease.

For the systems with hydrophobic inductor and with smaller amount of solvent, the viscosity decreases until reach a minimum value, that is reached later as larger it is the inductor concentration. After that, there is an increase of 
the viscosity until a constant value be obtained. It suggests the occurrence of a breakdown of the structure, proceeded by its reorientation by flow.

For the systems with D-(+)-Mannose, the rheological behavior observed is quite similar for phases with larger or smaller amount of solvent, i.e., increase of the viscosity to a maximum value, followed proceeded by its decrease. The difference is that in systems with larger amount of solvent, the maximum is reached earlier. The increase of the viscosity should characterize a deformation of the structure that after reaching a maximum tension, it will be orientated in a preferential direction, causing the decrease of the viscosity without break of the cholesteric building.

The flow activation free enthalpy $\left(\Delta H^{\#}\right)$ determination shows a decrease of energy value for increase of inductor concentration in lyotropic cholesteric liquid crystal that used cholesterol as inductor. When D-(+)-Mannose was used, the flow activation free enthalpy value increases. In the systems that hydrophobic inductor is used, the chiral forces should help in micelles flow orientation process, seemingly, after the movement of a micelle, the others would be dragged by the elastic forces, decreasing the flow activation enthalpy. When it is used a hydrophilic inductor, flow activation enthalpy increases with increases of inductor concentration, probably because the inductor nature that has a greater interaction with the solvent, acting as a barrier against the micelles flow orientation.

The oscillatory essays show that the storage energy capacity, determined by the value of the storage modulus $\left(G^{\prime}\right)$ is larger than heat or diffusion dissipation capacity of the particles, obtained by the loss modulus $\left(G^{\prime \prime}\right)$. Both modulus ( $G^{\prime}$ and $\left.G^{\prime \prime}\right)$ decrease for the phases with smaller amount of available water and stay constant for the systems with larger amount of water. 
The lyotropic mesophase studied can be described by a Burger model modified by taken into account a temporary dependence to the elastic Maxwell component. This effect should be probably due to the inertia of the system. 


\section{I - Introdução}

O estudo de cristal líquido liotrópico colestérico iniciou-se no IQ-USP, com o grupo do professor José Atílio Vanin na década de 80 , utilizando anfifilicos quirais e uma grande variedade de solutos opticamente ativos. A preocupação foi centrada no estudo das forças de interação responsáveis pela existência do edifício liotrópico e de sua colesterização. Este problema tem se mostrado bastante complexo, pois vários mecanismos diferentes estão envolvidos, dependendo do tipo de fase e da natureza de seus componentes (Alcantara \& Vanin, 1984a; Alcantara \& Vanin 1984b; Aido et al. 1990; Aido et al., 1991).

A necessidade de se procurar novas técnicas que pudessem contribuir para o esclarecimento das forças que atuam nestes colóides de associação nos levou ao estudo da Reologia.

A viscosidade de um material é um parâmetro versátil para esclarecer o comportamento de sistemas multicomponentes. Uma vez que ela se relaciona à sua resistência ao fluxo devido às interações entre suas partículas constituintes, sendo também sensível a parâmetros como densidade, estabilidade, massa molecular e dimensões das partículas presentes (Leong \& Boger, 1990; Hunter, 1993; Vinagradov \& Malkin, 1980), ela se torna um parâmetro versátil para o estudo de fluidos complexos. Nos últimos anos as propriedades reológicas têm sido utilizadas por vários grupos (Richetering et al., 1994; Laüger et al., 1996; Alcantara \& Vanin, 1995; Németh et al., 1998; Porte et al., 1966; Hantzschel et al., 1999; Moltalvo et al., 1998; Lyou \& Kim, 1997; Prevysh et al., 1997; Linemann et al., 1995; Walter \& Wagner, 1994; Berjano, et al., 1993; Takabe et al., 1990; Asada et al., 1980; Chen \& Koch, 1997; Rey, 1996; Smith et al., 2001; Trukhin et al., 2001; Mukherjee et al., 
2001; Patakfalvi \& Dékány, 2001; Nettesheim et al., 2001; Maffettone et al., 2001), com objetivo de se obter informações sobre o arranjo espacial das unidades constituintes do sistema e suas variações nas regiões de transição de fase (Richetering et al., 1994; Laüger et al., 1996; Alcantara \& Vanin, 1995).

Os estudos teóricos sobre a viscosidade em cristais líquidos se iniciaram com Ericksen (Ericksen, 1968) e Leslie (Leslie, 1968; Leslie, 1979) que propuseram a descrição do fluxo em nemáticos e colestéricos a partir da teoria do contínuo (Leslie, 1979). Outros autores também abordaram os efeitos dinâmicos em cristal líquido (DeGennes \& Prost, 1993), mas todos eles se limitaram às geometrias de fluxos entre placas paralelas, entre cilindros coaxiais ou em capilares de seção transversal circular.

As dificuldades de abordagem teórica são facilmente avaliáveis quando se leva em conta que a orientação do diretor não é conhecida no instante da medida. Como muito poucos trabalhos (Richetering et al., 1994; Laüger et al., 1996; Peuvrel \& Navard, 1990) realizam observações simultâneas sob luz polarizada, não são conhecidos os gradientes de orientação do diretor e conseqüentemente suas eventuais contribuições dinâmicas. Este problema é particularmente sério se o volume da amostra for grande. A isto se somam os efeitos orientacionais que podem ser causados pelas paredes do viscosímetro (Leslie, 1968) ou pela presença de disclinações (DeGennes \& Prost, 1993).

Esforços têm sido desenvolvidos no sentido de se determinar o arranjo da estrutura liquido cristalina acoplando a microscopia óptica sob luz polarizada com técnicas reológicas (Richetering et al., 1994; Laüger et al., 1996).

A modelagem do comportamento reológico de sistemas de cristal líquido colestéricos tem fornecido importante informações a respeito do posicionamento e do comportamento da hélice sob fluxo. Rey (Rey, 1996 a, 1996 b; Rey, 2000) determinou que se a hélice do edifício colestérico estiver 
alinhada na direção paralela ao fluxo, ela irá sofrer um desenrolamento e manter uma configuração semelhante ao nemático.

Mudanças cooperativas de conformação de camadas flexíveis foram associadas ao fluxo imposto por cisalhamento em sistemas de cristal líquido liotrópicos (Németh et al., 1998). Também foram obtidos resultados que mostraram que em baixa taxa de cisalhamento as lamelas se orientam paralelamente ao fluxo, enquanto em alta taxa de cisalhamento a orientação se torna perpendicular ao fluxo (Penfold et al., 1994).

A maioria dos estudos de sistemas liotrópicos envolve fases lamelares (Laüger et al, 1996; Gallegos I., 1991; Franco et al., 1995) ou micelas "wormlike"(Shikata et al., 1987; Shikata et al., 1988; Shikata et al., 1989; Soltero et al., 1995; Kern, et al., 1994), micelas que simulam sistemas de polímeros vivos. Existem poucos estudos desenvolvidos para sistemas liotrópicos de micelas disco e cilindro e de modo geral, envolvem mesofases obtidas a partir dos anfifilicos decilsulfato de sódio (Gallegos et al., 1991; Franco et al., 1995) e laurato de potássio (Franco et al, 1995). Observações com temperatura variável mostraram variações definidas nos pontos correspondentes às transições de fase (Shikata et al., 1987). Resultados publicados por nosso laboratório mostraram que sistemas ternários à base de decilsulfato de sódio/sulfato de sódio e água se caracterizam por um comportamento pseudoplástico reopéxico enquanto que sistemas quaternários (decilsulfato de sódio/sulfato de sódio/decanol/água) apresentam comportamento pseudoplástico tixotrópico (Alcantara \& Vanin, 1995). Foi possivel verificar que o processo de colesterização, em sistemas com micelas cilíndricas, conduz a uma diminuição do índice de fluidez e a um aumento do índice de consistência, evidenciando que as forças elásticas originadas pelo arranjo colestérico tornam o sistema mais resistente a deformações (Alcantara \& Dias, 1998). A ocorrência de fratura de borda em sistema nemático à base 
de laurato de potássio é clara indicação da existência de fortes contribuições elásticas que deveriam ser melhores avaliadas (Alcantara \& Moura, 2000).

Como conseqüência destes estudos, a presente dissertação apresenta os resultados reológicos obtidos para sistemas liquidocristalinos liotrópicos nemáticos e colestéricos à base de cloreto de decilamônio.

O comportamento reológico observado para estes sistemas é estudado em função do processo de colesterização utilizando diferentes indutores assim como diferentes composições.

Esta dissertação estará desenvolvida da seguinte maneira: no Capítulo I é apresentado um breve histórico do campo de cristais líquidos, além dos tipos existentes e sua classificação. No Capítulo II se encontra uma introdução à técnica de Reologia. No Capítulo III está apresentada a parte experimental, onde se encontram os componentes e as composições utilizadas, bem como os procedimentos experimentais. No Capítulo IV, estão os resultados obtidos e as discussões. No Capítulo V são apresentadas as conclusões e por fim no Capítulo VI as referências bibliográficas. 


\section{II. - Cristal Líquido}

Em 1888, o botânico austríaco Reinitzer, ao estudar o ponto de fusão do acetato e benzoato de colesterila, observou que ao se aquecer essas substâncias, elas apresentavam turbidez assim que passavam para fase líquida e com o aumento da temperatura, o líquido passava a ser um líquido límpido. Ele definiu essa faixa, em que o composto apesar de se encontrar na fase líquida possuía algumas características de um sólido, como cristal líquido.

Desde então muito tem sido descoberto sobre esses sistemas e suas características, mas o grande desenvolvimento se deu nas últimas duas décadas, quando foram descobertos outros tipos de cristal líquido, como os poliméricos, os ferronemáticos, os cristais líquidos dispersos em polímero (PDLCs), os cristais líquidos bananas entre outros.

Os cristais líquidos podem ser formados de duas maneiras ou por ação da temperatura, onde eles recebem a denominação de cristal líquido termotrópico, ou por ação de solventes, denominados como liotrópicos.

Dentro desses sistemas, eles podem ser classificados como nemáticos, esméticos e colestéricos.

\section{II.1 -Cristal Líquido Termotrópico}

Os cristais líquidos termotrópicos são formados a partir da fusão de moléculas orgânicas de cadeia longa que possuem grupos polares ou iônicos (Chandrasekhar, 1994). Os primeiros trabalhos referentes a esses sistemas foram feitos por Friedel (Friedel, 1922; Friedel, 1926), onde ele sintetizou diversos compostos que formavam diferentes tipos de mesofases. 


\section{II.1.1. Classificação dos Cristais Líquidos Termotrópicos}

\section{II.1.1.1. Nemático.}

Os cristais líquidos nemáticos são sistemas que apresentam um alto grau de ordem orientacional, mas nenhuma ordem posicional (Chandrasekhar, 1994). Isso quer dizer que os constituintes dos sistemas (moléculas ou agregados) apresentam uma direção preferencial na qual eles se organizam, como pode ser observado na Figura II.1.

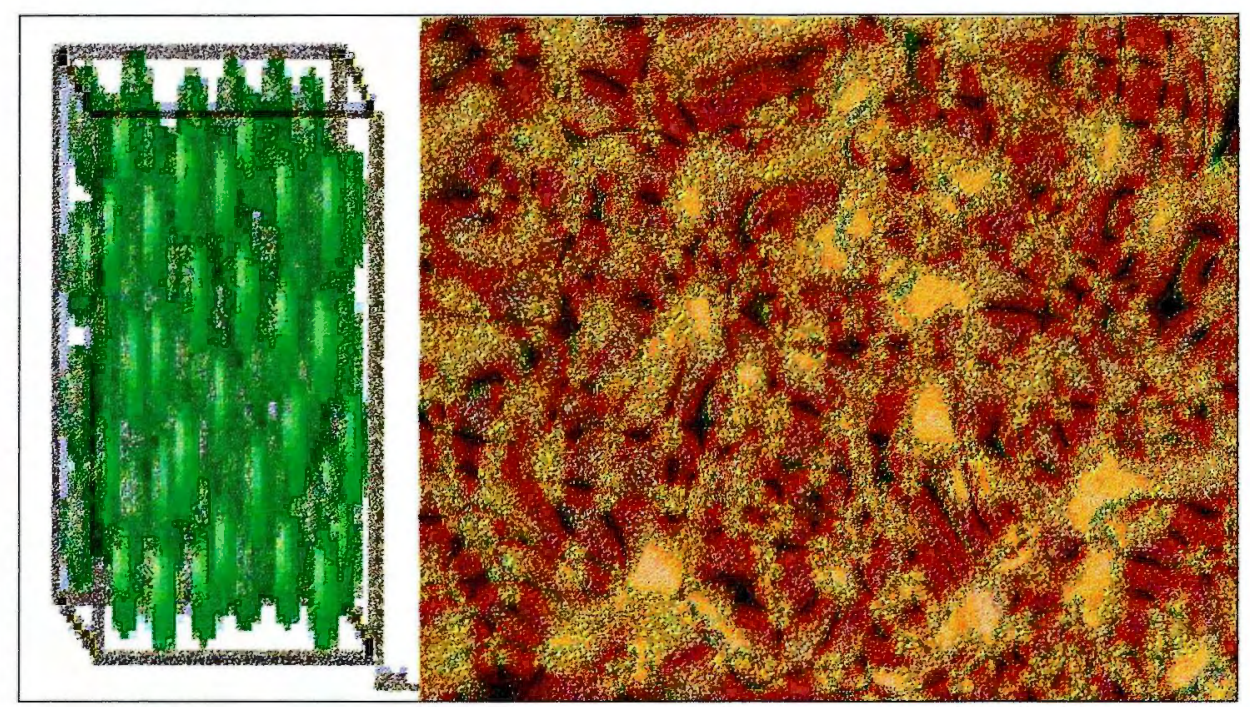

Figura II.1: Representação esquemática do sistema nemático (esquerda); textura típica de um cristal líquido nemático observado em um microscópio de luz polarizada (direita).

\section{II.1.1.2. Esmético.}

Os cristais líquidos esméticos apresentam tanto um arranjo orientacional quanto posicional (Chandrasekhar, 1994), formando estruturas lamelares (Figura II.2). 


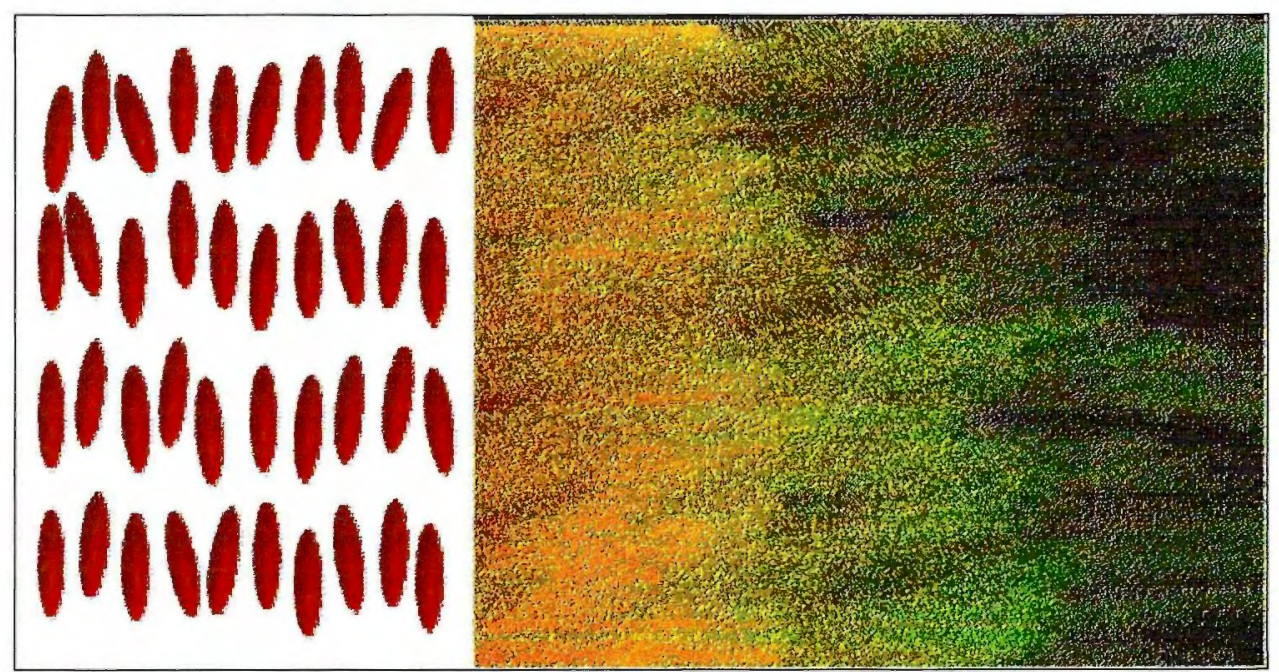

Figura II.2: Representação esquemática do sistema esmético (esquerda); textura típica de um cristal líquido nemático observado em um microscópio de luz polarizada (direita).

Existem vários tipos de estruturas esméticas descritas (Vries, 1951; Cano, 1960), sendo que a Esmética A, Esmética B, Esmética C e Esmética H são as principais. Elas se diferenciam pela disposição das moléculas nas camadas.

\section{II.1.1.3. Colestérico}

Os sistemas colestéricos, também chamados de nemáticos quirais, ou são formados no ponto de fusão de determinadas moléculas que possuem grupos opticamente ativos ou pela adição de compostos quirais a um sistema nemático. $\mathrm{O}$ centro quiral confere à estrutura do cristal líquido uma torção espontânea sobre um eixo normal à direção molecular (Chandrasekhar, 1994) (Figura II.3). 


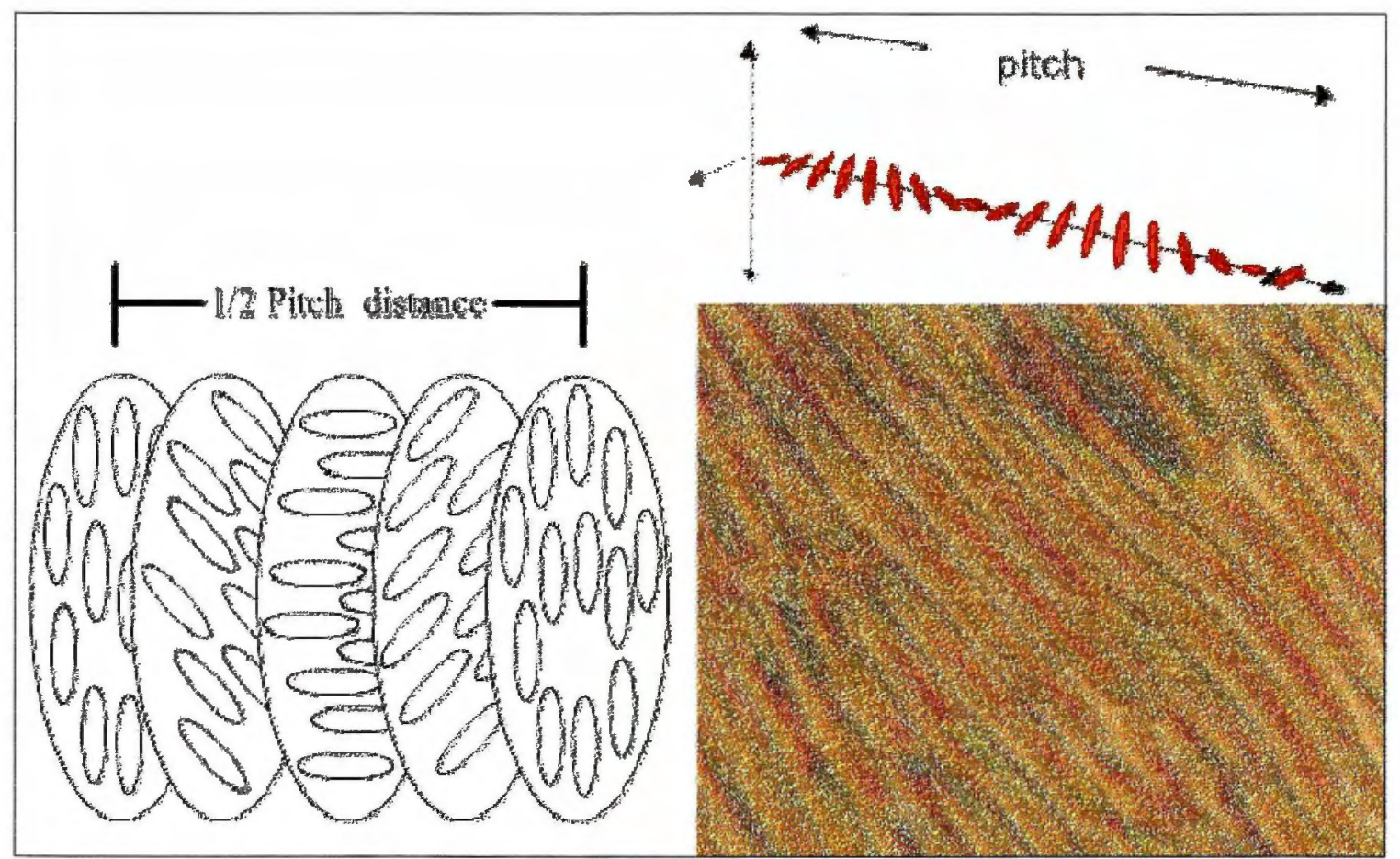

Figura II.3: Representação esquemática do sistema colestérico (esquerda); textura típica de um cristal líquido colestérico observado em um microscópio de luz polarizada (direita).

Essa estrutura primeiramente proposta por Friedel (Friedel, 1926), recebeu um suporte teórico com o trabalho de Vries (Vries, 1951) e mais tarde com os trabalhos de Cano e Chatelain (Cano \& Chatelain, 1960; Cano \& Chatelain, 1961; Cano \& Chatelain, 1964) tiveram sua estrutura experimentalmente confirmada.

\section{II.2. Novos Cristais Líquidos.}

A partir da década de 70 , começaram a surgir novas fases liquidocristalinas (Meyer et al., 1975; Clark \& Largewall, 1980; Chandani et al., 1989; Chandrasekhar et al., 1977) que, embora pertençam aos termotrópicos ou liotrópicos, devido ao seu desenvolvimento receberam novas definições. Podem ser destacados os cristais líquidos poliméricos, os cristais 
líquidos dispersos em polímeros (PDLCs), os ferroelétricos, os discóticos e o do tipo banana.

\section{II.2.1. Cristal Líquido Polimérico.}

Esse tipo de cristal líquido, como o próprio nome diz, é composto por polímeros com propriedades liquidocristalinas. Eles são formados por adição de unidades mesogênicas (moléculas de cristal líquido) na cadeia polimérica (Site 1). Neste caso, a característica liquidocristalina permite que o material se compacte devido à alta interação entre as moléculas, tornando-o mais resistente a choques mecânicos. Como se trata de um material polimérico, além de ser de fácil modelagem, também é leve, tornando-o mais atraente na utilização como blindagem ao invés de aço. Um dos principais exemplos desse material é o Kevlar ${ }^{\mathrm{TM}}$ bastante utilizado em blindagens.

A Figura II.4 mostra de forma esquemática como a estrutura de polímeros liquidocristalinos e polímeros convencionais se comportam ao se solidificarem. No caso do cristal líquido polimérico, quando ele se encontra no estado líquido (fundido) ele apresenta uma organização estrutural bem definida (nemática), ao contrário do polímero convencional, que neste caso se possui uma organização aleatória (randômica). Ao se solidificarem, o polímero que apresentava uma ordem nemática mantém uma estrutura de cadeia estendida, enquanto o polímero convencional uma estrutura lamelar. 


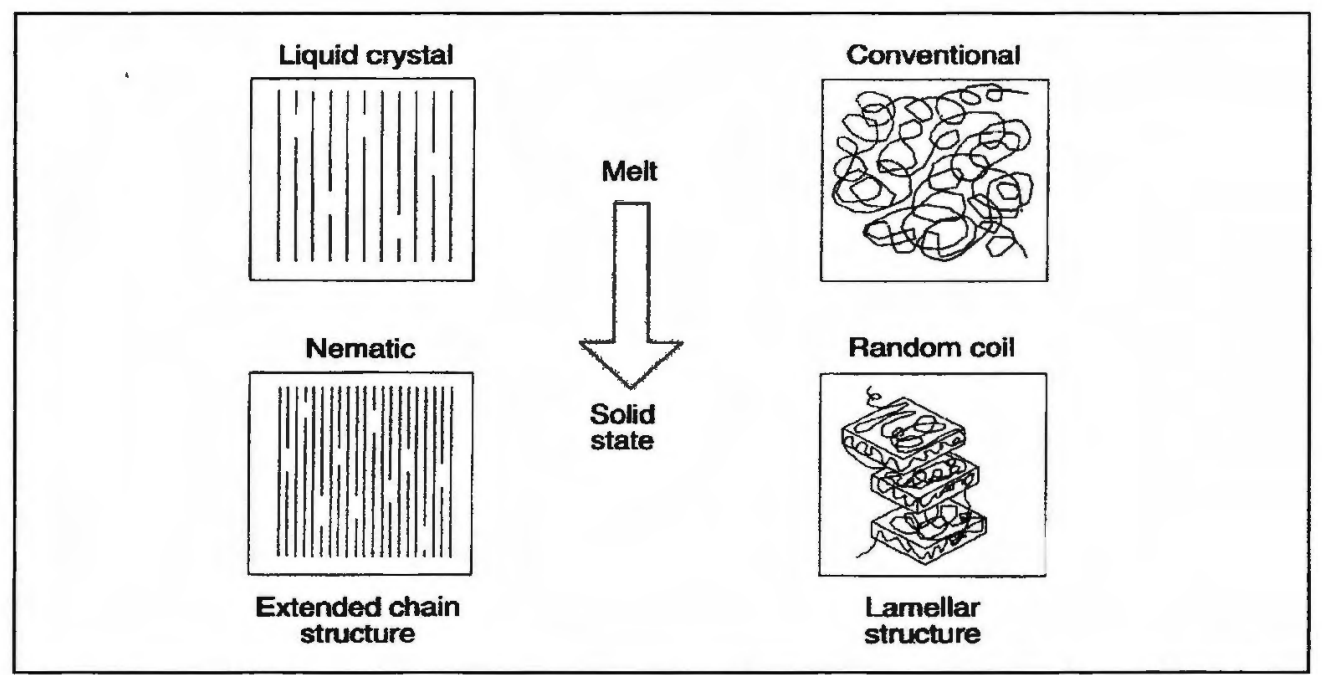

Figura II.4: Comparação esquemática das estruturas formadas durante o processo de cristalização de um cristal líquido polimérico e um convencional.

Os cristais líquidos poliméricos podem ser formados pela adição da unidade mesogênica na cadeia principal, recebendo o nome de MC-PLC (Main-chain polymer liquid crystal) ou lateralmente a cadeia principal com o nome de SC-PLC (Side-chain polymer liquid crystal) (Site 1) (Figura II.5).

MC-PLC
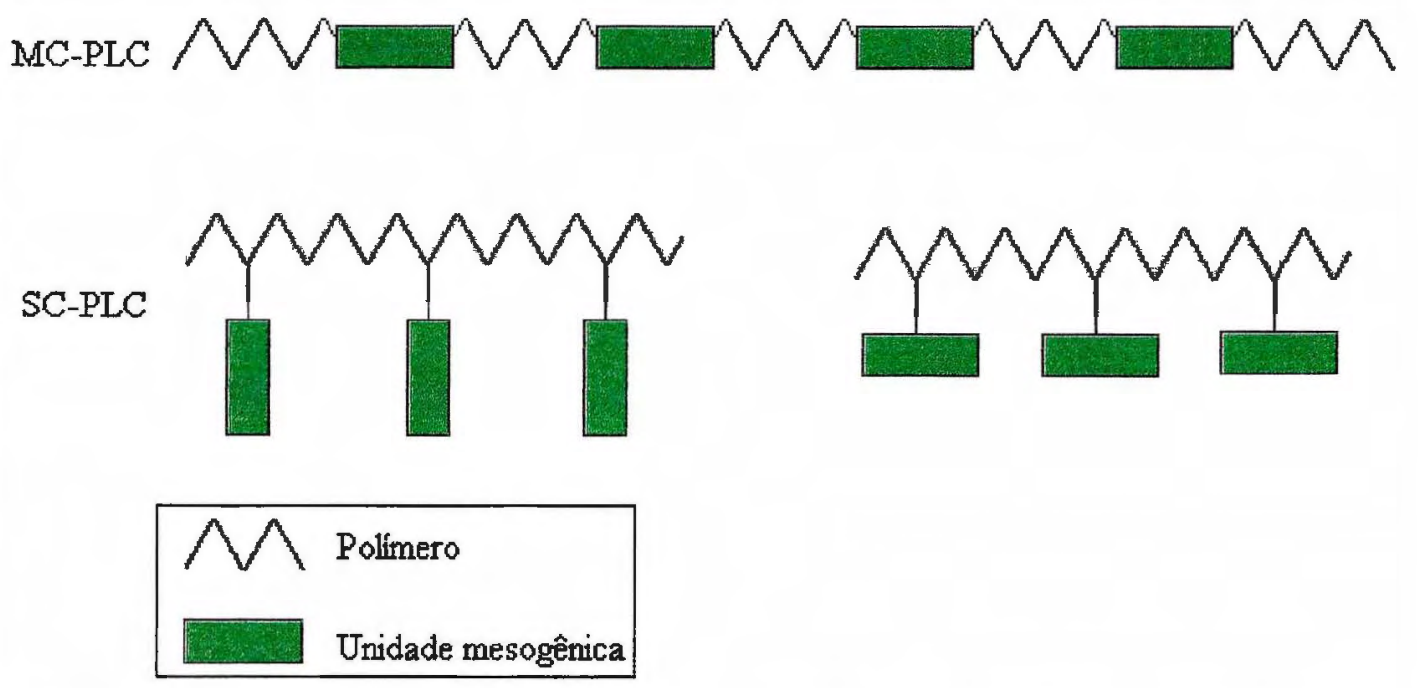

Figura II.5: Estruturas de cristal líquido polimérico. 
Esses materiais estão sendo pesquisados também para aplicações ópticas na área de displays, contudo a resposta desse material ao campo magnético ainda é lenta. Porém, como a sua manipulação é mais fácil quando comparada aos atuais cristais líquidos utilizados, muitos esforços têm sido realizados para melhorar essa resposta.

\section{II.2.2. Cristal Líquido Disperso em Polímero.}

Um outro tipo de sistema liquidocristalino é o de cristal líquido dispersos em polímeros ou mais conhecidos como PDLCs (polymer dispersed liquid crystals). Eles são formados pela adição de "gotas" de cristal líquido, da ordem de microns, dispersas em uma matriz polimérica (Chidichimo et al., 1989; Aphonin et al., 1993). Esses cristais líquidos podem ser formados ou por encapsulação ou por separação de fase.

Por encapsulação, o cristal líquido é misturado com um polímero dissolvido em água e quando a água é evaporada o cristal líquido é envolvido pelo polímero, formando-se cápsulas de cristal líquido aprisionadas no meio polimérico. O problema desse método é que as gotas se formam de tamanhos não uniformes e, às vezes, ligadas umas as outras.

No método de separação de fase, os PDLCs podem ser obtidos de várias formas (Craigead et al., 1982; Doane et al., 1986; Drzaic, 1986; Vaz et al., 1987; Doane et al., 1988). A partir de uma mistura homogênea de polímero (ou copolímero) e cristal líquido, a separação das gotas de cristal líquido pode ocorrer de três modos. No primeiro, a separação é obtida por indução da polimerização, PIPS (Polimerization-induced phase transition). Uma vez que a solução homogênea é formada a reação de polimerização é iniciada. Ao longo da reação as moléculas de cristal líquido se agregam formando gotas, que vão crescendo até o polímero se solidificar interrompendo o crescimento das gotas. Os dois fatores que interferem no tamanho das gotas são a temperatura de cura 
e a concentração dos constituintes, pois eles interferem na velocidade de polimerização, bem como na difusão e solubilidade dos cristais líquidos no polímero.

O segundo método de separação é por temperatura, mais conhecido por TIPS (thermally-induced phase transition). Esse método é utilizado quando o polímero tem temperatura de fusão abaixo da temperatura de decomposição. A mistura homogênea é feita com o polímero fundido e então a solução começa a ser resfriada com uma velocidade específica. As gotas de cristal líquido começam a se formar, com o enrijecimento do polímero até este atingir a sua temperatura de transição vítrea. Neste caso o principal fator que interfere no tamanho das gotas é a velocidade de resfriamento. Quanto mais rápida for a diminuição da temperatura, menores serão as gotas formadas.

O terceiro método de separação é por ação de solvente, ele é conhecido por SIPS (solvent-induced phase transition). Neste caso tanto o polímero quanto o cristal líquido são dissolvidos em um solvente, que é removido, normalmente por evaporação, a uma taxa controlada. O crescimento das gotas termina quando todo o solvente tiver sido evaporado.

As gotas de cristal líquido nos PDLCs podem ter diferentes configurações (Figura II.6) dependendo de fatores como tamanho da gota, formato, ancoramento da superficie, sendo as mais comuns a axial, quando as moléculas de cristal líquido estão orientadas perpendicularmente as paredes da gota; a radial, quando as moléculas estão ancoradas perpendicular ao eixo da gota e bipolar, quando os cristais líquidos estão ancorados tangencialmente a gota. 


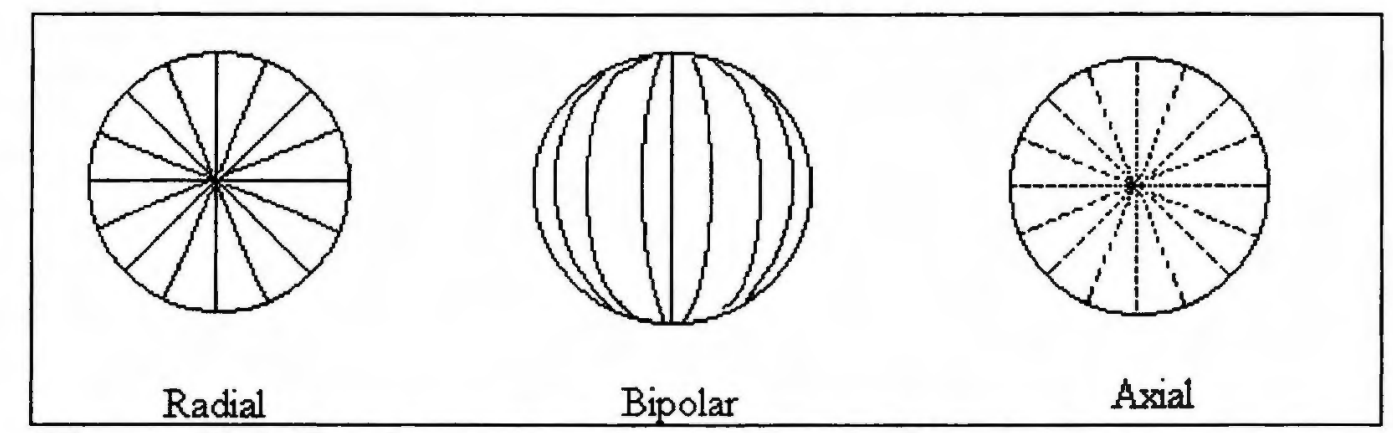

Figura II.6: Configurações típicas de PDLCs.

A principal utilização dos PDLCs nos dias de hoje é em janelas que controlam a passagem de luz. Essas janelas são placas de plástico transparentes, revestidas por uma fina camada de óxido de índio (ITO-indium tin oxide) e com o PDLC depositado entre as elas. Ao aplicar um campo elétrico as gotas de cristal líquido se orientam permitindo a passagem da luz. Ao desligar o campo elétrico, as gotas perdem a orientação, fazendo com que a luz seja espalhada em todas as direções causando a opacidade da janela (Figura II.7). 


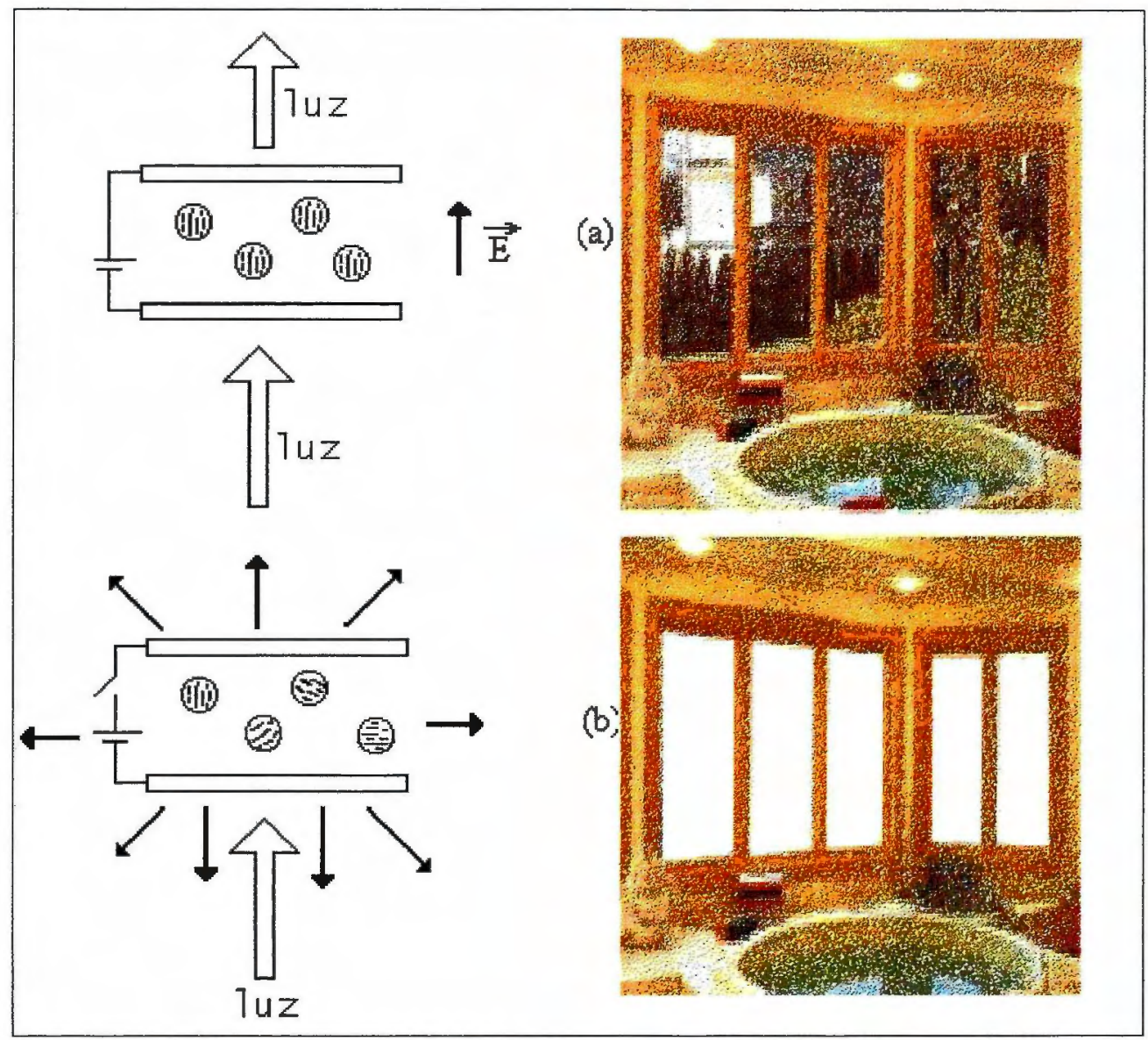

Figura II.7: Representação esquemática de um display de PDLC: (a) com campo elétrico e (b) sem campo elétrico (Chidichimo et.al., 1989) e aplicação do PDLC em janelas.

\section{II.2.3. Cristal Líquido Ferroelétrico.}

Esse tipo de cristal líquido, descoberto por Meyer (Meyer et al., 1975) em 1975, possui uma estrutura esmética C, que é um arranjo em camadas com as moléculas em ângulo com a direção normal de orientação. A diferença desse sistema para um esmético normal é que este possui uma polarização permanente, causada pela presença de um átomo quiral na molécula de cristal líquido. Neste caso, as camadas da estrutura esmética C quiral ( $\mathrm{SmC}^{*}$ ) apresentam uma gradual mudança no ângulo de inclinação o que cria uma estrutura helicoidal na mesofase. (Figura II.8) 


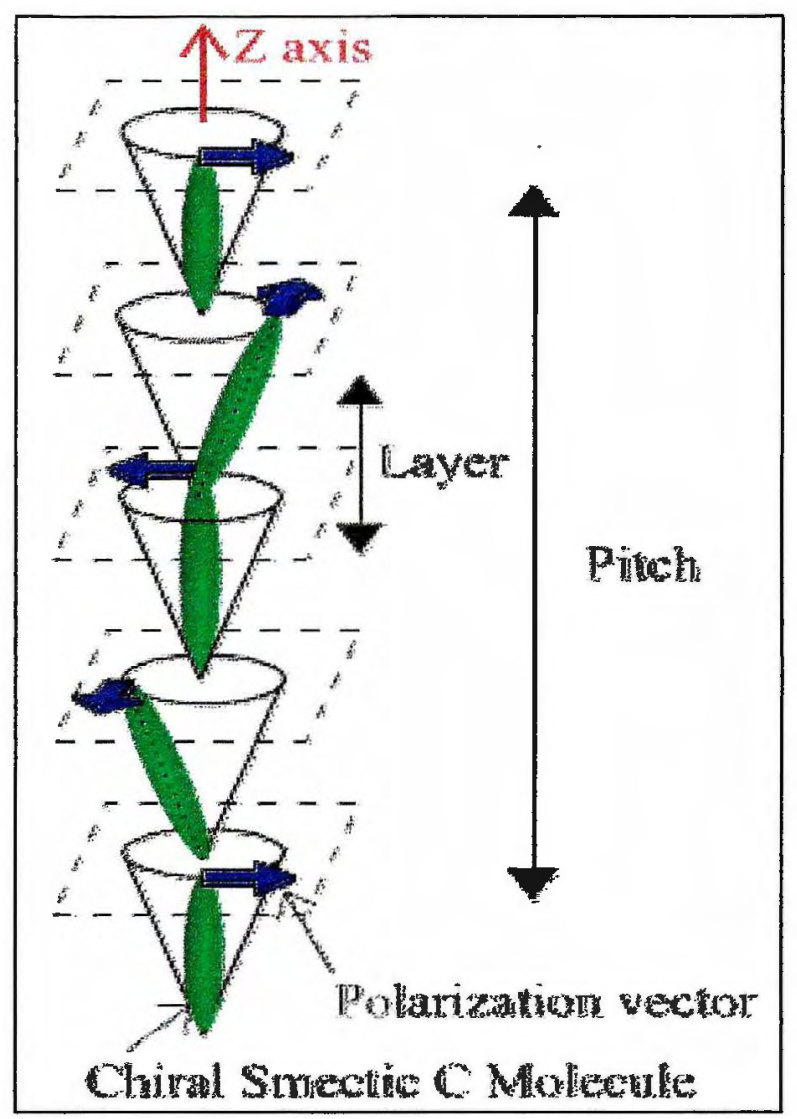

Figura II.8: Esquema estrutural de um cristal líquido ferroelétrico.

Os cristais líquidos ferroelétricos funcionam da seguinte maneira: Ao se aplicar uma voltagem específica, a molécula se orientaria de forma a não desviar a luz que passa pelo polarizador sendo, portanto, toda barrada no analisador (Figura II.9.(a)). Quando se aplica uma outra voltagem, a molécula do cristal líquido ferroelétrico se orientaria de forma a desviar a luz que passa pelo polarizador permitindo sua passagem pelo analisador (Figura II.9.(b)). 


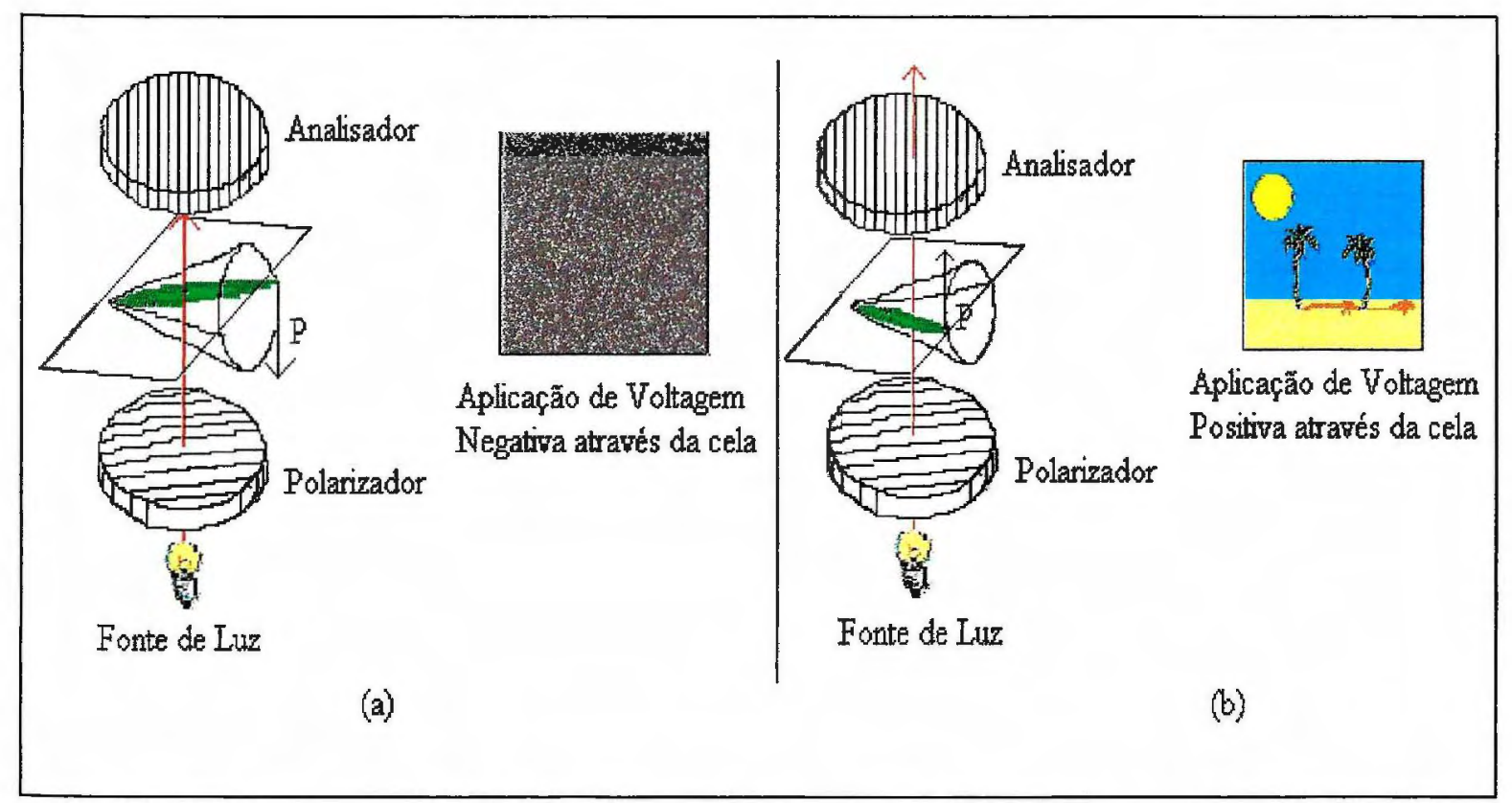

Figura II.9: Esquema de funcionamento do cristal líquido ferroelétrico; (a) orientação da molécula impedindo a passagem da luz e (b) orientação da molécula permitindo a passagem da luz.

O grande atrativo desse sistema liquidocristalino é sua rápida resposta ao campo elétrico e sua alta resolução, o que permite o seu uso em televisões de alta resolução (Figura II.10). 


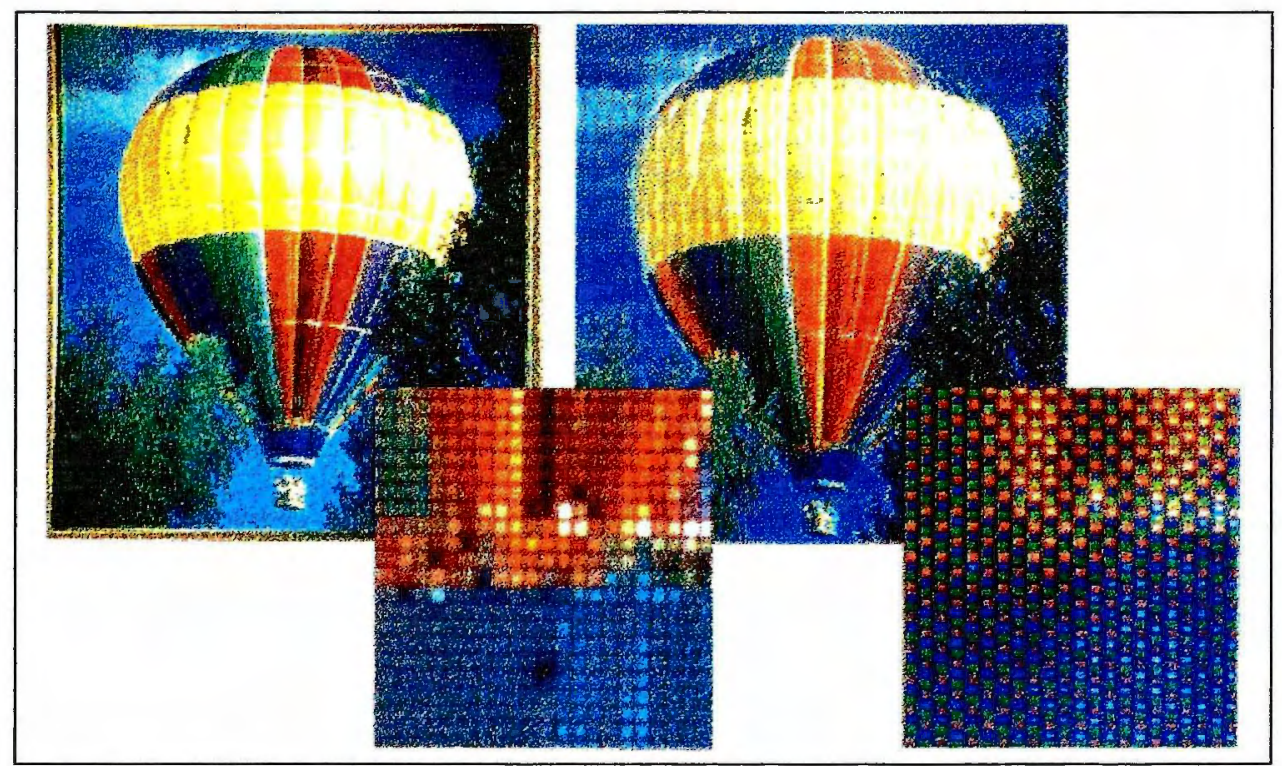

Figura II.10: O display da esquerda é feito com cristal líquido ferroelétrico e o da direita com cristal líquido comum.

\section{II.2.4. Cristal Líquido Discótico.}

Os cristais líquidos discóticos foram descobertos por Chandrasekhar et al. (Chandrasekhar et al, 1977) enquanto investigavam as propriedades ópticas de ésteres de benzeno hexa-substituídos. Esse tipo de cristal líquido é caracterizado por ter na sua estrutura um centro plano, ou quase plano, com cadeias alifáticas com pelo menos cinco carbonos, flexíveis ou semiflexíveis nas extremidades (Figura II.11). Muitos trabalhos têm sido publicados na área de síntese desses cristais líquidos alterando-se a estrutura do centro e das cadeias alifáticas (Robinson et al., 1997; Chandrasekhar \& Raganath, 1990; Markovitsi et al., 1989; Mertesdorf et al., 1991; Weber et al., 1991; Ohta et al., 1991 a; Ohta et al., 1991 b; Ohta et al., 1988; Ohta et al., 1989; Laschevsky \& Angew, 1989; Ringsdorf et al., 1989). 


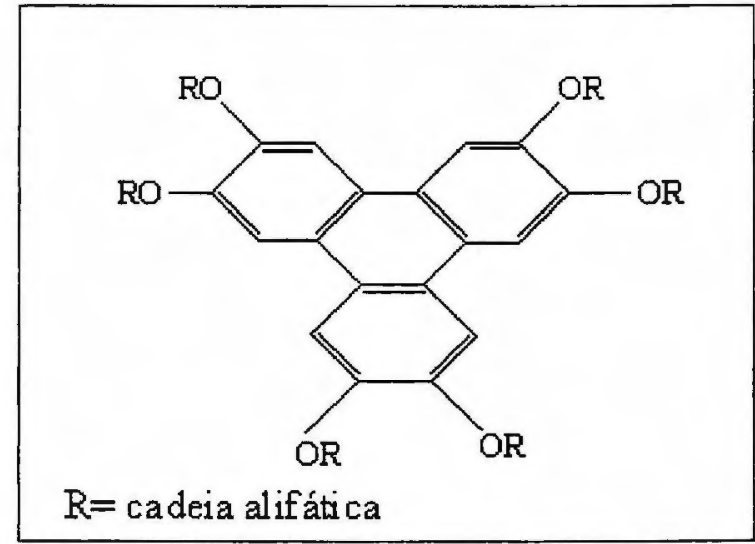

Figura II.11: Um exemplo da estrutura básica da molécula de cristal líquido discótico.

Uma classificação foi introduzida por Destrade et al. (Destrade et al., 1981) para esses mesógenos. Esse tipo de cristal líquido pode se alinhar basicamente de duas formas, na primeira, conhecida por "side on", os centros aromáticos se orientam paralelamente as paredes das celas (Figura II.12 (a)), na outra, denominada "edge on", os centros aromáticos se orientam perpendicularmente as paredes das celas (Figura II.12 (b)).

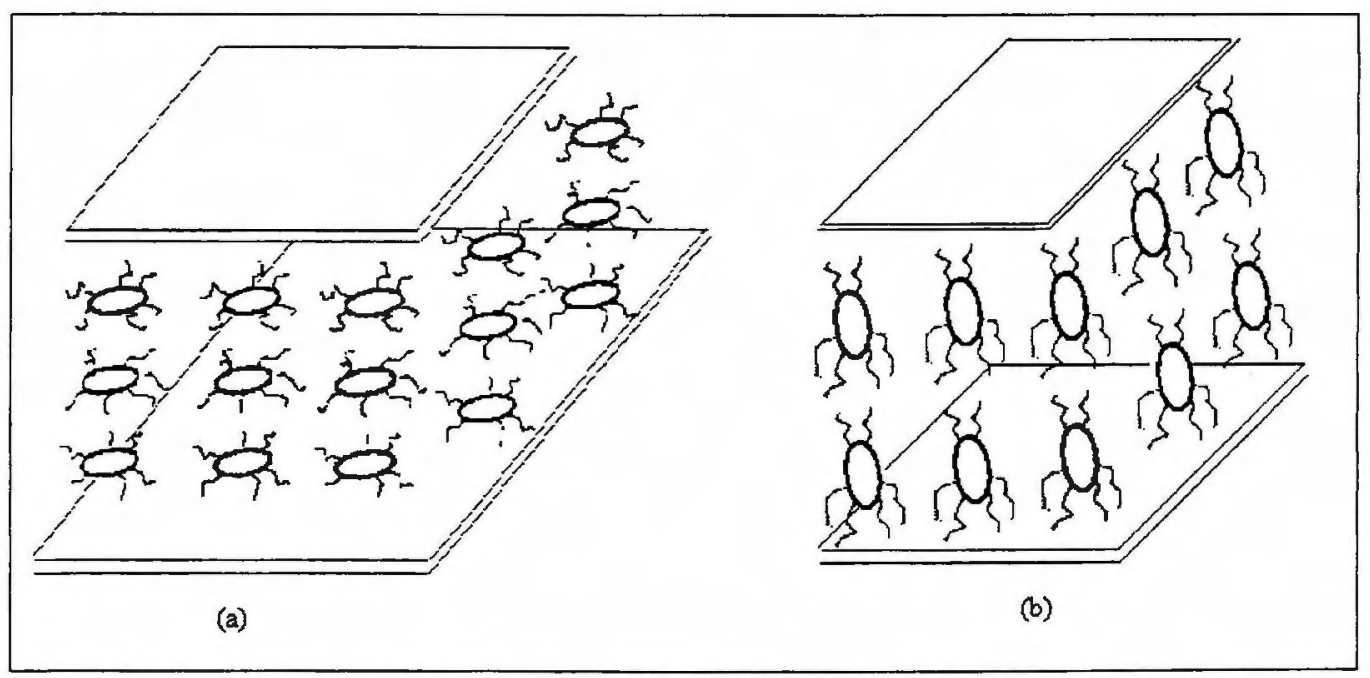

Figura II.12: Esquema dos dois alinhamentos principais de cristal líquido discóticos. (a) side on, (b) edge on. (Kruk et al., 1993). 
O grande atrativo tecnológico para este material é a sua propriedade de reorientação por fotoindução, o que habilitaria o seu uso em filtros e filmes.

\section{II.2.5. Cristal Líquido tipo Banana.}

O cristal líquido do tipo banana é a mais nova mesofase descoberta. Ele é uma fase esmética formada por moléculas em forma de banana, com polarização espontânea, mas que ao contrário dos ferroelétricos, não possuem átomos quirais (Kentischer et al., 1998; Pelzl et al., 1999; Heppke et al., 2000) (Figura II.13). Eles foram sintetizados pela primeira vez por Matsunaga et al. (Matsunaga et al., 1993; Akutagawa et al., 1994), mas suas propriedades ferroelétricas só foram reportadas por Niori et al. em 1996 (Niori et al., 1996).

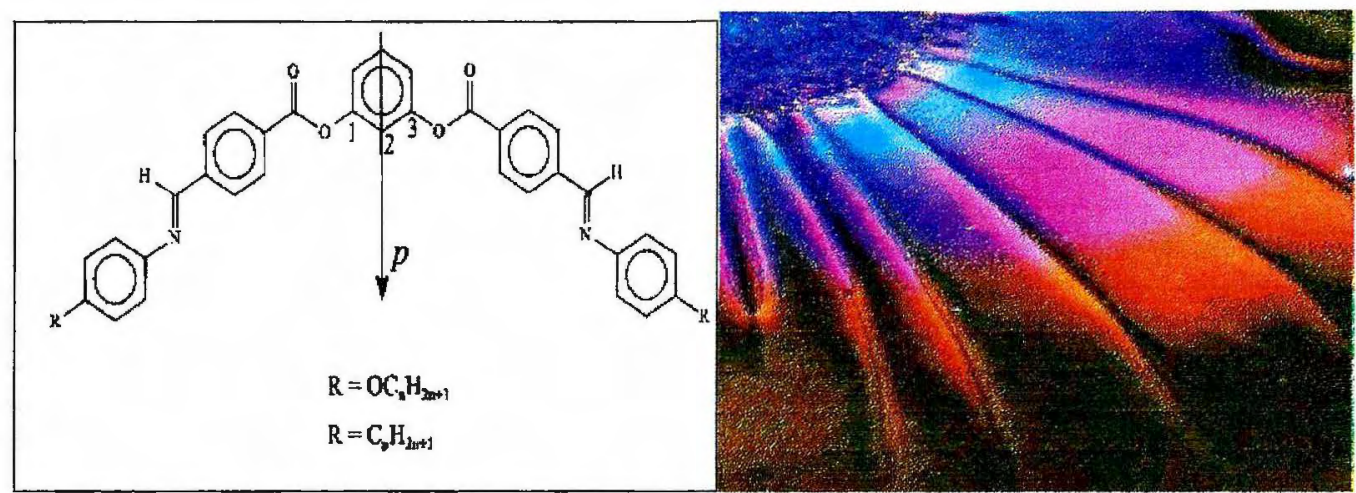

Figura II.13: Estrutura básica das moléculas do tipo banana(esquerda) (Kentischer et al., 1998); Textura sob luz polarizada de um cristal líquido do tipo banana (direita).

O grande atrativo deste tipo de sistema é que o arranjo formado é quiral embora suas moléculas constituintes não o sejam. Do mesmo modo que os cristais líquidos ferroelétricos, devido a sua polarização espontânea, esses compostos também poderiam ser utilizados na confecção de displays, sendo ainda necessárias mais pesquisas na área. 


\section{II.3 - Cristal Líquido Liotrópico}

Limosofases ou cristais líquidos liotrópicos são substâncias (polímeros, compostos de coordenação) ou agregados de substâncias (micelas, lamelas) que quando sob ação de solvente apresentam um ordenamento, devido às interações entre seus constituintes e o solvente.

Geralmente esses cristais líquidos são formados pela ação da água em compostos anfifilicos, substâncias que possuem uma parte hidrofóbica (normalmente uma cadeia hidrocarbônica alifática) e uma hidrofilica (iônica ou polar) (Suzuki, 1974; Vanin, 1974; Suzuki, 1979; Paoli, 1981; Forrest \& Reeves, 1981; Alcantara, 1982).

Estes compostos tendem a se associarem, devido à baixa solubilidade em água, formando entidades esférica (micelas) que com o aumento da concentração de anfifilicos tendem a se deformar, levando a formar bicamadas ou cilindros. As bicamadas podem ser infinitas, formando estruturas lamelares, ou finitas que representam as estruturas micelares em forma de disco. Os cilindros por sua vez originam duas fases, uma em que os cilindros têm tamanhos finitos e outra de tamanho infinito que formam as estruturas hexagonais (Alcantara, 1982). Os fatores que determinam esse arranjo são as forças de interação de van der Waals, efeito hidrofóbico, pontes de hidrogênio, interações eletrostáticas e parâmetros geométricos (Israelachvilli, 1992).

O comportamento liquidocristalino em uma solução foi reportado pela primeira vez em 1950 por Elliot \& Ambrose (Elliot \& Ambrose, 1950), quando observaram que uma solução de poli- $\gamma$-benzil-L-glutamato (PBLG) em clorofórmio apresentava birrefringência. Foi apenas em 1956 que Robinson (Robinson, 1956) estudando este sistema, apontou semelhanças entre cristais líquidos termotrópicos colestéricos e a superestrutura formada por soluções 
concentradas de polipeptídios (Robinson, 1961; Robinson, 1966; Robinson \& Ward, 1957; Robinson et al., 1958).

Os cristais líquidos liotrópicos se classificam em nemáticos e colestéricos, seguindo a mesma definição dos termotrópicos.

\section{II.3.1. -Cristal Líquido Liotrópico Nemático}

Foram definidos dois tipos de mesofases nemática para o sistema liotrópico. Essa classificação leva em consideração como o sistema se orienta espontaneamente sob o efeito de um campo magnético (Radley et al., 1976). Portanto, as fases cujos diretores micelares se orientam paralelo ao campo magnético são chamadas de mesofases nemática do Tipo $\mathrm{I}$, enquanto as fases em que os diretores se orientam perpendiculares ao campo magnético são chamadas Tipo II.

Uma outra nomenclatura proposta para as mesofases liotrópicas nemáticas leva em conta o formato das micelas, surgindo então os termos Nemático Discótico $\left(\mathrm{N}_{\mathrm{D}}\right)$, para as fases cujas micelas tinham o formato de disco (Figura II.14a) e Nemático Calamítico $\left(\mathrm{N}_{\mathrm{C}}\right)$, para as micelas cilíndricas (Figura II.14b) (Charvolin et al., 1979; Hendrikx \& Charvolin, 1981). 


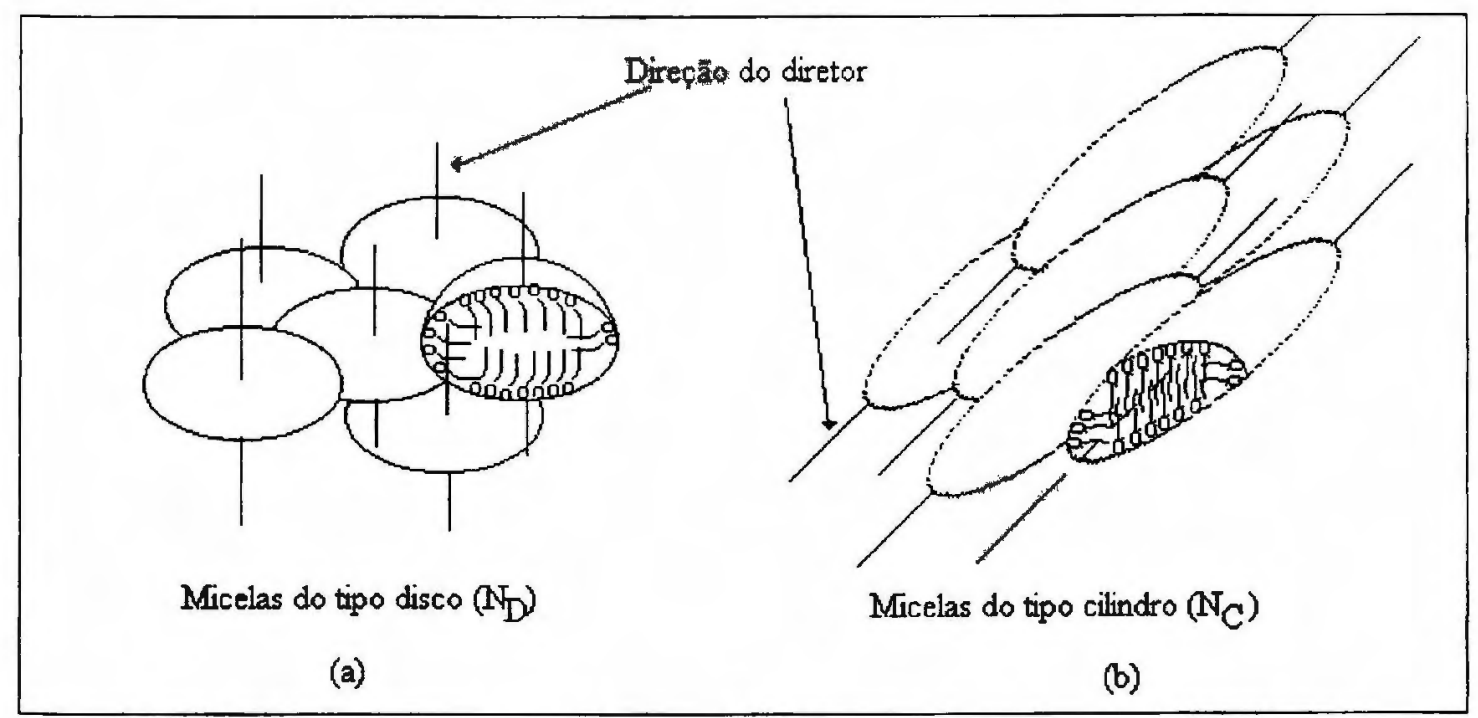

Figura II.14: Estrutura das micelas: (a) do tipo disco, (b) do tipo cilindro.

\section{II.3.2. -Cristal Líquido Liotrópico Colestérico}

As fases liotrópicas colestéricas possuem um arranjo semelhante ao dos cristais líquidos termotrópicos colestéricos. Nesse sistema as micelas estariam dispostas com seu diretores alinhados em um plano como na estrutura nemática. A direção de orientação em cada plano sofre uma torção dando origem ao edifício colestérico (Alcantara, 1988).

As mesofases liotrópicas colestéricas podem ser obtidas ou por adição de compostos quirais a matriz nemática ou pela utilização de anfifilicos quirais.

A adição de compostos quirais ao sistema liotrópico nemático forma um sistema conhecido por cristal líquido liotrópico colestérico induzido. A primeira vez que se obteve esse sistema colestérico foi em 1975 por Diehl \& Tracey, ao adicionarem 2-decilsulfato de sódio em um sistema de cristal líquido liotrópico composto por decilsulfato de sódio/decanol/ $/ \mathrm{Na}_{2} \mathrm{SO}_{4} / \mathrm{D}_{2} \mathrm{O}$. Em 1978 foi reportado por Raley \& Saupe a utilização de colesterol, ácido tartárico e sulfato de brucina para indução de uma hélice colestérica em sistemas nemáticos. Os resultados obtidos por eles mostraram que a textura 
apresentada no microscópio polarizado, depois de submetido ao campo magnético, era semelhante ao obtido pelo sistema formado pelo PBLG.

A utilização de anfifilicos quirais pode formar sistemas liomesomórficos colestéricos intrínsecos. Estes sistemas começaram a ser estudados em 1980 por Acimis \& Reeves em fases preparadas a partir do cloridrato do éster decílico- $\alpha$-alanina. Esses sistemas apresentam propriedades colestéricas mais pronunciadas, porém semelhantes às obtidas para os colestéricos induzidos. Vários outros anfifilicos puderam ser sintetizados e utilizados, abrindo um campo fértil voltado para o estudo das interações intermicelares (Alcantara, 1988). 


\section{III.Reologia}

Reologia é a ciência que estuda a deformação e o fluxo da matéria. Esse termo, inventado pelo professor Bingham, vem do grego "pєเu" que significa fluir e foi aceito em 1929 quando a Sociedade Americana de Reologia foi fundada.

No início, a reologia foi restrita apenas ao estudo das relações fundamentais entre força e deformação em materiais (Macosko, 1994).

Provavelmente a primeira relação entre força e deformação foi proposta por Robert Hook em 1678, quando postulou que em uma mola, quando se dobra a tensão aplicada a deformação também dobra.

$$
\tau=\mathrm{G} \gamma \quad \text { Lei de Hooke } \quad \text { Equação III.1. }
$$

onde $\tau$ é força por unidade de área, ou simplesmente tensão, $\gamma$ é a deformação e $\mathrm{G}$ é a constante de proporcionalidade, chamada de módulo elástico (Barnes et al., 1993). G é uma propriedade intrínseca do material, relacionada no início apenas a sólidos.

Isaac Newton, trabalhando com líquidos, propôs que ao se colocar um fluido entre duas placas paralelas e se aplicar uma tensão sobre uma delas, esta se movimenta com uma velocidade proporcional a tensão aplicada. Esta proporcionalidade se refere a sua resistência ao fluxo, conhecida hoje como viscosidade, sendo, portanto uma característica do fluido (Barnes et al., 1993).

$$
\tau=\eta \frac{d \gamma}{d t} \text { Lei de Newton } \quad \text { Equação III.2. }
$$


Onde $\tau$ é a tensão aplicada, $\mathrm{d} \gamma / \mathrm{dt}$ é a taxa de deformação e $\eta$ é coeficiente de viscosidade, ou simplesmente viscosidade (Barnes et al., 1993).

Durante muito tempo, as leis de Hooke para sólidos e de Newton para líquidos foram suficientes para explicar as propriedades observadas. Porém, no século XIX, alguns resultados começaram a lançar dúvidas sobre estas leis (Markovitz, 1968). Wilhelm Weber ao trabalhar com fios de seda descobriu que eles não se comportavam perfeitamente como sólidos elásticos, pois ao tencioná-los, estes se esticavam e quando a tensão era retirada, eles imediatamente se contraiam seguido de uma gradual diminuição do comprimento, até atingir o tamanho original. Apesar do material ser um sólido, ele possuía um comportamento que podia ser associado ao de um líquido e que hoje se define como viscoelasticidade. De modo geral podemos dizer que a viscoelasticidade é a propriedade de um material que apresenta um comportamento elástico e viscoso ao mesmo tempo. Mais tarde, James Clerk Maxwell propôs um modelo matemático (Equação III.3) para fluidos que possuíam propriedades elásticas, que foi publicado em 1867 na "Encyclpaedia Britannica" com o título de "On the dynamical theory of gases" (Barnes et al., 1993).

$$
\tau+\lambda_{M} \cdot \dot{\tau}=\eta \dot{\gamma}
$$

Equação III.3.

$\tau$ é a tensão aplicada, $\lambda$ é constante referente ao tempo de relaxação, $\dot{\tau}$ é derivada da tensão em relação ao tempo, $\eta$ é o coeficiente de viscosidade e $\dot{\gamma}$ é a taxa de cisalhamento.

Apesar dos resultados observados, pouca pesquisa nessa área foi feita, até a II Guerra Mundial, quando a Reologia tornou a emergir com o estudo dos materiais usados em lança-chamas, pois estes apresentavam propriedades 
viscoelásticas. O interesse nesse assunto cresceu muito, principalmente com o aparecimento das fibras sintéticas, os processos poliméricos e o desenvolvimento de tintas e adesivos.

Atualmente podemos considerar que todos os materiais são viscoelásticas dependendo da escala de tempo que é observado. Neste sentido, não é de todo correto se afirmar que um líquido é newtoniano e um sólido hookeano e sim que, em certas condições, um líquido apresenta comportamento newtoniano ou um sólido apresenta comportamento hookeano.

Embora seja notória a importância dessa ciência, já se tornou um consenso entres os pesquisadores da área que ela encerra uma grande dificuldade intrínseca. Um dos motivos alegados é a sua interdisciplinaridade, que leva a maioria dos cientistas a sair do seu conhecimento específico e desenvolver uma abordagem científica ampla. Para facilitar sua abordagem é comum dividi-la em sub-áreas como reometria, equações constitutivas e fluxos complexos.

$\mathrm{Na}$ reometria, os materiais são estudados em fluxo, em condições simples como fluxo estacionário e fluxo por cisalhamento oscilatório em pequena amplitude. Pois estes ensaios são importantes para controle de qualidade e controle de processos, fornecendo informações a respeito do comportamento do material e propondo modelos que facilitem o processo industrial (Barnes et al., 1993).

As equações constitutivas são as equações relacionadas com as variáveis do processo como tensão e deformação. Essas equações levam em consideração à estrutura molecular servindo de ferramenta para se determinar o arranjo estrutural do sistema.

Os fluxos complexos são encontrados principalmente em fluidos elásticos, pois nestes materiais têm-se que se considerar vários efeitos e 
componentes ao mesmo tempo, tais como inércia, cisalhamento, tempo e componentes.

Os estudos reológicos podem se realizados basicamente de dois métodos, o primeiro é o método rotacional, onde se caracterizam os fluidos como newtoniano e não-newtoniano e onde se observam os efeitos de temperatura e tempo de cisalhamento; e o outro é o método oscilatório, que é mais utilizado para a caracterização das contribuições elásticas aos sistemas viscoelásticos.

\section{III.1 Método Rotacional}

No método rotacional, o parâmetro mais importante é a viscosidade. Ela pode ser definida qualitativamente como sendo a resistência à deformação de um material com o aumento da velocidade de deformação. Quantitativamente ela é definida como a tensão de cisalhamento dividida pela taxa de cisalhamento (Equação III.2).

A viscosidade da maioria dos fluidos não é constante em quaisquer condições sendo dependente de vários fatores, o que resulta em diferentes comportamentos. Os principais fatores que influem na viscosidade são a taxa de cisalhamento, temperatura e pressão. 


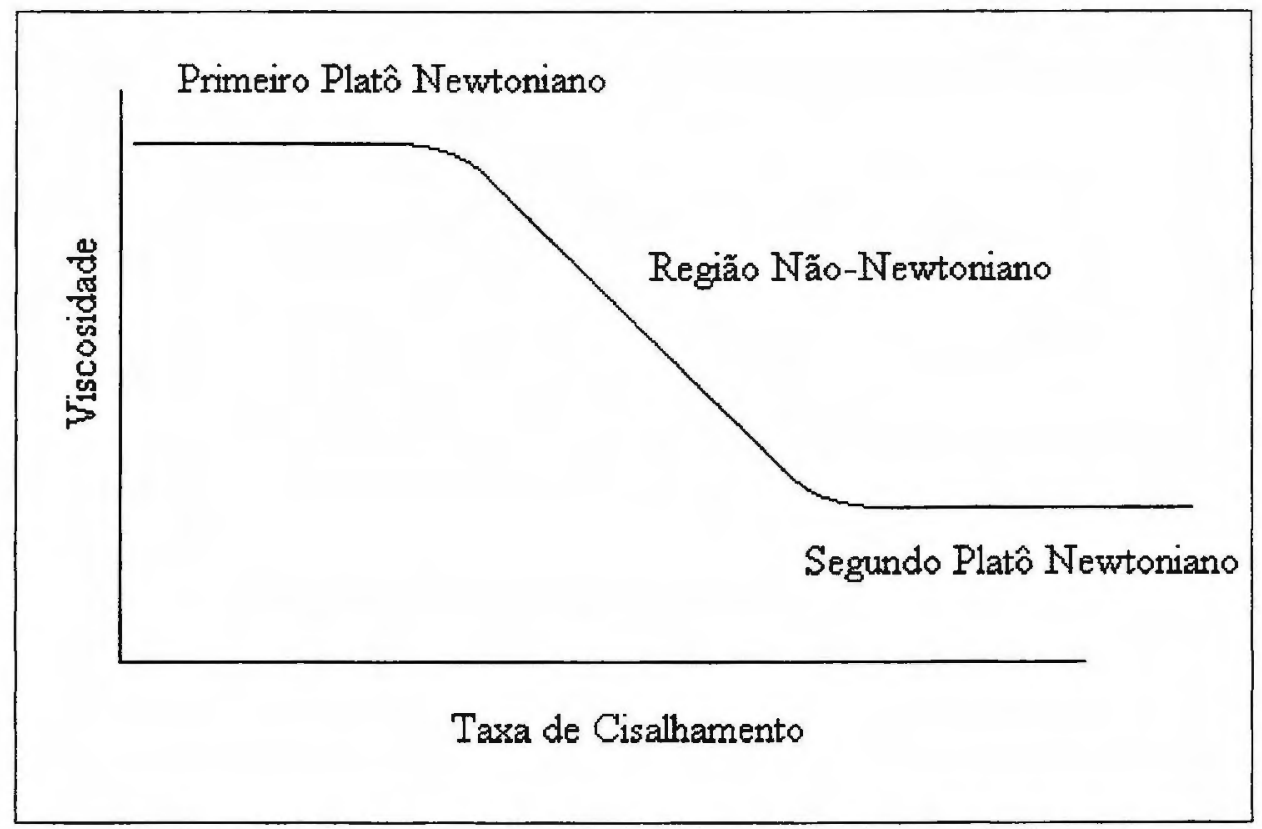

Figura III.1: Reograma do comportamento geral descrito por qualquer fluido

A Figura III.1 mostra o comportamento geral de qualquer fluido em relação à taxa de cisalhamento. Podem ser observadas duas regiões onde a viscosidade se mantém constante com o aumento da taxa de cisalhamento que recebem o nome de primeiro platô newtoniano e segundo platô newtoniano, respectivamente. A região intermediária é chamada de região não-newtoniana e é caracterizada pela variação da viscosidade em função da taxa de cisalhamento. Por causa deste perfil, muitos consideram a viscosidade não um coeficiente mas uma função da taxa de cisalhamento - $\eta(\dot{\gamma})$ - recebendo o nome de viscosidade de cisalhamento ou de viscosidade aparente.

Quando um fluido se encontra na região não-newtoniana, pode apresentar quatro comportamentos básicos: dilatante, pseudoplástico, plástico e binghmaniano. O fluido dilatante é definido quando a viscosidade aumenta com a taxa de cisalhamento. O fluido pseudoplástico é definido pela diminuição da viscosidade com o aumento da taxa de cisalhamento. Os fluidos plásticos e binghmaniano têm comportamentos semelhante ao pseudoplástico e newtoniano respectivamente, porém, apresentando uma tensão limite 
mínima para que o fluido comece a fluir. Após atingir essa tensão, o fluido plástico tem sua viscosidade diminuída com o aumento da taxa de cisalhamento, enquanto o binghmaniano tem sua viscosidade constante. Todos esses comportamentos podem ser observados pelo diagrama apresentado na Figura III.2.

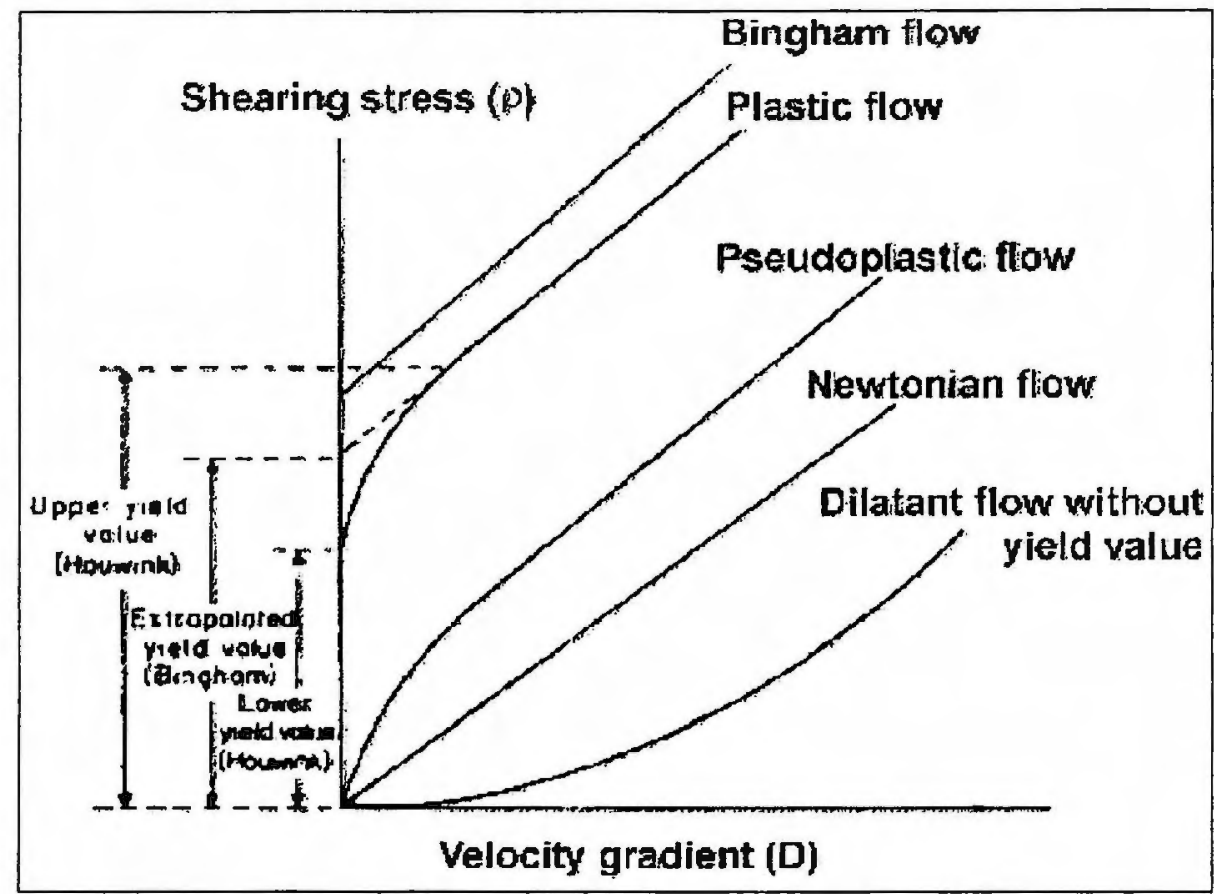

Figura III.2: Reogramas de diferentes comportamentos reológicos em função da taxa de cisalhamento (Shaw, 1997).

Esses comportamentos podem ser definidos matematicamente pela seguinte equação:

$$
\tau=\tau_{0}+k \cdot \dot{\gamma}^{n} \quad \text { Equação III.4. }
$$

Nesta equação $\tau$ é a tensão de cisalhamento; $\tau_{0}$ é a tensão limite; $\mathrm{k}$ é definido como índice de consistência; $\dot{\gamma}$ é a taxa de cisalhamento; e n é o índice de fluidez (Barnes et al., 1993).

Quando o índice de fluidez (n) é igual a 1 (um) e $\tau_{0}$ é zero, o sistema é newtoniano e $\mathbf{k}=\eta$. Quando $\tau_{0}$ é diferente de zero, o fluido é binghmaniano. 
Quando n é menor do que 1 o fluido é pseudoplástico para $\tau_{0}$ igual a zero e plástico quando $\tau_{0}$ diferente de zero. Quando o índice de fluidez é maior do que 1 o sistema é chamado de dilatante.

O comportamento reológico de um fluido em função da temperatura é de grande interesse na aplicação industrial (Figura III.3). Para fluidos newtonianos a variação da viscosidade em função da temperatura nos permite obter a Energia Livre de Ativação de Fluxo $\left(\Delta G^{\#}\right)$. Para fluidos newtonianos a variação da viscosidade em função da Temperatura segue uma relação de Arrhenius.

A energia livre de ativação de fluxo $\left(\Delta G^{\#}\right)$ é a energia mínima necessária para colocar o sistema em movimento e está relacionada com a composição e ordenamento do sistema (Németh et al., 1998; Linemann et al.,1995; Walter \& Wagner, 1994; Berjano et al., 1993; Soltero et al., 1996; Thurn et al., 1985).

$\Delta \mathrm{G}^{\#}$ é uma constante do sistema que é proporcional a barreira de energia potencial $\left(\varepsilon_{0}\right)$ devida às interações entre partículas ou micelas vizinhas na direção de fluxo e pode ser definida como,

$$
\Delta G^{\sharp}=N_{A} \varepsilon_{0}-R T \ln \left(\frac{F^{*}}{F}\right) \quad \text { Equação III.5. }
$$

Onde $\mathrm{N}_{\mathrm{A}}$ é o número de Avogadro e $\mathrm{F}^{\#}$ e $\mathrm{F}$ são funções de partição de unidade de volume das partículas no estado ativado e no estado inicial, respectivamente (Arrhenius, 1916; Alcantara et al., 2002) A energia pode ser obtida através da variação da viscosidade em função da tẹmperatura, utilizando para isto a teoria de Andrade-Eyring que descreve o fluxo viscoso 
como um processo de difusão termicamente ativado (Bird \& Stuart, 1960; Glasstone et al., 1941, Alcantara et al., 2002).

$$
\eta=\frac{h}{V} \exp \left(\frac{\Delta G^{\#}}{R T}\right) \quad \text { Equação III.6. }
$$

Nesta equação $\eta$ é a viscosidade, $V$ é o volume médio ocupado por uma micela, $\mathrm{h}$ é constante de Planck, $\mathrm{R}$ a constante universal dos gases e $\mathrm{T}$ a temperatura absoluta. $\Delta \mathrm{G}^{\#}$ também pode ser substituído por suas componentes entrópica $\left(\Delta S^{\#}\right)$ e entálpica $\left(\Delta H^{\#}\right)$.

$$
\eta=\frac{h}{V} \exp \left(\frac{\Delta H^{\sharp}}{R T}-\frac{\Delta S^{\#}}{R}\right) \quad \text { Equação III.7. }
$$

Considerando-se que o volume do líquido não varia muito com a temperatura é possível se considerar $\Delta \mathrm{S}^{\#}$ como constante, portanto,

$$
\eta=\eta_{0} \exp \left(\frac{\Delta H^{\sharp}}{R T}\right), \text { onde } \eta_{0}=\frac{h}{V} \exp \left(-\frac{\Delta S^{\#}}{R}\right)
$$

Esta relação foi primeiramente sugerida de forma empírica por $\mathrm{S}$. Arrhenius (Arrhenius, 1916) e por J. de Guzmán (Guzmán, 1913) e depois derivada de outra maneira por E. N. de C. Andrade (Andrade, 1934).

É comum encontrarmos na literatura a equação numa forma simplificada.

$$
\eta=A e^{B / T} \quad \text { Equação III.9. }
$$


Onde A e B são constante do fluido e T a temperatura absoluta (Barnes et al., 1993).

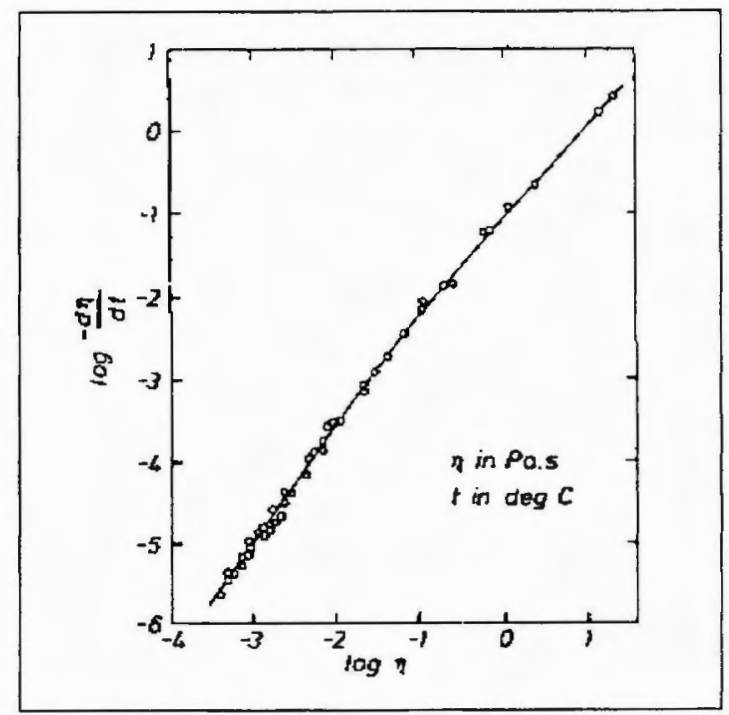

Figura III.3: Curva logarítmica da derivada da viscosidade pela temperatura em função do logaritmo da viscosidade para várias frações de óleo lubrificante (Barnes, 1993).

De acordo com o modelo de Andrade-Eyring, o fator pré-exponencial $\left(\eta_{0}\right)$ é uma função do volume ocupado pelas partículas que constituem o fluido e da entropia de ativação de fluxo $\left(\Delta \mathrm{S}^{\#}\right)$. Este volume pode ser aproximado como sendo uma caixa cúbica, tomando-se a aresta como a soma do diâmetro (d) e da separação das partículas (r) (Equação III.10).

$$
\eta=\eta_{0} \exp \left[\frac{\Delta H^{\#}}{R T}\right]=\frac{h}{(d+r)^{3}} \exp \left[-\frac{\Delta S^{*}}{R}\right] \exp \left[\frac{\Delta H^{*}}{R T}\right]
$$

Fazendo-se algumas considerações a respeito do empacotamento das micelas em sistemas de cristal líquido liotrópicos é possível se determinar à contribuição entrópica no fator pré-exponencial. Em sistemas mesomórficos do tipo disco, o diâmetro da micela (d) é aproximadamente de $10 \mathrm{~nm}$ (Hantzschel et al., 1999). Portanto: 


$$
\begin{array}{ll}
\ln \left(\eta_{0}\right)=\ln \left(\frac{h}{d^{3}}\right)-\frac{\Delta S^{\#}}{R}, \quad \text { onde } & \frac{h}{d^{3}}=\frac{6,63 \times 10^{-34} J s}{\left(10^{-8} \mathrm{~m}\right)^{3}} \\
\frac{h}{d^{3}}=6,63 \times 10^{-10} \text { Pas }=6,63 \times 10^{-7} & \therefore \ln \left(\frac{h}{d^{3}}\right) \approx-14
\end{array}
$$

ou seja,

$$
\Delta S^{\#}=-R\left[\ln \left(\eta_{0}\right)+14\right]
$$

Equação III.11.

Embora a maioria das medidas reológicas seja realizada a pressão ambiente. Podemos observar que a viscosidade aumenta exponencialmente com o aumento da pressão (Figura III.4).

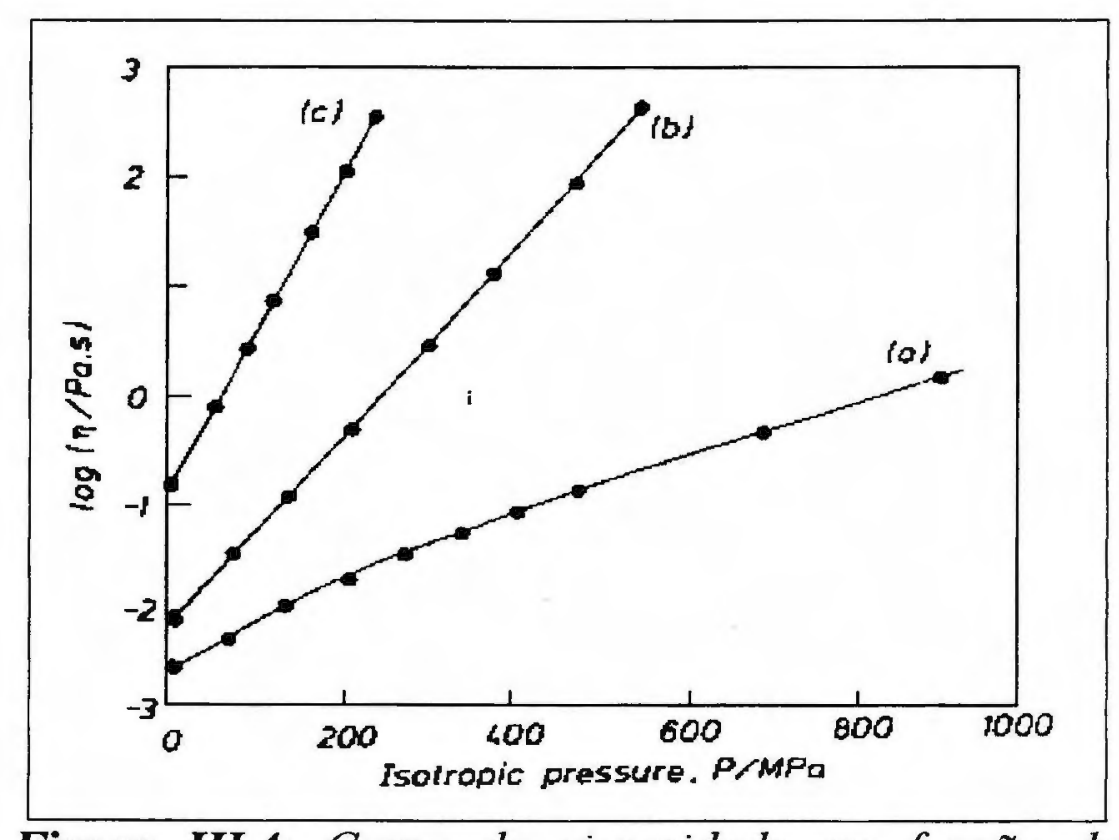

Figura III.4: Curva da viscosidade em função da pressão: (a) Di-(2-etilhexil) sebacato; (b) óleo mineral de nafta a $210^{\circ} \mathrm{F}$, (c) óleo mineral de nafta a $100^{\circ} \mathrm{F}$ (Barnes 1993).

Outro parâmetro que também influi no comportamento reológico de um material é o tempo de cisalhamento. Existem dois fenômenos relacionados 
com este tempo de cisalhamento: a tixotropia e a reopexia ou anti-tixotropia. A tixotropia é a diminuição da viscosidade ao longo de um experimento realizado em taxa de cisalhamento constante. A reopexia, ou anti-tixotropia, como se pode deduzir é o aumento da viscosidade com o tempo de cisalhamento em taxa constante.

\section{III.2 - Método Oscilatório}

Os ensaios oscilatórios, como já foi dito, são utilizados principalmente no estudo das contribuições elásticas dos materiais viscoelásticos.

Se uma deformação for aplicada em uma pequena amplitude ou muito lentamente, podemos assumir que todas as moléculas permanecem muito próximas ao seu estado de equilíbrio. Esta região é a chamada de região de viscoelasticidade linear.

$\mathrm{Na}$ região de viscoelasticidade linear as equações diferenciais são lineares e os coeficientes das diferenciais são constantes e características do material, como o coeficiente de viscosidade e módulo rígido.

$\mathrm{Na}$ região não linear $\mathrm{o}$ tratamento matemático se torna muito complicado, pois envolve vários fatores externos independentes do material (como a energia perdida para o meio em forma de calor e a energia gasta na difusão das partículas) o que dificulta a sua compreensão.

O comportamento viscoelástico linear pode ser descrito por esta equação diferencial (Equação III.12).

$$
\left(1+\alpha_{1} \frac{\partial}{\partial t}+\alpha_{2} \frac{\partial^{2}}{\partial t^{2}}+\ldots+\alpha_{n} \frac{\partial^{n}}{\partial t^{n}}\right) \tau=\left(\beta_{0}+\beta_{1} \frac{\partial}{\partial t}+\beta_{2} \frac{\partial^{2}}{\partial t^{2}}+\ldots+\beta_{n-1} \frac{\partial^{n-1}}{\partial t^{n-1}}\right) \gamma
$$

\section{Equação III.12.}


Onde $\tau$ e $\gamma$ são a tensão de cisalhamento e a deformação respectivamente, e $\alpha$ e $\beta$ são coeficientes de proporcionalidades relacionados com as características elásticas e viscosas do material (Barnes et al., 1993). Um caso específico desta equação é a Equação III.3 que foi proposta por Maxwell em 1867.

Outro caso especial é obtido quando apenas o parâmetro $\beta_{0}$ é diferente de zero.

$$
\tau=\beta_{0} \gamma \quad \text { Equação III.13. }
$$

Essa é a equação de um sólido hookeano e o parâmetro $\beta_{0}$ é o módulo rígido. Outro caso especial aparece quando apenas $\beta_{1}$ é diferente de zero (Barnes et al., 1993):

$$
\tau=\beta_{1} \frac{\partial \gamma}{\partial t} \quad \text { Equação III.14. }
$$

Essa equação representa um fluido newtoniano em que $\beta_{1}$ é o coeficiente de viscosidade (Barnes et al., 1993).

As duas equações apresentadas acima (Equações III.13 e III.14), não representam sistemas viscoelásticos, mas ajudam a corroborar a idéia de que todo material é viscoelástico e que dependendo das condições experimentais, ele pode se comportar como um material elástico ou viscoso.

A representação mais simples do comportamento viscoelástico de um material é obtido quando $\beta_{0}$ e $\beta_{1}$ diferentes de zero(Barnes et al., 1993):

$$
\tau=\beta_{0} \gamma+\beta_{1} \frac{\partial \gamma}{\partial t} \quad \text { Equação III.15. }
$$

Podendo ser reescrita como:

$$
\tau=G \gamma+\eta \frac{\partial \gamma}{\partial t} \quad \text { Equação III.16. }
$$


Essa equação é conhecida como modelo de Kelvin ou modelo de Kelvin-Voigt (Schramm, 1994).

Segundo o modelo de Kelvin-Voigt, ao aplicarmos uma tensão de cisalhamento constante $(\tau)$ a um fluido no instante $t=0$ a deformação pode ser descrita por:

$$
\gamma=\left(\frac{\tau}{G}\right)\left[1-e^{(t / 2)}\right] \quad \text { Equação III.17. }
$$

onde $\lambda=\frac{\eta}{G}$, como $\lambda$ tem dimensão de tempo sendo conhecida como tempo de relaxação ou tempo de retardo (Schramm, 1994).

Para se auxiliar no estudo da viscoelasticidade linear dos materiais foram introduzidos modelos mecânicos que descrevem o comportamento viscoelástico. Esses modelos mecânicos são molas (que representam a parte elástica) e amortecedores (que representam a parte viscosa) que podem ser arranjados em série ou paralelo ou em associações de modo a melhor descrever um comportamento observado.

\section{III.2.1 Creep e Recuperação}

Um dos melhores ensaios que permite se observar e modelar um comportamento viscoelástico é o teste de "creep e recuperação". Nele, medimos a deformação sofrida, durante um intervalo de tempo, em que a tensão é aplicada e retirada. O gráfico obtido nesse tipo de experimento permite se observar o quanto o material recupera da sua forma original e está descrito na Figura III.5. 


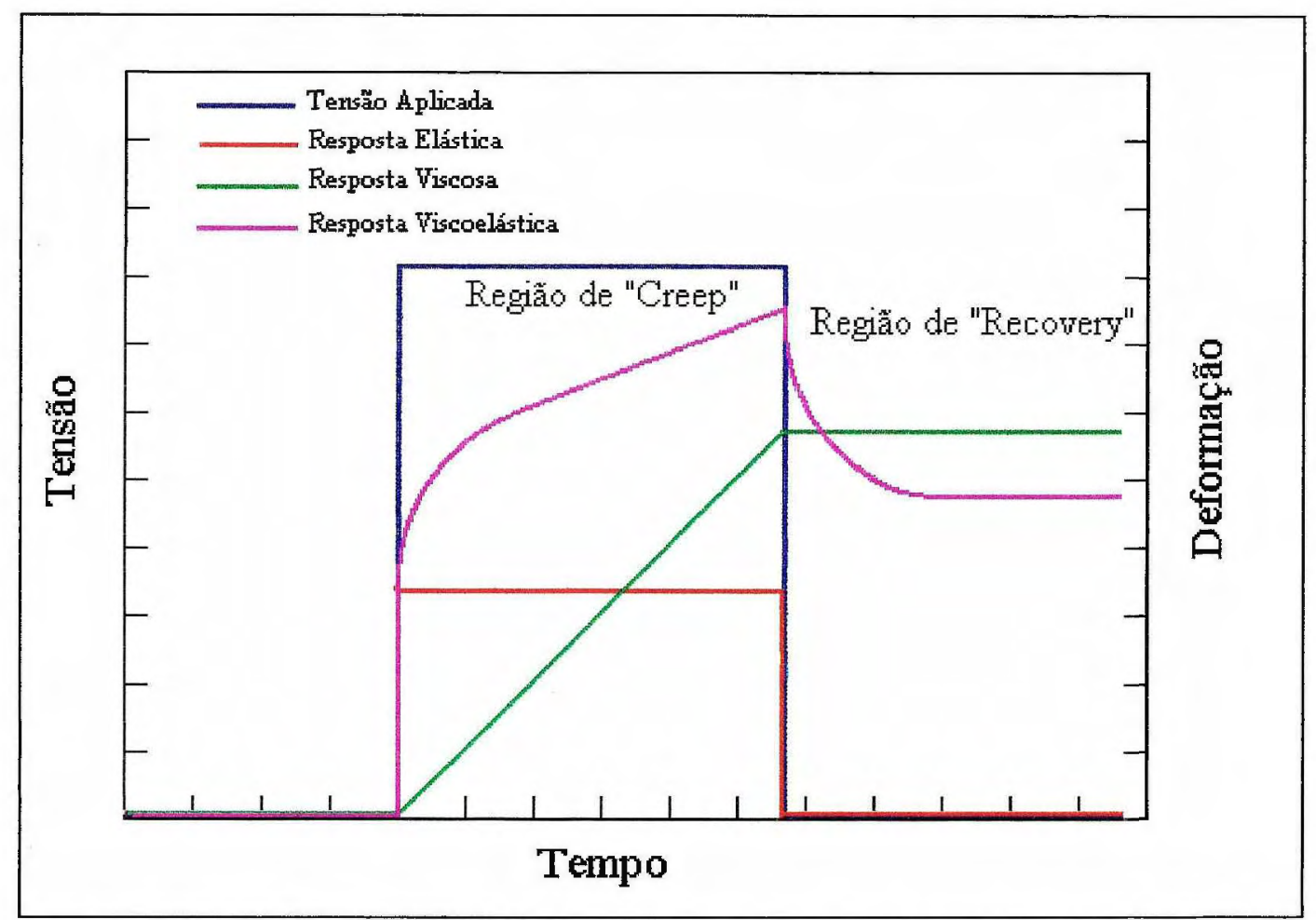

Figura III.5: Gráfico obtido nos ensaios de creep e recuperação para os três tipos de resposta reológicas (Schramm, 1994).

Quando um material elástico é submetido a uma tensão ele se deforma imediatamente e quando a tensão é retirada, a deformação volta ao seu estado original também imediatamente (Figura III.5). Um material viscoso, por sua vez, vai se deformando gradualmente durante a aplicação da tensão e quando esta é retirada, a deformação sofrida permanece. $O$ material viscoelástico apresenta as duas respostas. Durante a aplicação ele sofre uma deformação imediata seguida de uma deformação gradual até o fim da etapa de creep. Ao se iniciar a etapa de recuperação, o material tem uma recuperação que, em um primeiro instante é imediata, mas que se torna gradual. Essa recuperação pode atingir o estado original da amostra ou não, dependendo apenas do tipo do material.

Veremos agora alguns modelos matemáticos que procuram descrever fluidos viscoelásticos. $\mathrm{O}$ primeiro e mais simples modelo que descreve o comportamento de um sólido viscoelástico é o de Kelvin-Voigt. Este consiste 
em um conjunto de uma mola e um amortecedor associados em paralelo (Figura III.6b).

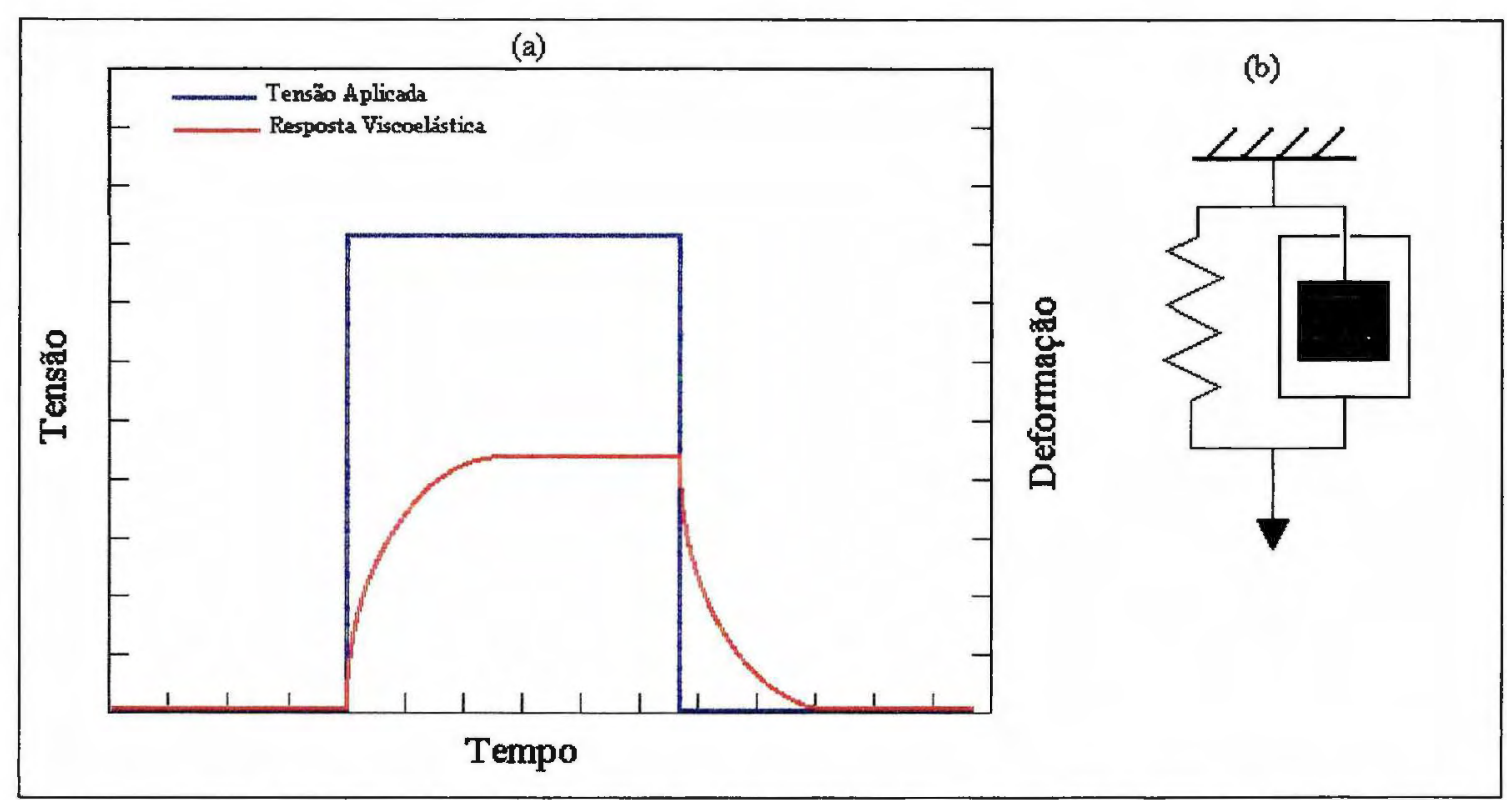

Figura III.6: (a) Curva de Creep e Recuperação para um sólido KelvinVoigt; (b) Modelo mecânico de um sólido Kelvin-Voigt (Schramm, 1994).

A deformação sofrida pela parte elástica (mola) e pela parte viscosa (amortecedor) é igual à deformação total. A tensão total aplicada a este material é a soma de cada uma das contribuições. Matematicamente a equação de estado é (Schramm, 1994):

$$
\tau=\tau_{\text {elastica }}+\tau_{v i s \cos a}=G \cdot \gamma+\eta \cdot \frac{d \gamma}{d t}
$$

Como a tensão aplicada é constante $\left(\tau_{0}\right)$, a solução dessa equação diferencial fica:

$$
\gamma(t)=\frac{\tau_{0}}{G} \cdot\left[1-e^{(-t / \lambda)}\right] \quad \text { Equação III.19. }
$$


Onde $\lambda=\eta / G$, sendo $\eta$ a constante viscosa do amortecedor e $G$ a constante elástica da mola (Schramm, 1994).

Para descrever um líquido viscoelástico, podemos utilizar uma associação em série de uma mola com um amortecedor, essa associação representa um fluido de Maxwell (Figura III.7b).

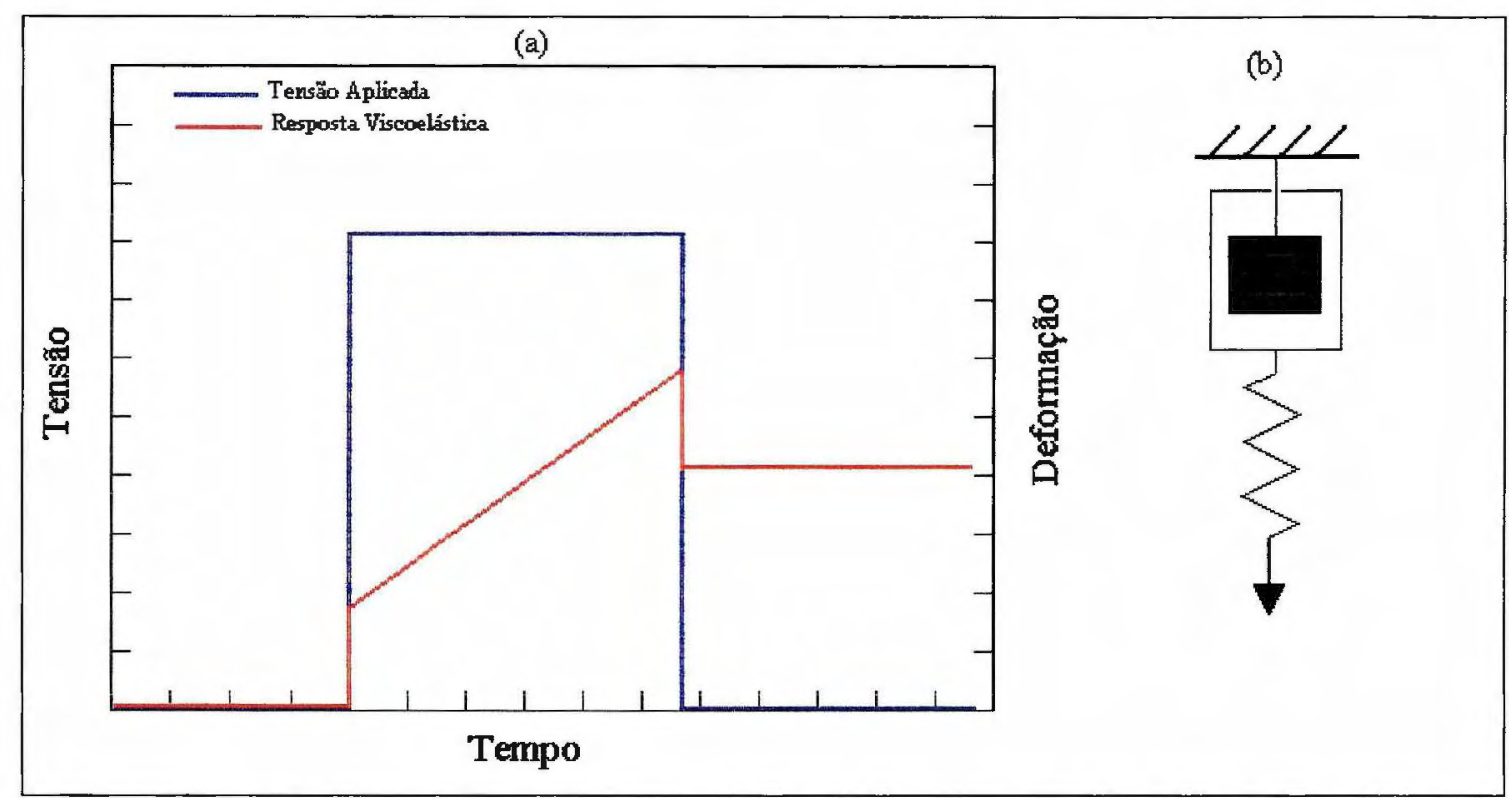

Figura III.7: (a) Curva de Creep e Recuperação para um fluido de Maxwell; (b) Modelo mecânico de um fluido de Maxwell (Schramm, 1994).

Neste caso a tensão total $\left(\tau_{0}\right)$ aplicada é igual à tensão tanto na parte elástica quanto na parte viscosa e a deformação total é a soma das deformações de cada contribuição, portanto a equação de estado nesse caso fica (Schramm, 1994):

$$
\begin{array}{cc}
\gamma_{\text {total }}=\gamma_{\text {elissica }}+\gamma_{\text {viscos } a} & \text { Equação III.20. } \\
\frac{d \gamma_{\text {total }}}{d t}=\frac{d \gamma_{\text {elisstica }}}{d t}+\frac{d \gamma_{v i s \cos \alpha}}{d t}=\frac{1}{G} \frac{d \tau}{d t}+\frac{\tau}{\eta} & \text { Equaçã }
\end{array}
$$


Como a tensão aplicada é constante, a solução da Equação III.21 é (Schramm, 1994):

$$
\gamma(t)=\frac{\tau_{0}}{G}+\frac{\tau_{0}}{\eta} . t \quad \text { Equação III.22. }
$$

Os dois modelos acima apresentados conseguem descrever comportamentos de sólidos e líquidos viscoelásticos ideais, contudo os fluidos viscoelásticos reais têm comportamentos mais complicados. Um dos modelos que consegue melhor descrever estes fluidos é o modelo de Burger, que é representado pela associação dos modelos de Maxwell e Kelvin-Voigt em série (Figura III.8b).

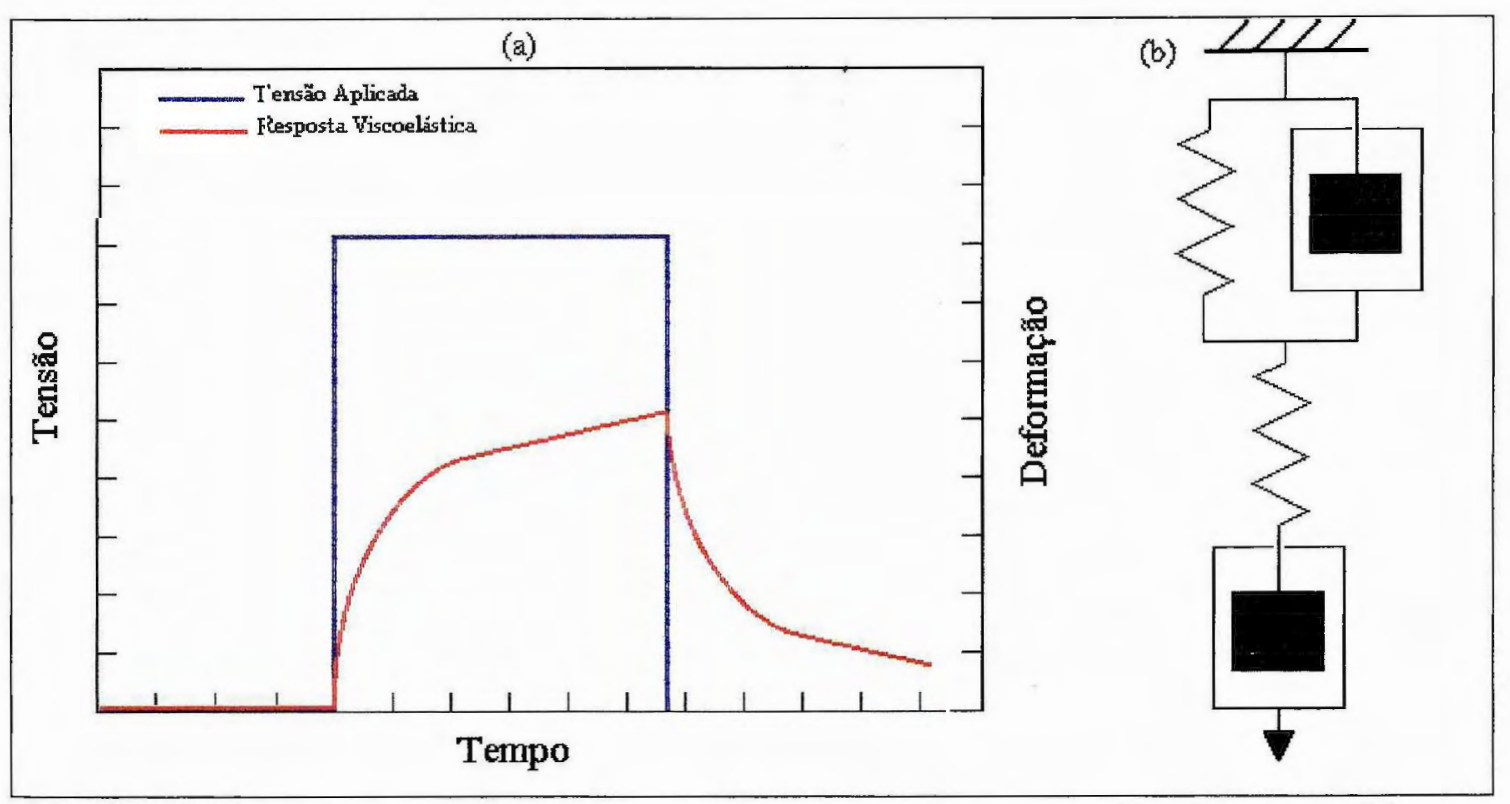

Figura III.8: Curva de Creep e Recuperação para um fluido viscoelástico real; (b) Modelo mecânico de um fluido de Burger (Schramm, 1994).

No modelo de Burger a tensão sofrida nos dois elementos é igual à tensão total enquanto que a deformação é a soma das deformações dos dois modelos, gerando a seguinte equação de estado: 


$$
\tau=G_{1} \gamma_{1}+\eta_{1} \frac{d \gamma}{d t}-\eta_{1}\left[\frac{1}{G_{0}}\left(\frac{d \tau}{d t}\right)+\frac{\tau_{0}}{\eta_{0}}\right]
$$

Equação III.23.

Os índices 0 e 1 representam os elementos de Maxwell e Kelvin-Voigt respectivamente (Schramm, 1994).

A resolução matemática total desta equação é complicada, tendo que ser resolvida para as partes de creep e recuperação separadamente. A fase de creep apresenta a seguinte solução:

$$
\gamma(t)=\frac{\tau_{0}}{G_{0}}+\frac{\tau_{0}}{\eta_{0}} t+\frac{\tau_{0}}{G_{1}}\left[1-e^{\left(-t / z_{1}\right)}\right]
$$

Equação III.24.

Onde $\lambda_{1}=\eta_{1} / G_{1}$ (Schramm, 1994).

$\mathrm{Na}$ fase de recuperação a solução é:

$$
\gamma(t)=\frac{\tau_{0}}{G_{0}}+\frac{\tau_{0}}{\eta_{0}} t+\frac{\tau_{0}}{G_{1}}\left[1-e^{-\left(t-r_{1} / s_{1}\right)}\right]
$$

Equação III.25.

Sendo $t$ maior que $t_{1}$ e $\lambda_{1}=\eta_{1} / G_{1}$ (Schramm, 1994).

\section{III.2.2 - Regime Dinâmico de Cisalhamento de Pequena Amplitude}

O regime dinâmico de cisalhamento de pequena amplitude é quando a tensão de cisalhamento (ou deformação) imposta à amostra varia com a freqüência. Para que se possa garantir que o regime de viscoelasticidade seja linear, a amplitude de tensão ou deformação de cisalhamento deve ser pequena, porque nesta condição a deformação sofrida oscilará com a mesma freqüência da tensão aplicada (Bretas \& D’Ávila, 2000).

A deformação, no regime oscilatório, varia com o tempo de forma senoidal ou cossenoidal (Figura III.9). 


$$
\gamma(t)=\gamma_{0} e^{i \omega t}
$$

Onde $\gamma_{0}$ é a amplitude de deformação e $\omega$, a freqüência (Bretas \& D’Ávila, 2000).

Sendo $\gamma(t)$ uma função complexa ela pode ser representada na forma trigonométrica, por $\mathrm{e}^{\mathrm{i} \omega \mathrm{t}}=\cos (\omega \mathrm{t})+\mathrm{i}$.sen $(\omega \mathrm{t})$.

Como a tensão de cisalhamento oscilará com a mesma freqüência, fora de fase (Figura III.9), ela será representada matematicamente por:

$$
\tau(t)=\tau_{0} e^{i(\omega t+\delta)}
$$

Onde $\tau_{0}$ é a amplitude da tensão de cisalhamento e $\delta$ é o ângulo de fase relativo a deformação (Bretas \& D’Ávila, 2000).

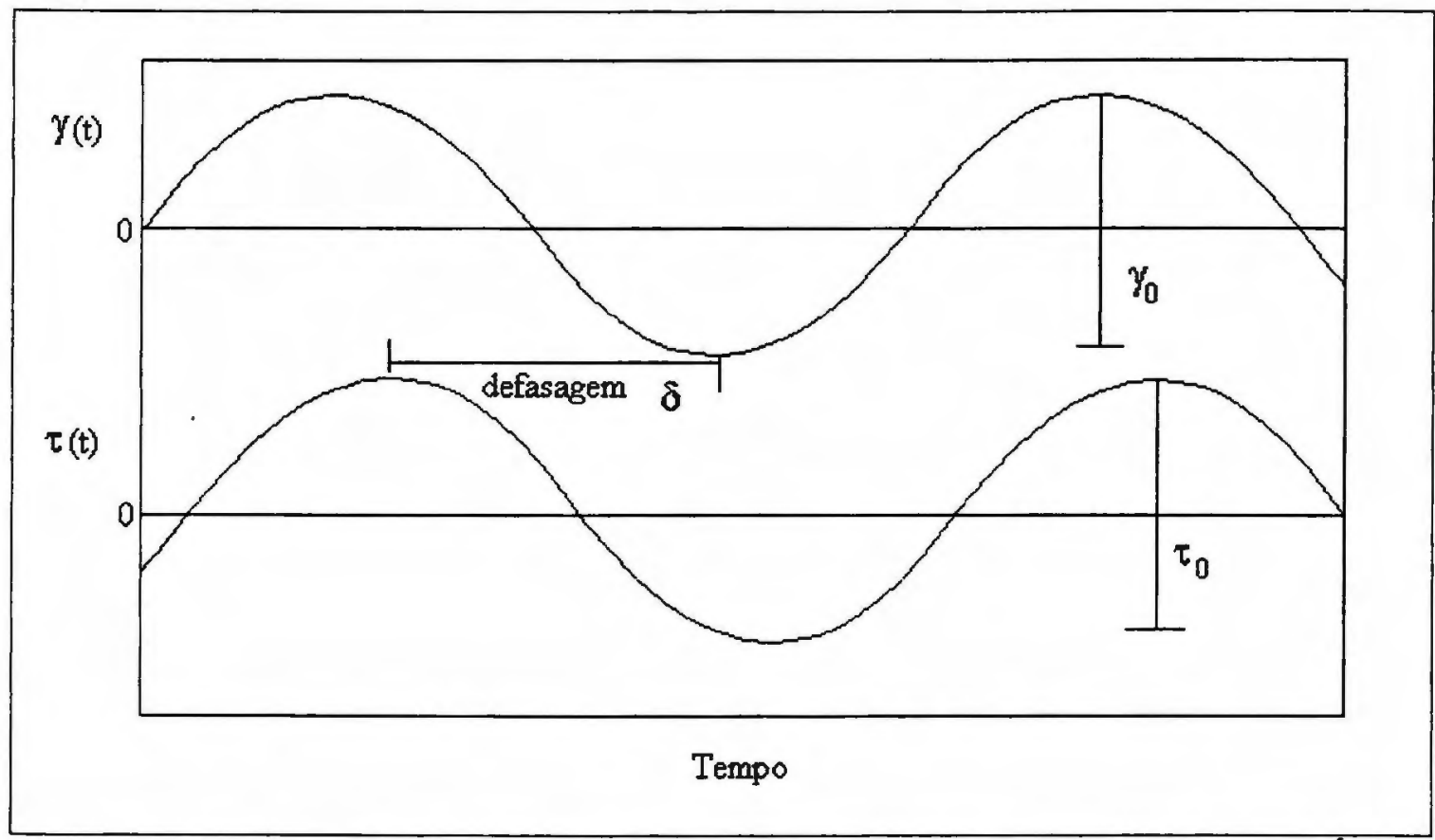

Figura III.9: Fluxo Oscilatório em cisalhamento (Bretas \& D'Ávila, 2000). 
Com as Equações III.26 e III.27, pode se obter a relação de deformação por tensão de cisalhamento:

$$
G^{*}=\frac{\tau(t)}{\gamma(t)}=\frac{\tau_{0}}{\gamma_{0}} e^{i \delta}=\left[\frac{\tau_{0}}{\gamma_{0}} \cos (\delta)\right]+i\left[\frac{\tau_{0}}{\gamma_{0}} \operatorname{sen}(\delta)\right]
$$

Nessa equação G* é chamado de módulo complexo de cisalhamento (Bretas \& D’Ávila, 2000).

Os termos entre colchetes da Equação III.28 são definidos como:

$$
\begin{array}{ll}
G^{\prime}=\frac{\tau_{0}}{\gamma_{0}} \cos (\delta) & \text { Equação III.29. } \\
G^{\prime \prime}=\frac{\tau_{0}}{\gamma_{0}} \operatorname{sen}(\delta) & \text { Equação III.30. }
\end{array}
$$

Neste caso G' é denominado de módulo de armazenamento em cisalhamento, ou simplesmente módulo de armazenamento e está associado à contribuição elástica ou de armazenamento de energia em cada ciclo, sendo muitas vezes definido como módulo elástico (Bretas \& D’Ávila, 2000). G” é denominado módulo de perda em cisalhamento, ou apenas módulo de perda e está associado à contribuição viscosa ou de dissipação de energia em cada ciclo, sendo algumas vezes chamado de módulo viscoso (Bretas \& D’Ávila, 2000).

Deste modo, podemos reescrever a equação do módulo complexo como:

$$
\mathrm{G}^{*}=\mathrm{G}^{\prime}+i \mathrm{G} \quad \text { Equação III.31. }
$$

A relação de G" por G' é conhecida como coeficiente de amortecimento e é definida como sendo igual a tangente do ângulo de fase $\delta$ (Bretas \& D’Ávila, 2000). 


\section{Parte Experimental}

\section{IV.1 Ensaios Rotacionais}

As amostras de cristais líquidos liotrópicos foram preparadas por pesagem dos componentes, em balança analítica, seguida de agitação para facilitar a solubilização dos compostos e centrifugação para a eliminação das bolhas. As mesofases colestéricas eram obtidas primeiramente separando a matriz nemática em diferentes alíquotas, nas quais eram adicionadas quantidades específicas de indutor. Este procedimento foi adotado para se garantir que em todas as fases a concentrações de detergente, sal e água fossem iguais.

O cloreto de decilamônio (CDA) foï gentilmente cedido pelo professor Dr. Hugo Gallardo da Universidade Federal de Santa Catarina. Ele foi preparado pela reação de $\mathrm{n}$-decilamina com $\mathrm{HCl}$, seguida de recristalizações sucessivas em etanol absoluto.

Os outros compostos utilizados, cloreto de amônio, colesterol e D-(+)Manose, foram obtidos da Merck e utilizados sem prévia purificação. A água utilizada para a preparação das amostras, foi obtida por destilação simples.

Todos os ensaios descritos nos itens IV.1.1 a IV.1.3 foram obtidos utilizando-se um reômetro tipo cone placa Brookfield, modelo LVDV-III. O cone utilizado foi o CP-52 (raio 1,2 cm e ângulo de $3^{\circ}$ ) e a temperatura era mantida a $25,0^{\circ} \mathrm{C}$ com o auxilio de um banho termostático da Brookfield, modelo TC-500.

\section{IV.1.1 Caracterização do Fluido em Função da Taxa de} Cisalhamento.

Para este ensaio foram preparadas duas matrizes nemáticas com diferentes concentrações de água. Depois essas matrizes eram divididas em 
alíquotas, as quais eram adicionadas quantidades específicas de colesterol. As concentrações finais estão descritas na Tabela IV.1.

Tabela IV.1: Composição das fases em porcentagem molar nos ensaios de taxa de cisalhamento variado e de tempo de repouso.

\begin{tabular}{cccccc}
\hline Fases & $\mathrm{CDA}$ & $\mathrm{NH}_{4} \mathrm{Cl}$ & $\mathrm{H}_{2} \mathrm{O}$ & Colesterol & $\frac{\text { [Hidrofilico] }}{[\text { Hidrofóbico] }}$ \\
\hline $\mathrm{CDA}-01$ & 6,06 & 1,77 & 92,17 & - & 15,5 \\
$\mathrm{CDA}-02$ & 6,06 & 1,77 & 92,16 & 0,01 & 15,5 \\
$\mathrm{CDA}-03$ & 6,06 & 1,77 & 92,14 & 0,03 & 15,4 \\
$\mathrm{CDA}-04$ & 6,06 & 1,77 & 92,11 & 0,06 & 15,3 \\
$\mathrm{CDA}-05$ & 6,06 & 1,77 & 92,08 & 0,09 & 15,3 \\
\hline $\mathrm{CDA}-06$ & 6,81 & 1,97 & 91,22 & - & 13,7 \\
$\mathrm{CDA}-07$ & 6,81 & 1,97 & 91,21 & 0,01 & 13,7 \\
$\mathrm{CDA}-08$ & 6,80 & 1,97 & 91,20 & 0,03 & 13,6 \\
$\mathrm{CDA}-09$ & 6,80 & 1,97 & 91,17 & 0,06 & 13,6 \\
$\mathrm{CDA}-10$ & 6,80 & 1,97 & 91,14 & 0,09 & 13,5 \\
$\mathrm{CDA}-11$ & 6,80 & 1,98 & 91,07 & 0,15 & 13,4 \\
$\mathrm{CDA}-12$ & 6,80 & 1,98 & 91,01 & 0,21 & 13,3 \\
\hline
\end{tabular}

A última coluna apresentada na Tabela IV.1 mostra o balanço hidrofilico/hidrofóbico, que é a soma das concentrações, em porcentagem molar, das espécies hidrofilicas $\left(\mathrm{H}_{2} \mathrm{O}\right.$ e $\left.\mathrm{NH}_{4} \mathrm{Cl}\right)$ e hidrofóbicas (CDA e colesterol) presentes em cada fase.

As amostras foram submetidas a ciclos de aumento (subida) e diminuição (descida) de velocidade, com diferentes tempos de repouso entre um ciclo e outro. Cada ciclo começava com velocidade de $0,1 \mathrm{rpm}$, que para este cone corresponde a uma taxa de cisalhamento de $\dot{\gamma}=0,2 \mathrm{~s}^{-1}$, indo até 
$100,1 \mathrm{rpm}\left(\dot{\gamma}=200,2 \mathrm{~s}^{-1}\right)$, com incrementos de $5 \mathrm{rpm}$ a cada $30 \mathrm{~s}$. Ao todo foram realizados quatro ciclos (corrida) de subida e descida. Da primeira para a segunda corrida não havia tempo de repouso; da segunda para a terceira o tempo de repouso era de 10 minutos; e da terceira para a quarta, 30 minutos. Esses ensaios foram realizados em ambiente saturado de vapor d'água para evitar perda de massa de água. A saturação da câmara era conseguida colocando-se uma fita adesiva com algodão umedecido em água no compartimento do reômetro onde se colocava a amostra, com o cuidado para que elas não se tocassem. Para se garantir a estabilização do ambiente aguardava-se 30 minutos antes do início do ensaio.

\section{IV.1.2 Caracterização do Fluido em Função do Tempo de Cisalhamento.}

Após os ensaios de taxa de cisalhamento variado, para se identificar o comportamento reológico geral das amostras, inicializou os ensaios com taxa constante de cisalhamento. Com estes ensaios pretendíamos analisar a dependência do tempo de cisalhamento no processo orientacional destes sistemas liquidocristalinos.

Nesses experimentos foram utilizadas, além de amostras com as mesmas concentrações dos ensaios de taxa de cisalhamento variada, fases de cristal líquido com um outro indutor quiral (D-(+)-Manose), a composição de todas as amostras utilizadas nesse ensaio estão descritas na Tabela IV.2. 
Tabela IV.2: Composições das fases de cristal líquido utilizadas nos ensaios de cisalhamento constante em função do tempo com indutor hidrofóbico, em porcentagem molar.

\begin{tabular}{llllll}
\hline Fases & $\mathrm{CDA}$ & $\mathrm{NH}_{4} \mathrm{Cl}$ & $\mathrm{H}_{2} \mathrm{O}$ & Colesterol & D-(+)-Manose $\frac{\text { [Hidrofiliog] }}{\text { [Hidrofóbio] }}$
\end{tabular}

\begin{tabular}{lcccccc}
\hline CDA-13 & 6,06 & 1,77 & 92,17 & - & - & 15,5 \\
CDA-14 & 6,06 & 1,77 & 92,16 & 0,01 & - & 15,5 \\
CDA-15 & 6,06 & 1,77 & 92,14 & 0,03 & - & 15,4 \\
CDA-16 & 6,06 & 1,77 & 92,11 & 0,06 & - & 15,3 \\
CDA-17 & 6,06 & 1,77 & 92,08 & 0,09 & - & 15,3 \\
\hline CDA-18 & 6,81 & 1,97 & 91,22 & - & - & 13,7 \\
CDA-19 & 6,81 & 1,97 & 91,21 & 0,01 & - & 13,7 \\
CDA-20 & 6,80 & 1,97 & 91,20 & 0,03 & - & 13,6 \\
CDA-21 & 6,80 & 1,97 & 91,17 & 0,06 & - & 13,6 \\
CDA-22 & 6,80 & 1,97 & 91,14 & 0,09 & - & 13,5 \\
CDA-23 & 6,80 & 1,98 & 91,07 & 0,15 & - & 13,4 \\
CDA-24 & 6,80 & 1,98 & 91,01 & 0,21 & - & 13,3 \\
\hline CDA-25 & 6,05 & 1,77 & 92,18 & - & - & 15,5 \\
CDA-26 & 6,05 & 1,77 & 92,08 & - & 0,10 & 15,5 \\
CDA-27 & 6,04 & 1,76 & 92,00 & - & 0,20 & 15,5 \\
CDA-28 & 6,02 & 1,76 & 91,71 & - & 0,50 & 15,6 \\
CDA-29 & 5,99 & 1,75 & 91,25 & - & 1,00 & 15,7 \\
\hline CDA-30 & 6,80 & 1,98 & 91,22 & - & - & 13,7 \\
CDA-31 & 6,80 & 1,98 & 91,12 & - & 0,10 & 13,7 \\
CDA-32 & 6,79 & 1,98 & 91,04 & - & 0,20 & 13,7 \\
CDA-33 & 6,77 & 1,97 & 90,76 & - & 0,50 & 13,8 \\
CDA-34 & 6,73 & 1,96 & 90,31 & - & 1,00 & 13,8 \\
\hline & & & & & & - \\
\hline
\end{tabular}


Para as fases em que o indutor utilizado foi D-(+)-Manose, na relação hidrofilico/hidrofóbico, a concentração do indutor se soma aos componentes hidrofilicos, diferentemente do caso do colesterol.

Os ensaios reológicos consistiam em cisalhar as amostras a uma taxa de cisalhamento constante de $100 \mathrm{~s}^{-1}$ e se medir a tensão de cisalhamento a cada 30 segundos até se obter 500 pontos. Os ensaios foram realizados em câmara seca e úmida. Nos ensaios em câmara seca não se utilizava a fita umedecida.

Procedeu-se também a medida de atividade das fases de cristal líquido antes e depois dos ensaios reológicos, para isto utilizou-se o equipamento Aqualab da Decagon Devices, Inc. que mede a atividade da água nas amostras através do ponto de orvalho e cujo erro é de $\pm 0,001$.

\section{IV.1.3 Determinação da Energia de Ativação de Fluxo.}

Para se determinar a energia de ativação de fluxo foram utilizadas somente as amostras com maior quantidade de solvente, pois apesar de se trabalhar em câmara saturada de água, os experimentos eram longos e o aumento de temperatura poderia acarretar uma degradação da amostra (perda de água), podendo levar o sistema a uma região fora da região de cristal líquido. As amostras utilizadas estão descritas na Tabela IV.3. 
Tabela IV.3: Composições das fases de cristais líquidos utilizadas nos ensaios de entalpia de ativação de fluxo, em porcentagem molar.

\begin{tabular}{|c|c|c|c|c|c|c|}
\hline Fases & $\mathrm{CDA}$ & $\mathrm{NH}_{4} \mathrm{Cl}$ & $\mathrm{H}_{2} \mathrm{O}$ & Colesterol & D-(+)-Manose & $\frac{[\text { Hidrofilico }]}{\text { [Hidrofóbico }]}$ \\
\hline CDA-35 & 6,05 & 1,77 & 92,18 & - & - & 15,5 \\
\hline CDA-36 & 6,05 & 1,77 & 92,17 & 0,01 & - & 15,5 \\
\hline CDA-37 & 6,05 & 1,77 & 92,16 & 0,02 & - & 15,5 \\
\hline CDA-38 & 6,05 & 1,77 & 92,15 & 0,03 & - & 15,4 \\
\hline CDA-39 & 6,04 & 1,77 & 92,15 & 0,04 & - & 15,4 \\
\hline $\mathrm{CDA}-40$ & 6,04 & 1,77 & 92,14 & 0,05 & - & 15,4 \\
\hline CDA-41 & 6,04 & 1,77 & 92,13 & 0,06 & - & 15,4 \\
\hline CDA-42 & 6,04 & 1,77 & 92,12 & 0,07 & - & 15,4 \\
\hline CDA-43 & 6,04 & 1,77 & 92,11 & 0,08 & - & 15,3 \\
\hline CDA-44 & 6,04 & 1,77 & 92,10 & 0,09 & - & 15,3 \\
\hline CDA-45 & 6,04 & 1,77 & 92,09 & 0,10 & - & 15,3 \\
\hline CDA-46 & 6,04 & 1,76 & 92,08 & 0,12 & - & 15,2 \\
\hline $\mathrm{CDA}-47$ & 6,04 & 1,76 & 92,05 & 0,15 & - & 15,1 \\
\hline CDA-48 & 6,05 & 1,77 & 92,18 & - & - & 15,5 \\
\hline CDA-49 & 6,05 & 1,77 & 92,08 & - & 0,10 & 15,5 \\
\hline CDA-50 & 6,04 & 1,77 & 91,99 & - & 0,20 & 15,5 \\
\hline CDA-51 & 6,03 & 1,77 & 91,90 & - & 0,30 & 15,6 \\
\hline CDA-52 & 6,03 & 1,77 & 91,80 & - & 0,40 & 15,6 \\
\hline $\mathrm{CDA}-53$ & 6,02 & 1,76 & 91,72 & - & 0,50 & 15,6 \\
\hline CDA-54 & 6,01 & 1,76 & 91,61 & - & 0,62 & 15,6 \\
\hline CDA-55 & 6,01 & 1,76 & 91,53 & - & 0,71 & 15,6 \\
\hline CDA-56 & 6,00 & 1,75 & 91,45 & - & 0,80 & 15,7 \\
\hline CDA-57 & 6,00 & 1,75 & 91,35 & - & 0,90 & 15,7 \\
\hline CDA-58 & 5,99 & 1,76 & 91,26 & - & 1,00 & 15,7 \\
\hline CDA-59 & 5,98 & 1,75 & 91,06 & - & 1,21 & 15,7 \\
\hline CDA-60 & 5,96 & 1,74 & 90,78 & - & 1,52 & 15,8 \\
\hline
\end{tabular}


As amostras foram mantidas a uma taxa de cisalhamento constante de $100 \mathrm{~s}^{-1}$ e se media a viscosidade a cada 30 segundos durante 10 minutos para cada temperatura. A faixa de temperatura utilizada foi de 20,0 a $40,0^{\circ} \mathrm{C}$, com incremento de $2,0^{\circ} \mathrm{C}$.

Todas as fases foram analisadas na faixa de temperatura de 20,0 até $40,0^{\circ} \mathrm{C}$, obtendo-se gráficos semelhantes ao da Figura IV.1.

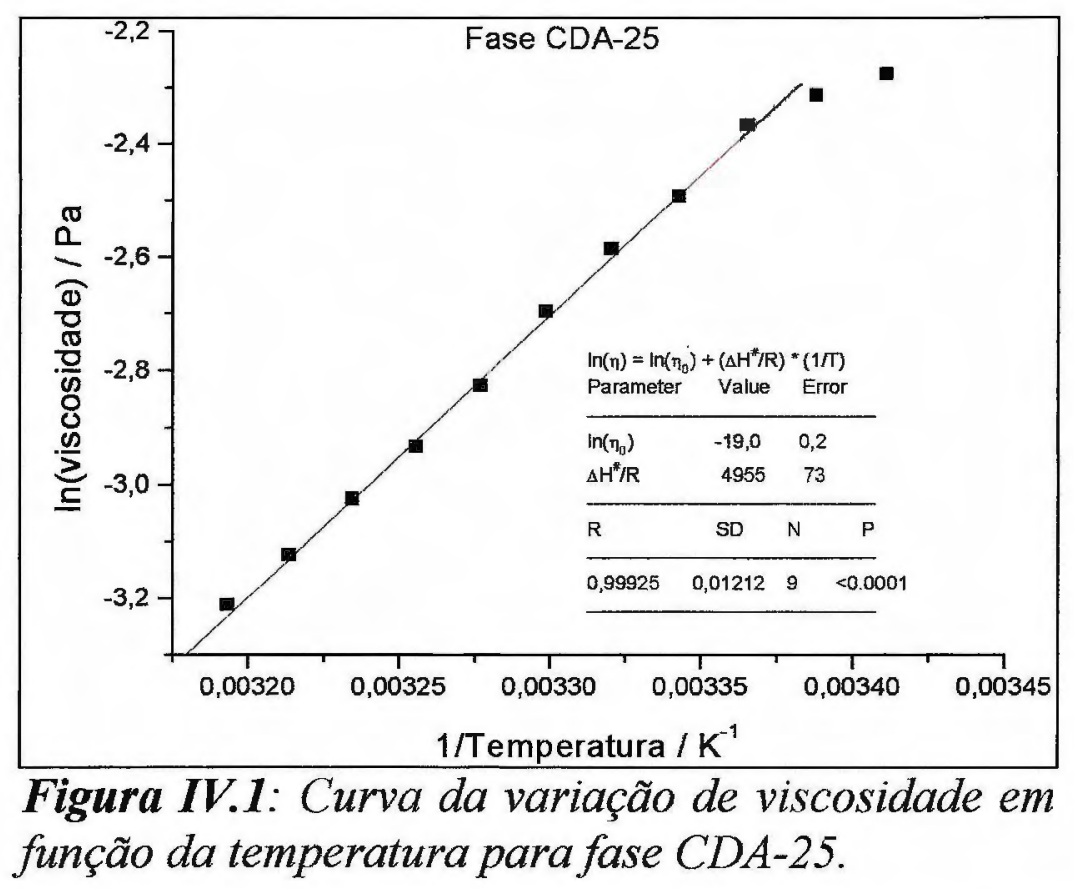

Todas as amostras apresentaram um patamar nas temperaturas mais baixas $\left(20,0\right.$ e $\left.22,0^{\circ} \mathrm{C}\right)$, indicando uma possível transição de fase. Portanto, para efeito da determinação da entalpia de ativação de fluxo $\left(\Delta H^{\#}\right)$, esses pontos foram descartados. 


\section{IV.2 Ensaios Oscilatórios.}

Nesta parte do trabalho, utilizou-se um reômetro PAAR-PHYSICA de tensão controlada, modelo MCR-300. O cone usado foi o CP25-1 (diâmetro = $24,94 \mathrm{~mm}$, ângulo $=1^{\circ}$ ). A temperatura foi mantida a $25,00^{\circ} \mathrm{C}$ com o auxílio de uma placa peltier que fornece um controle de temperatura com precisão de $0,01^{\circ} \mathrm{C}$.

As amostras utilizadas nestes ensaios estão descritas nas Tabela IV.4 e Tabela IV.5. 
Tabela IV.4: Composição em porcentagem molar das fases, com maior relação hidrofilico/hidrofóbico, utilizadas nos ensaios oscilatórios.

\begin{tabular}{ccccccc}
\hline Fases & $\mathrm{CDA}$ & $\mathrm{NH}_{4} \mathrm{Cl}$ & $\mathrm{H}_{2} \mathrm{O}$ & Colesterol & $\mathrm{D}-(+)-M a n o s e$ & {$[$ [Hidrofilico] } \\
\hline [Hidrofobico]
\end{tabular}


Tabela IV.5: Composição em porcentagem molar das fases, com menor relação hidrofilico/hidrofóbico, utilizadas nos ensaios oscilatórios.

\begin{tabular}{ccccccc}
\hline Fases & $\mathrm{CDA}$ & $\mathrm{NH}_{4} \mathrm{Cl}$ & $\mathrm{H}_{2} \mathrm{O}$ & Colesterol & $\mathrm{D}-(+)-M a n o s e$ & $\frac{[\text { Hidrofilico] }}{[\text { Hidrofobico] }}$ \\
\hline CDA-87 & 6,80 & 1,98 & 91,22 & - & - & 13,7 \\
CDA-88 & 6,79 & 1,99 & 91,21 & 0,01 & - & 13,7 \\
CDA-89 & 6,79 & 1,99 & 91,20 & 0,02 & - & 13,7 \\
CDA-90 & 6,79 & 1,98 & 91,20 & 0,03 & - & 13,6 \\
CDA-91 & 6,79 & 1,98 & 91,19 & 0,04 & - & 13,6 \\
CDA-92 & 6,79 & 1,98 & 91,18 & 0,05 & - & 13,6 \\
CDA-93 & 6,79 & 1,98 & 91,17 & 0,06 & - & 13,6 \\
CDA-94 & 6,79 & 1,98 & 91,16 & 0,07 & - & 13,6 \\
CDA-95 & 6,79 & 1,98 & 91,15 & 0,08 & - & 13,5 \\
CDA-96 & 6,79 & 1,99 & 91,13 & 0,09 & - & 13,5 \\
CDA-97 & 6,79 & 1,98 & 91,13 & 0,10 & - & 13,5 \\
CDA-98 & 6,79 & 1,98 & 91,11 & 0,12 & - & 13,5 \\
CDA-99 & 6,79 & 1,97 & 91,09 & 0,15 & - & 13,4 \\
\hline CDA-100 & 6,80 & 1,98 & 91,22 & - & - & 13,7 \\
CDA-101 & 6,79 & 1,98 & 91,13 & - & 0,10 & 13,7 \\
CDA-102 & 6,78 & 1,98 & 91,04 & - & 0,20 & 13,7 \\
CDA-103 & 6,77 & 1,98 & 90,95 & - & 0,30 & 13,8 \\
CDA-104 & 6,77 & 1,98 & 90,85 & - & 0,40 & 13,8 \\
CDA-105 & 6,77 & 1,97 & 90,73 & - & 0,53 & 13,8 \\
CDA-106 & 6,75 & 1,97 & 90,68 & - & 0,60 & 13,8 \\
CDA-107 & 6,75 & 1,96 & 90,59 & - & 0,70 & 13,8 \\
CDA-108 & 6,74 & 1,97 & 90,48 & - & 0,81 & 13,8 \\
CDA-109 & 6,74 & 1,97 & 90,40 & - & 0,90 & 13,8 \\
CDA-110 & 6,73 & 1,96 & 90,30 & - & 1,01 & 13,8 \\
CDA-111 & 6,71 & 1,96 & 90,12 & - & 1,21 & 13,9 \\
CDA-112 & 6,69 & 1,95 & 89,78 & - & 1,58 & 13,9 \\
\hline & & & & & & \\
\hline
\end{tabular}


Os ensaios oscilatórios consistiam em três ensaios básicos, o de determinação da região de viscoelasticidade linear; o de creep e recuperação e o de determinação dos módulos de armazenamento $\left(G^{\prime}\right)$ e de perda ( $\left(G^{\prime \prime}\right)$. De posse da informação da região de viscoelasticidade linear, escolhia-se uma tensão dentro da região de viscoelasticidade linear determinada e realizava os ensaios de creep e recuperação. Por fim, o ensaio de determinação dos módulos de armazenamento e de perda era realizado mantendo-se a deformação constante e dentro da região de viscoelasticidade linear e variavase a freqüência de oscilação.

\section{IV.2.1 Determinação da Região de Viscoelasticidade Linear.}

Neste ensaio, as amostras (CDA-61 a CDA-112) foram submetidas a uma tensão de cisalhamento que variava de 0,1 a $500 \mathrm{~Pa}$ em uma freqüência constante em $1 \mathrm{~Hz}$. Nestas condições se media como o módulo complexo (G*) variava em função da tensão aplicada.

\section{IV.2.2. Creep e Recuperação}

Nos ensaios de creep, as amostras (CDA-61 a CDA-112) foram submetidas a uma tensão escolhida dentro da faixa de viscoelasticidade linear, durante um intervalo de tempo de 5 segundos, onde se media a deformação sofrida. Após esse tempo, se retirava a tensão e media-se quanto a amostra recuperava do seu estado inicial. 
IV.2.3. Determinação dos Módulos G' e G" em Função da Freqüência.

Nestes ensaios as amostras (CDA-61 a CDA-112) eram submetidas à variação de freqüência angular de 0,5 a $100 \mathrm{~s}^{-1}$ com uma deformação constante de $0,1 \%$, escolhida por estar dentro da região de viscoelasticidade linear. Nestas condições os valores de $G^{\prime}$ e $G$ " foram obtidos em função da freqüência angular de oscilação. 


\section{Resultados e Discussões.}

\section{V.1. Ensaios Rotacionais}

V.1.1. Caracterização do Fluido em Função da Taxa de Cisalhamento

Ao se analisar os reogramas (Figuras V.1 a V.5) das fases com maior concentração de água (CDA-01 a CDA-05), nota-se que todas as amostras apresentam comportamento basicamente newtoniano com índices de fluidez variando de 0,97 a 1,01 (Tabela V.1). Observa-se também que ao se adicionar indutor, $o$ índice de consistência (k) tende a diminuir ao longo das sucessivas corridas.

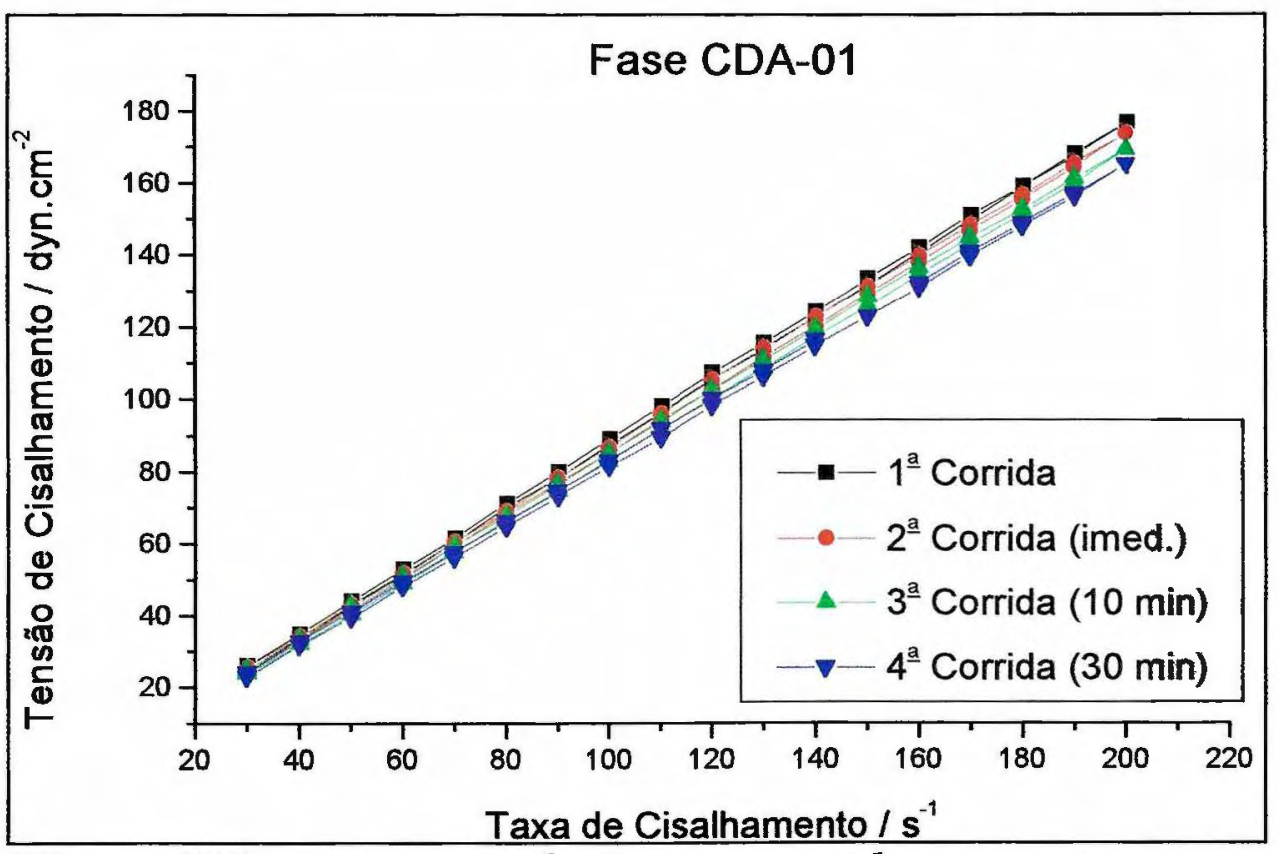

Figura V.1: Reograma de quatro corridas sucessivas com intervalo de repouso diferente para a fase CDA-01, com variação de taxa de cisalhamento a $25,0^{\circ} \mathrm{C}$. 


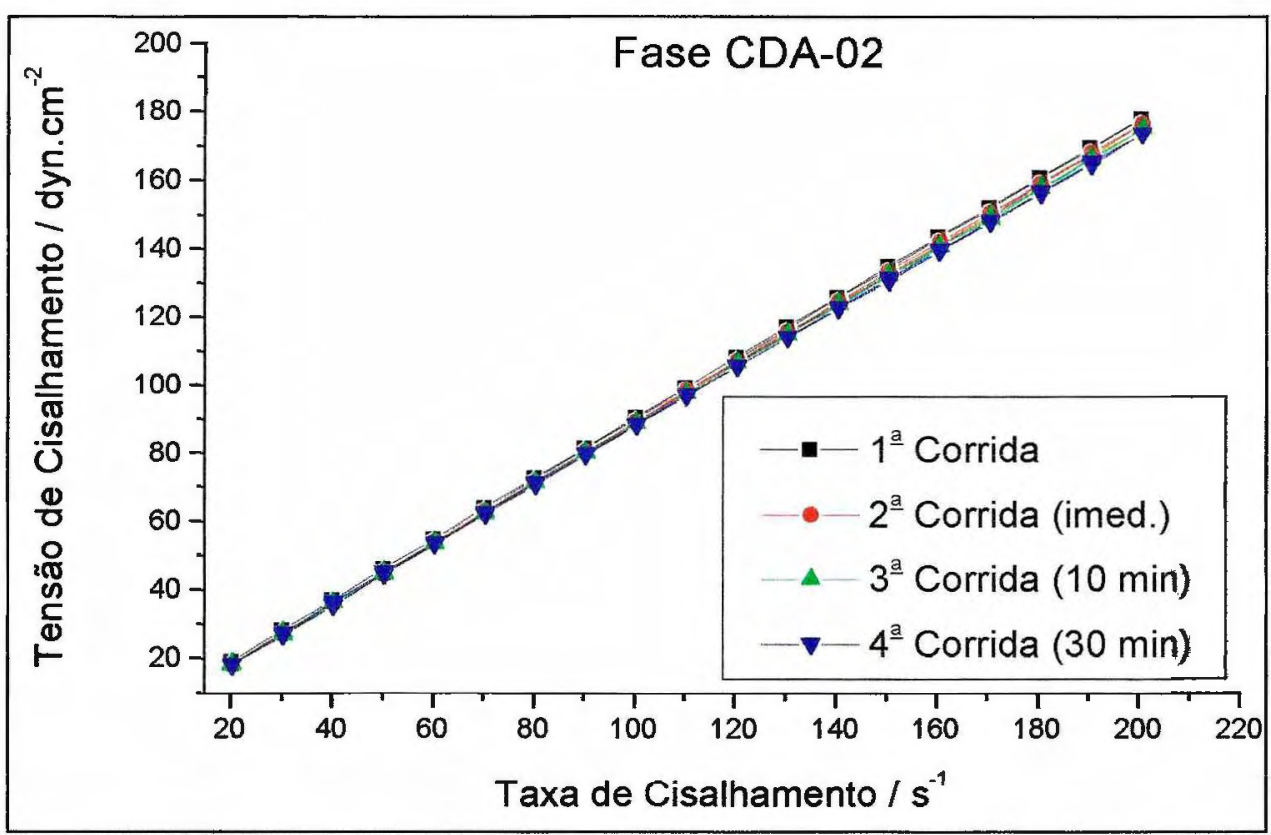

Figura V.2: Reograma de quatro corridas sucessivas com intervalo de repouso diferente para a fase CDA-02, com variação de taxa de cisalhamento a $25,0^{\circ} \mathrm{C}$.

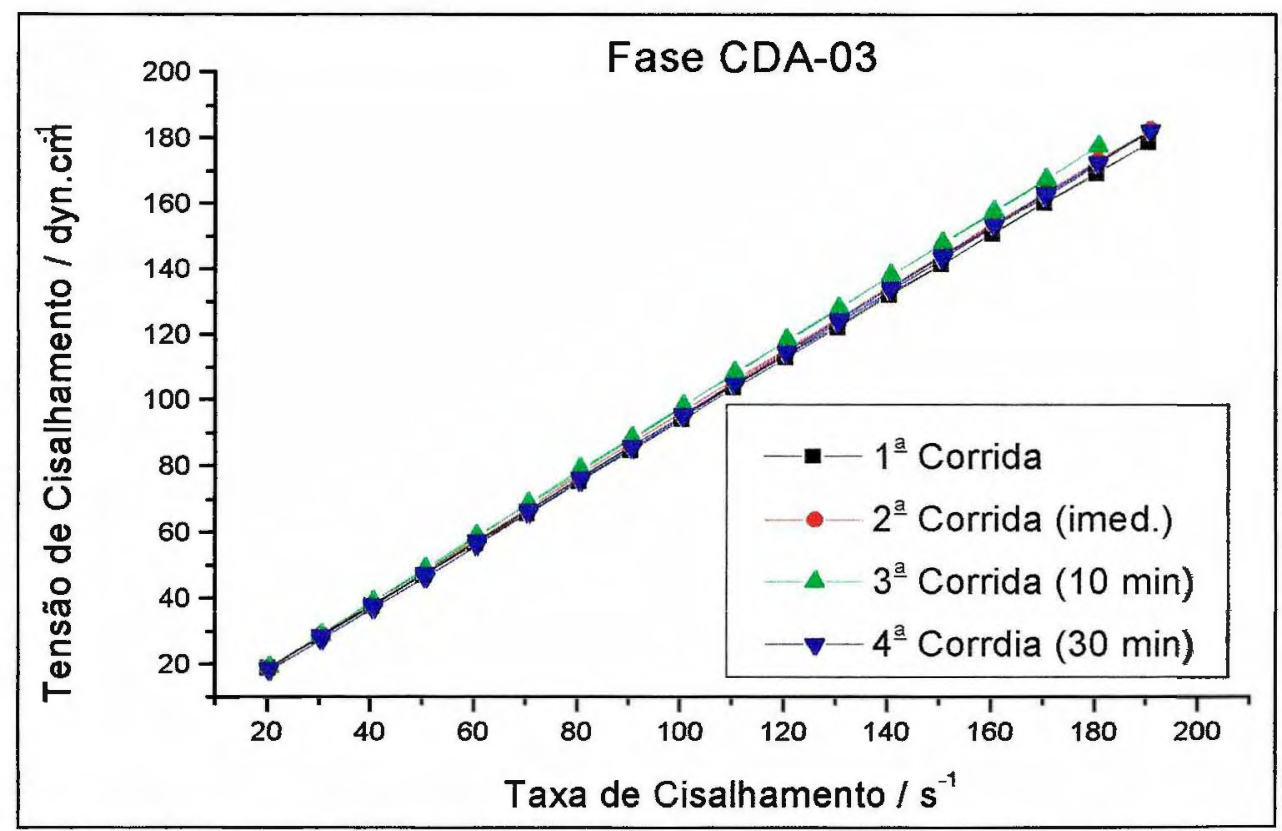

Figura V.3: Reograma de quatro corridas sucessivas com intervalo de repouso diferente para a fase CDA-03, com variação de taxa de cisalhamento a $25,0^{\circ} \mathrm{C}$. 


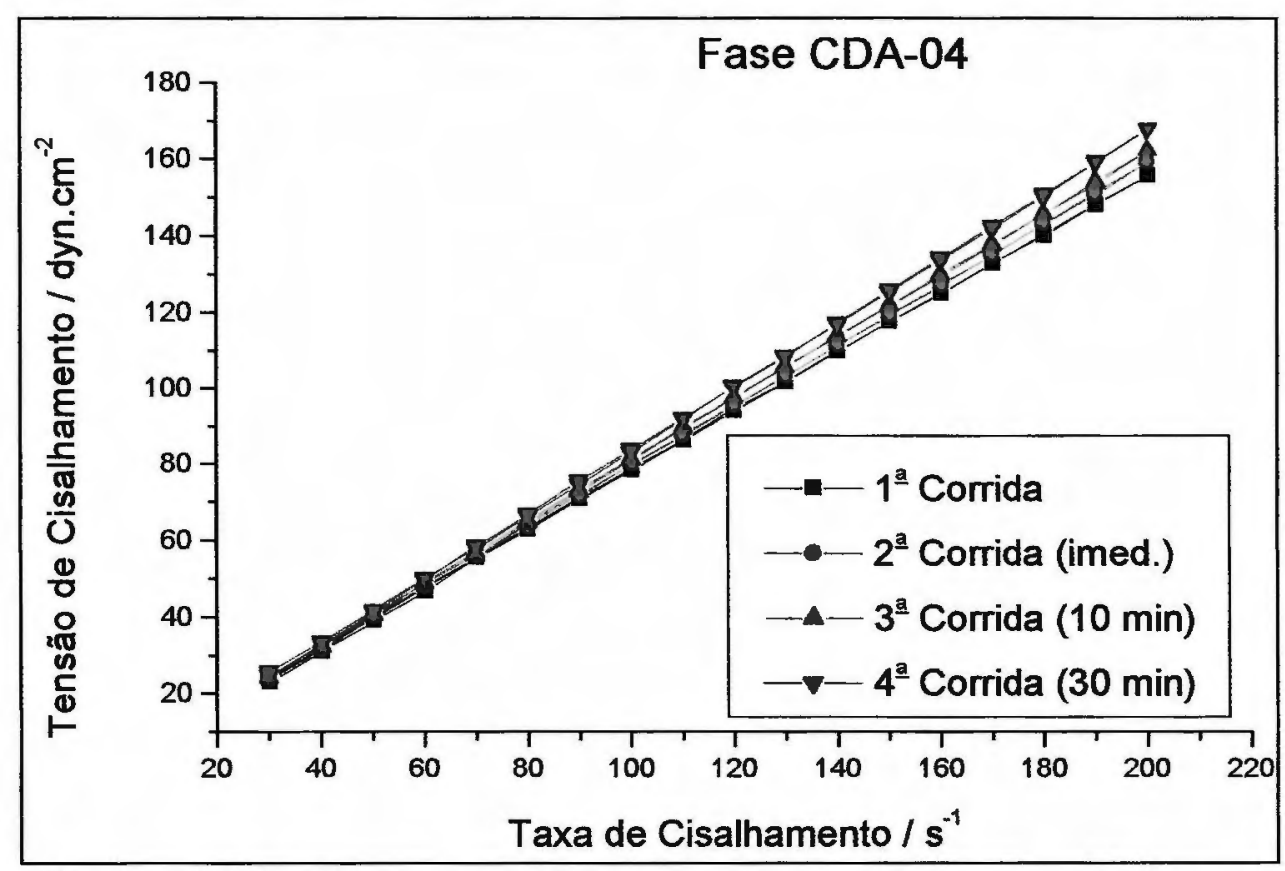

Figura V.4: Reograma de quatro corridas sucessivas com intervalo de repouso diferente para a fase CDA-04, com variação de taxa de cisalhamento a $25,0^{\circ} \mathrm{C}$.

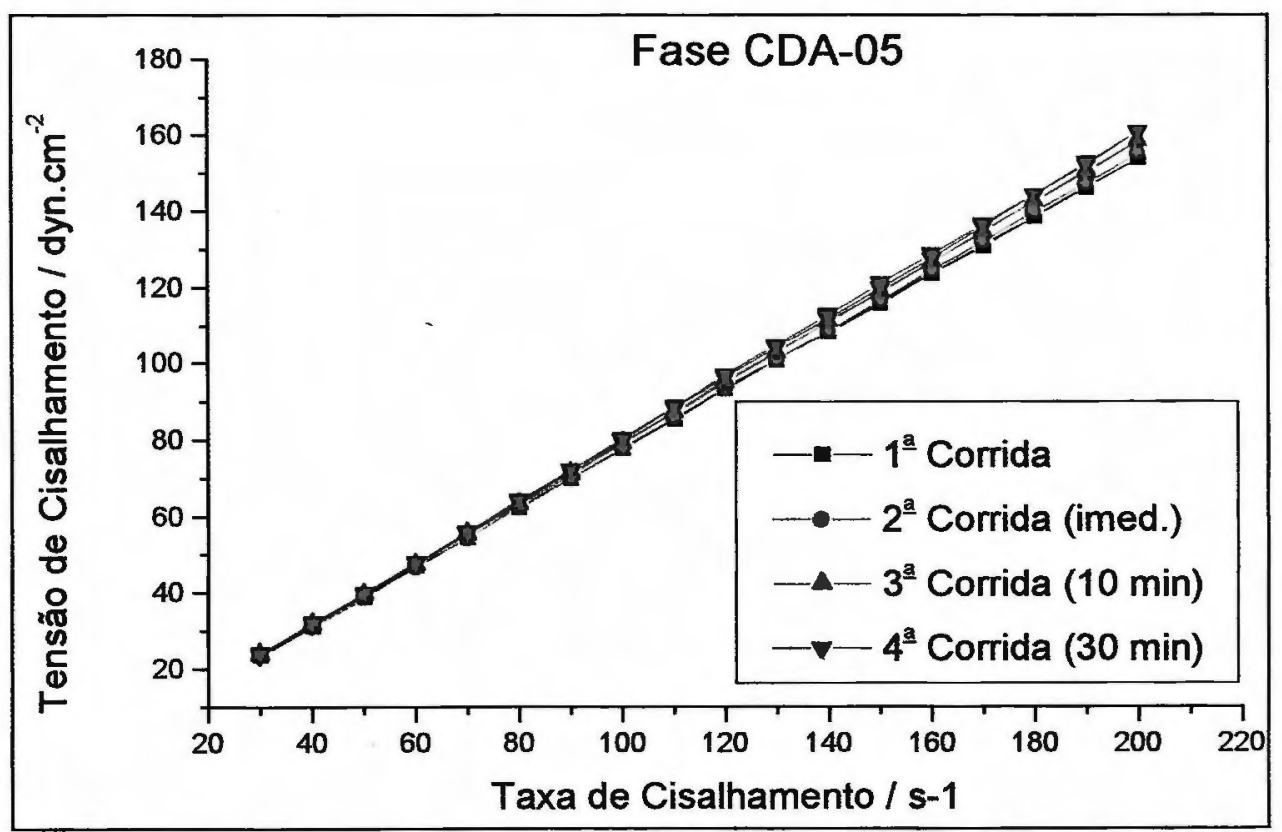

Figura V.5: Reograma de quatro corridas sucessivas com intervalo de repouso diferente para a fase CDA-05, com variação de taxa de cisalhamento a $25,0^{\circ} \mathrm{C}$. 
Tabela V.1: Valores de índice de fluidez (n) e consistência (k) para as fases CDA-01 a CDA-10.

\begin{tabular}{|c|c|c|c|c|c|c|c|}
\hline Fase & Reograma & $\mathrm{n}$ & $\mathrm{k}(\mathrm{cP})$ & Fase & Reograma & $\mathrm{n}$ & $\mathrm{k}(\mathrm{cP})$ \\
\hline & $1^{\circ}$ & 1,00 & 88,0 & & $1^{\circ}$. & 0,97 & 97,8 \\
\hline \multirow[t]{4}{*}{ CDA-01 } & $2^{\circ}$. & 1,00 & 85,0 & CDA-06 & $2^{\circ}$. & 0,97 & 97,8 \\
\hline & $3^{\circ}$. & 1,00 & 84,6 & & $3^{\circ}$ & 1,00 & 97,3 \\
\hline & $4^{\circ}$ & 1,00 & 82,8 & & $4^{\circ}$ & 1,00 & 97,3 \\
\hline & $1^{\circ}$ & 0,98 & 99,6 & & $1^{\circ}$ & 0,90 & 113 \\
\hline \multirow[t]{4}{*}{ CDA-02 } & $2^{\circ}$ & 0,98 & 96,6 & CDA-07 & $2^{\circ}$. & 0,94 & 107 \\
\hline & $3^{\circ}$. & 0,98 & 98,1 & & $3^{\circ}$. & 0,99 & 83,7 \\
\hline & $4^{\circ}$ & 0,97 & 99,0 & & $4^{\circ}$ & 1,01 & 81,5 \\
\hline & $1^{\circ}$ & 1,00 & 93,3 & & $1^{\circ}$ & 0,25 & 1617 \\
\hline \multirow[t]{4}{*}{ CDA-03 } & $2^{o}$ & 1,00 & 93,3 & CDA-08 & $2^{\circ}$. & 0,77 & 199 \\
\hline & $3^{\circ}$ & 1,01 & 95,7 & & $3^{\circ}$ & 0,96 & 103 \\
\hline & $4^{\circ}$ & 1,01 & 93,5 & & $4^{\circ}$ & 0,98 & 93,4 \\
\hline & $1^{\circ}$. & 0,99 & 82,0 & & $1^{\circ}$. & 0,24 & 1621 \\
\hline \multirow[t]{4}{*}{ CDA-04 } & $2^{\circ}$ & 1,00 & 78,9 & CDA-09 & $2^{\circ}$ & 0,53 & 430 \\
\hline & $3^{0}$ & 1,00 & 80,0 & & $3^{\circ}$ & 1,00 & 75,5 \\
\hline & $4^{\circ}$ & 1,01 & 80,1 & & $4^{\circ}$ & 1,00 & 80,9 \\
\hline & $1^{\circ}$ & 0,98 & 83,1 & & $1^{\circ}$. & 0,28 & 1450 \\
\hline \multirow[t]{3}{*}{ CDA-05 } & $2^{\circ}$ & 0,99 & 80,1 & CDA-10 & $2^{\circ}$ & 0,51 & 474 \\
\hline & $3^{\circ}$. & 1,00 & 78,1 & & $3^{\circ}$ & 0,99 & 77,0 \\
\hline & $4^{\circ}$ & 1,00 & 78,8 & & $4^{\circ}$ & 1,00 & 77,7 \\
\hline
\end{tabular}

Para as fases com menor concentração de água (CDA-06 a CDA-10) os resultados apresentados foram diferentes das amostras anteriores. A fase nemática (Figura V.6) se mantém visualmente newtoniana e a análise de 
Power Law (Tabela V.1) mostrou que não houve uma variação significativa no índice de fluidez, variando de 0,97 para primeira corrida a 1,00 para quarta corrida. O índice de consistência se manteve praticamente de $97,8 \mathrm{cP}$ para $97,3 \mathrm{cP}$.

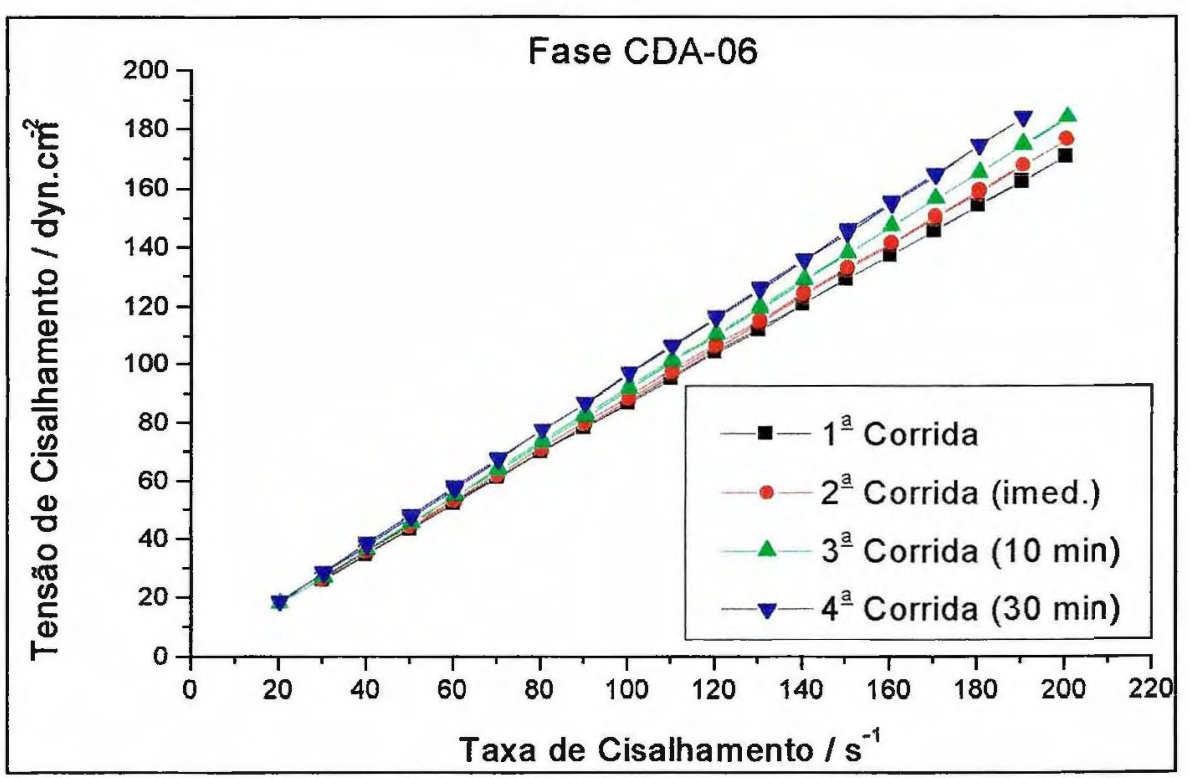

Figura V.6: Reograma de quatro corridas sucessivas com intervalo de repouso diferente para a fase CDA-06, com variação de taxa de cisalhamento a $25,0{ }^{\circ} \mathrm{C}$.

Os reogramas para a fase colestérica com $0,01 \%$ molar de indutor quiral (CDA-07) estão apresentados na Figura V.7. Podemos observar uma característica pseudoplástica, com índice de fluidez de 0,90 para a primeira varredura com a progressiva mudança para um comportamento newtoniano, com índice de fluidez variando de 0,94 a 1,01 (Tabela V.1). O índice de consistência tende a diminuir, ao longo das sucessivas corridas. 


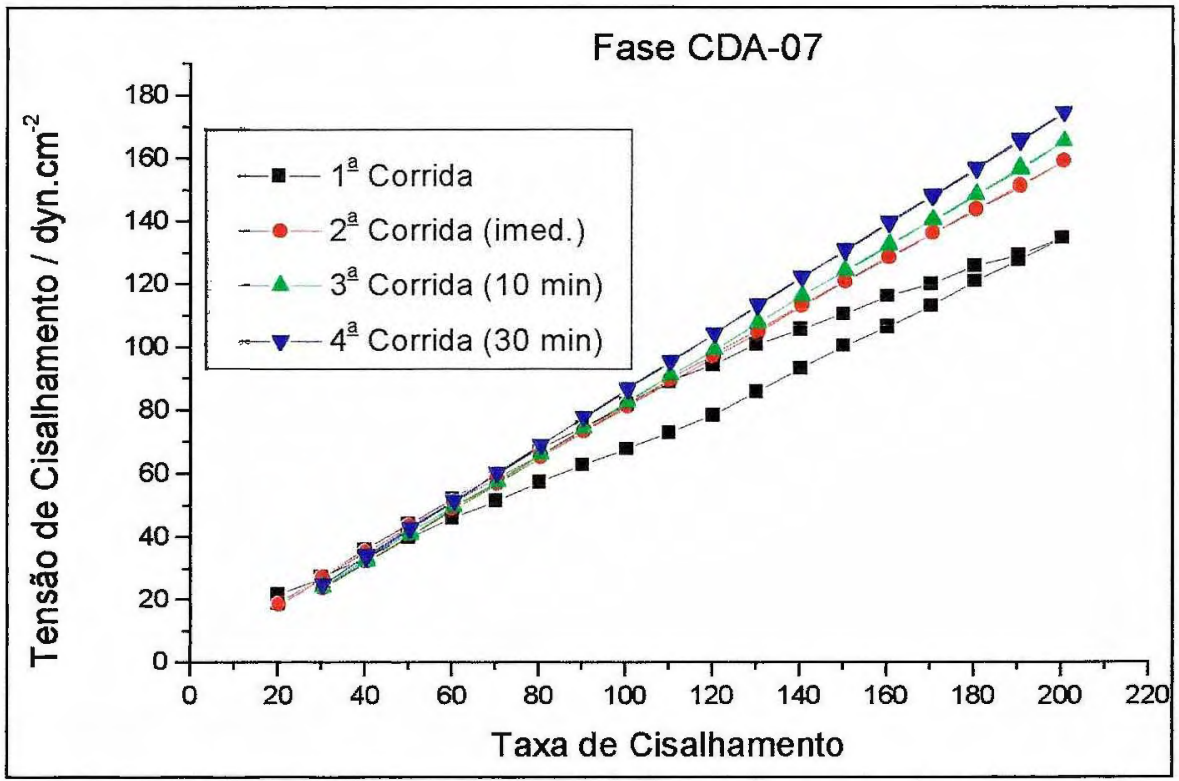

Figura V.7: Reograma de quatro corridas sucessivas com intervalo de repouso diferente para a fase CDA-07, com variação de taxa de cisalhamento a $25,0^{\circ} \mathrm{C}$.

No reograma da fase colestérica com $0,03 \%$ molar de indutor quiral (Figura V.8), a primeira corrida tem característica pseudoplástica bem definida, com índice de fluidez de 0,25. A segunda corrida também apresenta um comportamento pseudoplástico, com índice de fluidez igual a 0,77 , porém mostra uma tendência menos pseudoplástica que a primeira. Na terceira e na quarta corridas o comportamento já é praticamente newtoniano, com índice de fluidez de 0,96 e 0,98 respectivamente. 


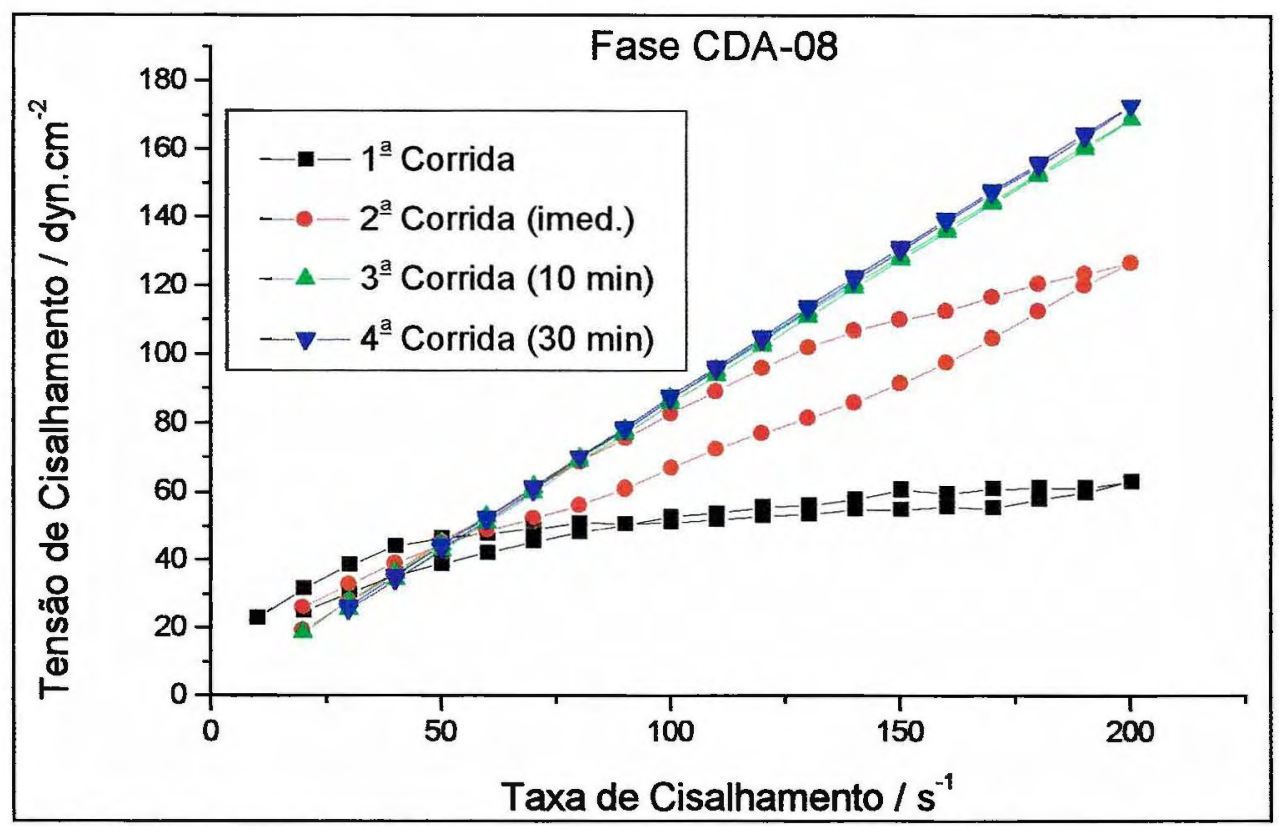

Figura V.8: Reograma de quatro corridas sucessivas com intervalo de repouso diferente para a fase CDA-08, com variação de taxa de cisalhamento a $25,0^{\circ} \mathrm{C}$.

As fases colestéricas com $0,06 \%$ e $0,09 \%$ molar de colesterol (fases CDA-09 e CDA-10 respectivamente) apresentam reogramas muito semelhantes (Figura V.9 para CDA-09 e Figura V.10 para CDA-10). Para ambos os sistemas, as duas primeiras corridas apresentam um comportamento pseudoplástico bem definido, já a terceira e quarta corridas apresentam um comportamento newtoniano. 


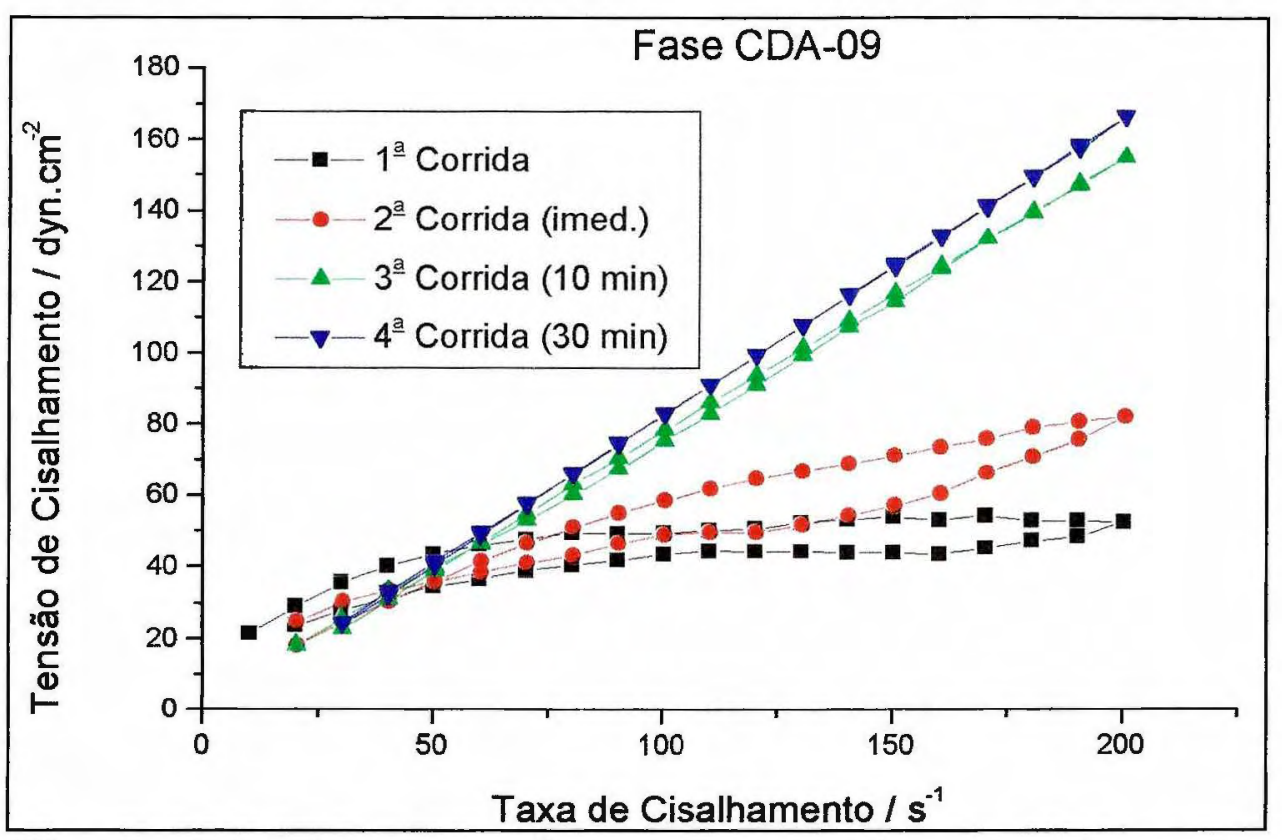

Figura V.9: Reograma de quatro corridas sucessivas com intervalo de repouso diferente para a fase CDA-09, com variação de taxa de cisalhamento a $25,0^{\circ} \mathrm{C}$.

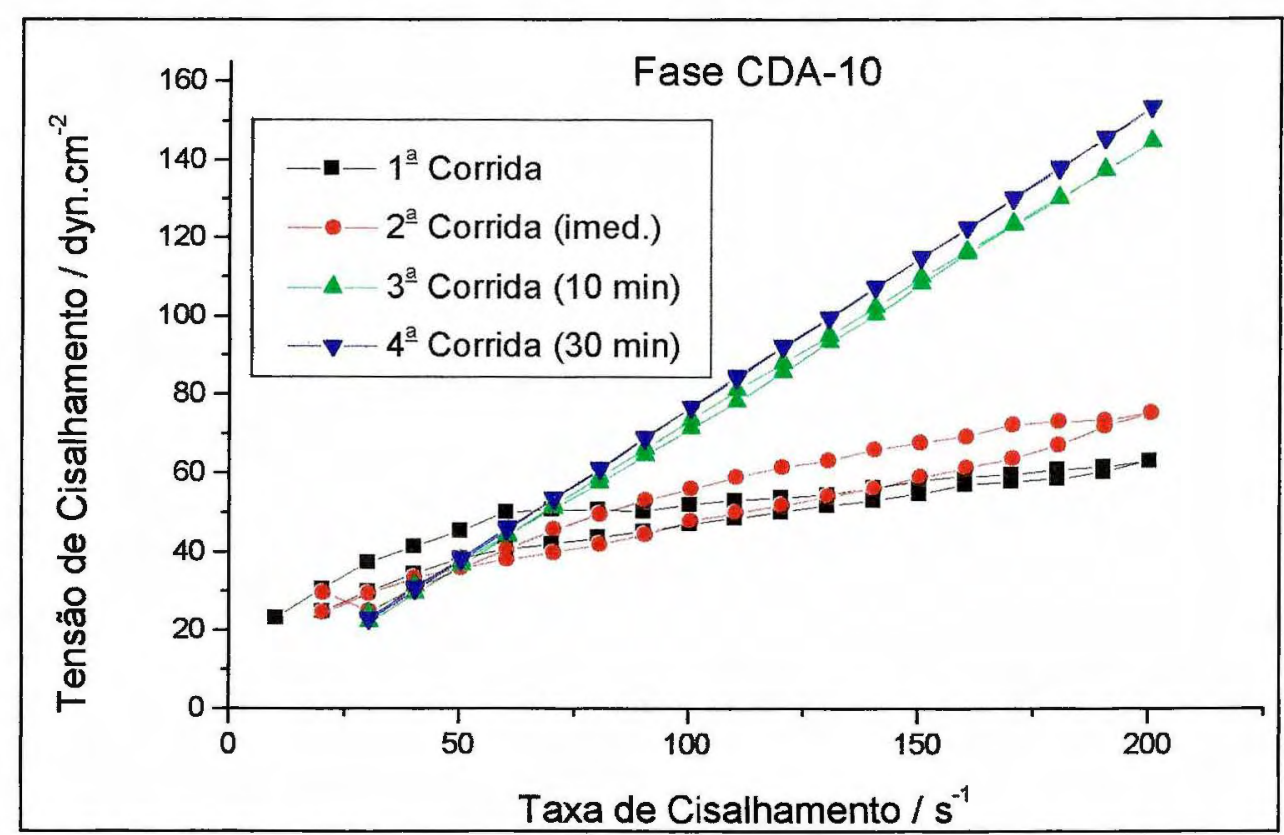

Figura V.10: Reograma de quatro corridas sucessivas com intervalo de repouso diferente para a fase CDA-10, com variação de taxa de cisalhamento a $25,0^{\circ} \mathrm{C}$. 
A pseudoplasticidade observada para as fases colestéricas pode ser devida à fragmentação da estrutura colestérica em microdomínios pelo cisalhamento. Com os sucessivos cisalhamentos, os microdomínios devem se orientar parcialmente e com o auxilio das forças elásticas. Atuando principalmente durante o intervalo entre as corridas, o sistema tende a adquirir orientação similar a obtida pelo sistema nemático levado à alteração do comportamento de pseudoplástico para newtoniano (Alcantara \& Fernandes, 2001).

A diminuição dos valores de índice de consistência (Tabela V.2), indicaria a formação de uma estrutura menos rígida, o que não é esperado para um sistema colestérico.

Para as amostras CDA-06, CDA-10, CDA-11 e CDA-12 (Tabela IV.1) foi realizado outro ensaio com corridas sucessivas (em um total de nove ciclos) sem nenhum tempo entre ciclos.

A fase nemática (CDA-06) apresentou comportamento newtoniano para todas as corridas como na Figura V.6. Para as fases colestéricas, observou-se uma transição de um comportamento pseudoplástico para um comportamento newtoniano. Essa mudança ocorreu na terceira corrida para a fase com $0,09 \%$ molar de colesterol (CDA-10), na sexta para a fase com $0,15 \%$ molar (CDA11) (Figura V.11) e na nona corrida para a fase com $0,21 \%$ molar (CDA-12) (Figura V.12). 


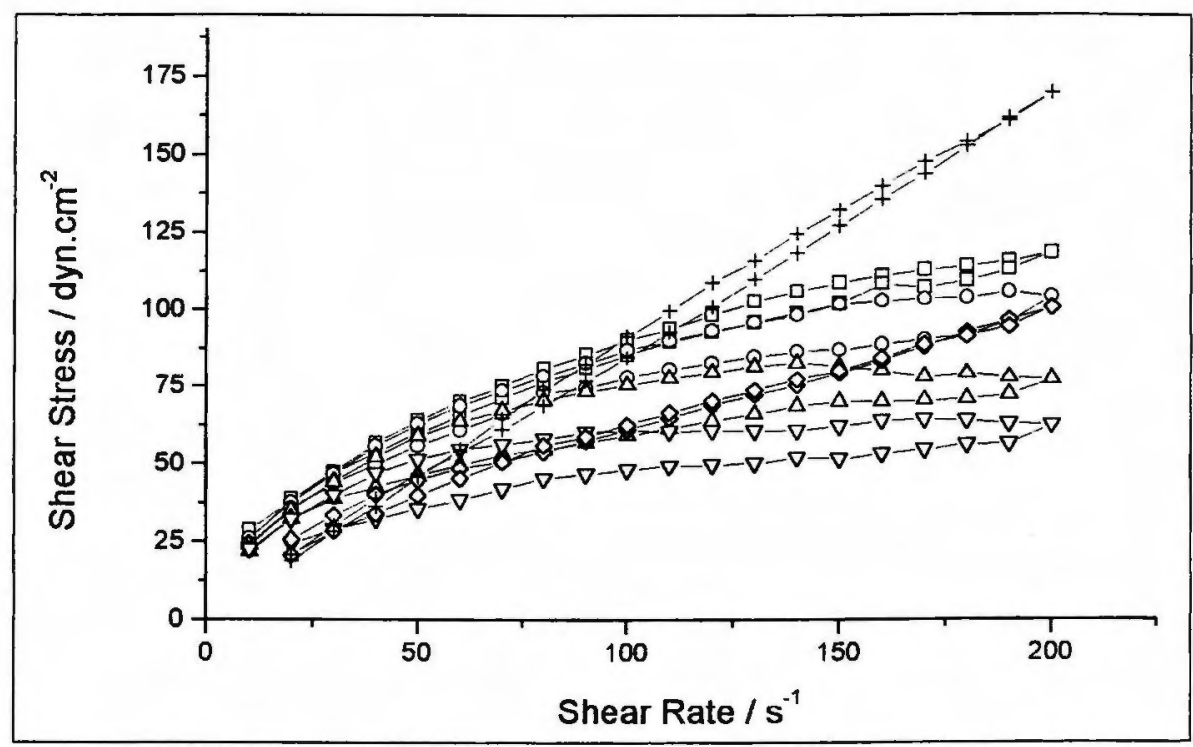

Figura V.11: Reograma para a fase $C D A-11$ a $25,0^{\circ} \mathrm{C}$. (D) $1^{a}$. Corrida; (o) $2^{a}$. Corrida ; (A) $3^{a}$. Corrida; (D) $4^{a}$. Corrida; ( () $5^{a}$. Corrida; (t) $6^{a}$. Corrida. (Alcantara \& Fernandes Jr., 2001).

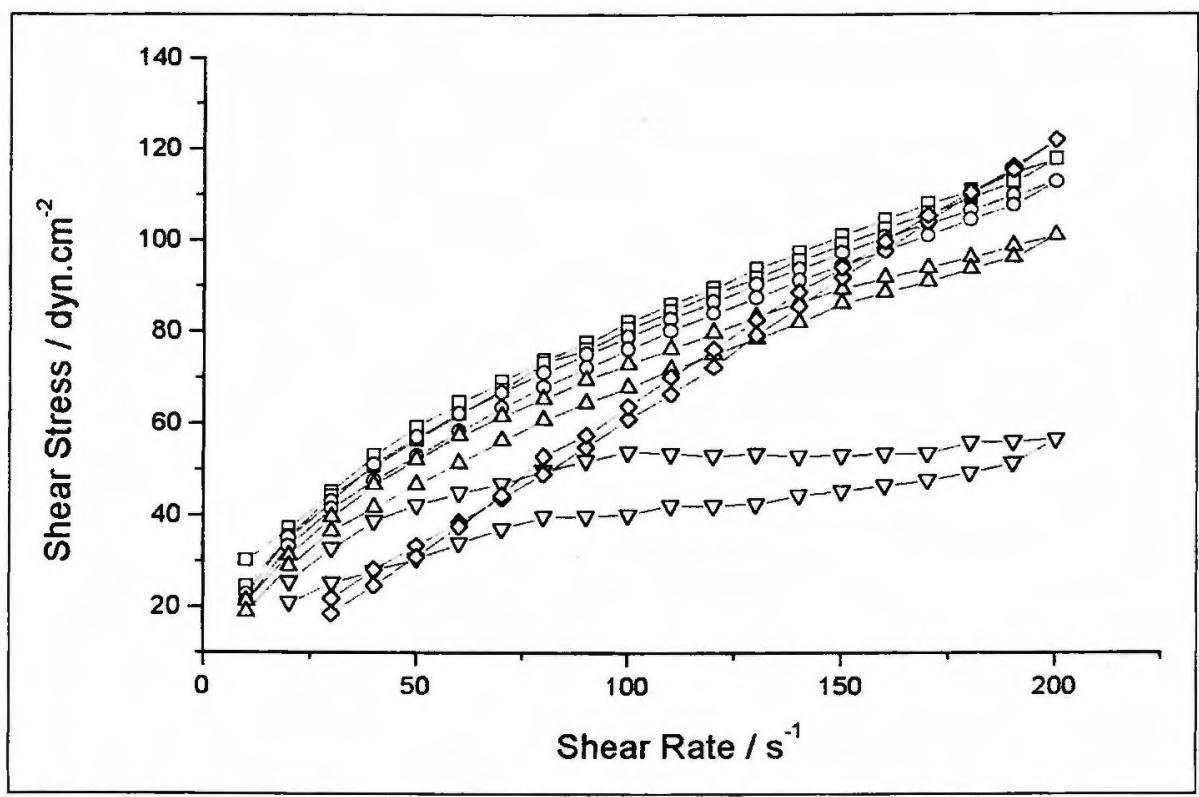

Figura V.12: Reograma para a fase $C D A-12$ a $25,0^{\circ} \mathrm{C}$. (D) $1^{a}$. Corrida; (o) $3^{a}$. Corrida; (A) $5^{a}$. Corrida; (D) $7^{a}$. Corrida; ( ( ) $9^{a}$. Corrida. (Alcantara \& Fernandes $J r$, 2001). 
A mudança do comportamento pseudoplástico para o newtoniano mostra que o arranjo inicial das micelas nos sistemas colestéricos deve ser diferente do arranjo final após o cisalhamento. Pode-se observar também que o rearranjo pode ser obtido tanto por tempo de repouso após o cisalhamento, quanto durante o tempo de cisalhamento. Nestes resultados, parece obvio que a força quiral age na direção contrária a direção do alinhamento por fluxo. De maneira geral, pode se dizer que o processo de cisalhamento envolve uma etapa inicial de destruição da estrutura colestérica, levando a formação de microdomínios com diferentes orientações. Na etapa seguinte ocorreria uma reorientação por cisalhamento, dos microdomínios conduzindo a um arranjo semelhante ao nemático. Um comportamento similar a esse foi descrito por Takebe et al. (Takebe et al., 1990) e Asada et al. (Asada et al., 1980) para cristais líquidos poliméricos, onde estruturas em polidomínios gradualmente tendem a se transformarem em monodomínios pelo aumento da taxa de cisalhamento.

\section{V.1.2 Caracterização do Fluido em Função do Tempo de Cisalhamento.}

Os reogramas obtidos para as fases com indutor hidrofóbico, CDA-13 a CDA17, em ambiente em câmara seca e saturada apresentam o seguinte comportamento mostrado respectivamente nas Figuras V.13 a V.14. 


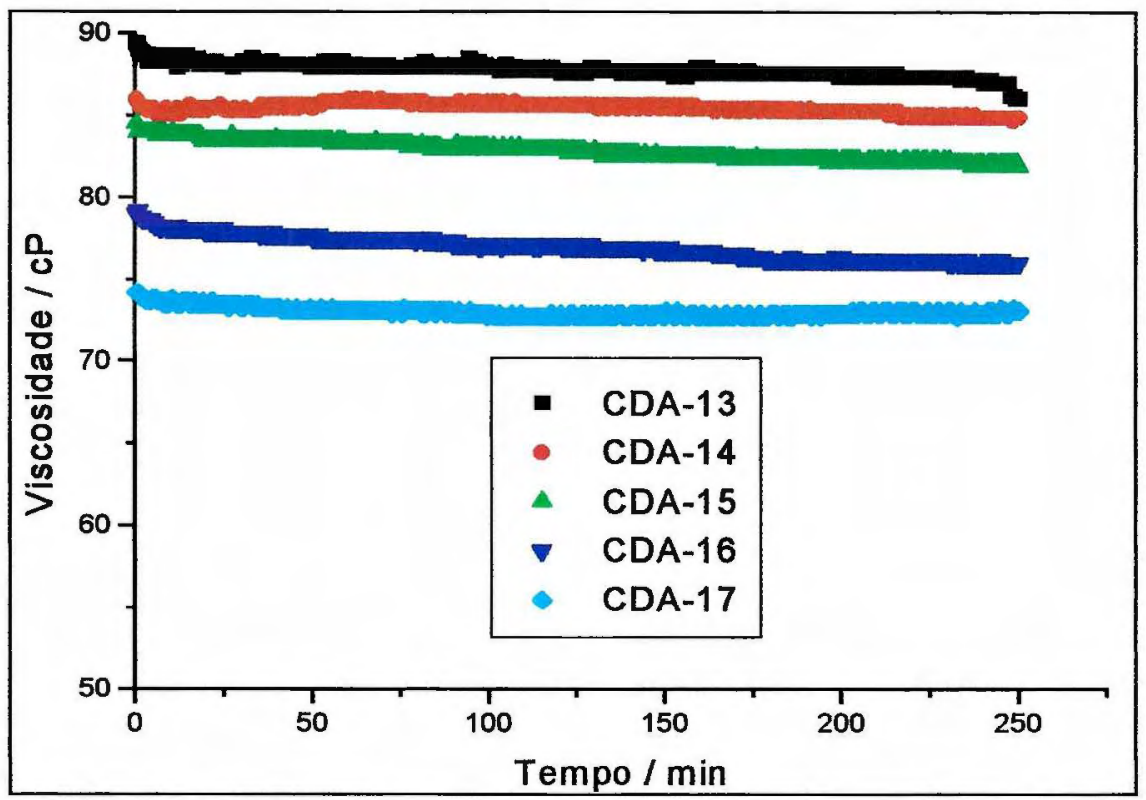

Figura V.13: Reograma das fases CDA-13 a CDA-17 em câmara seca a $25,0^{\circ} \mathrm{C}$, com taxa de cisalhamento constante de $100 \mathrm{~s}^{-1}$.

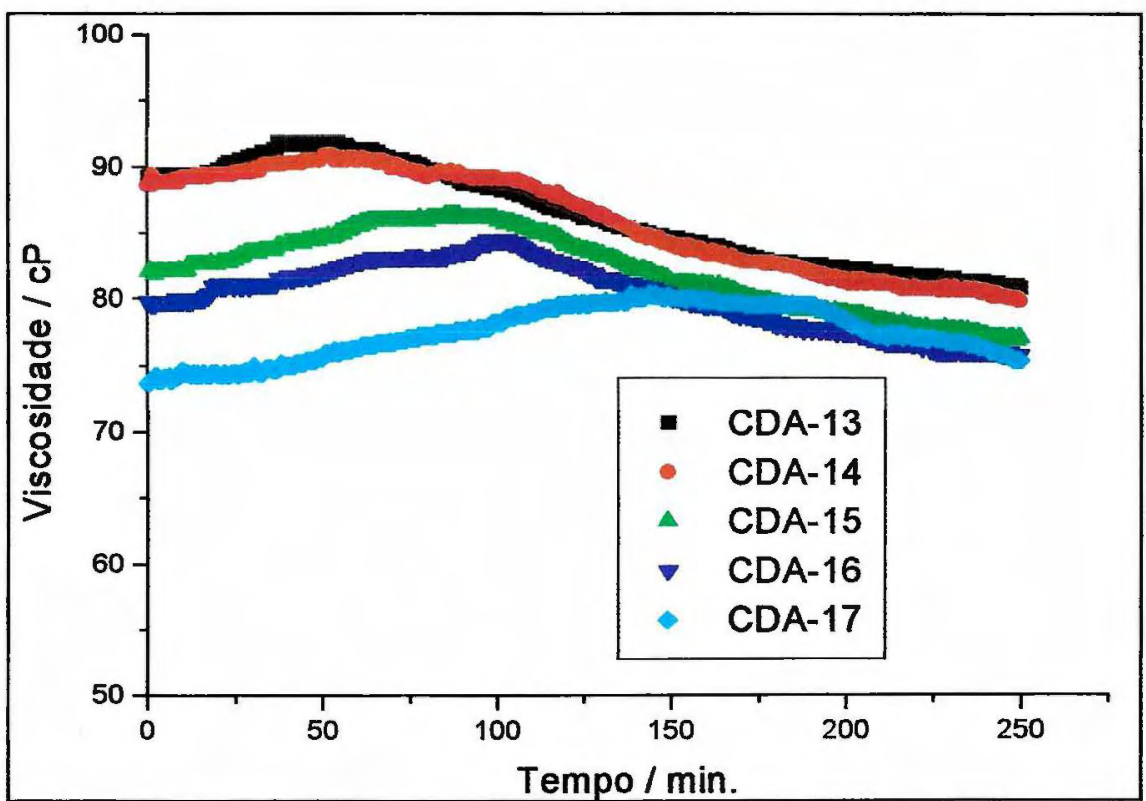

Figura V.14: Reograma das fases CDA-13 a CDA-17 em câmara saturada a $25,0^{\circ} \mathrm{C}$, com taxa de cisalhamento constante de $100 \mathrm{~s}^{-1}$. 
Podemos observar que, em câmara seca (Figura V.13), a viscosidade se mantém constante para todas as fases e que ela diminui com o aumento da concentração de colesterol. Em câmara saturada (Figura V.14), os reogramas apresentam um aumento da viscosidade até atingir um valor máximo a partir do qual começa a diminuir. Em particular neste caso, notamos também que quanto maior a concentração de indutor, maior é o tempo para se atingir o máximo e menor é o valor obtido para a viscosidade.

Os resultados obtidos para as fases com menor relação hidrofilico/hidrofóbico, CDA-18 a CDA-24 são mostrados na Figura V.15 para as amostras analisadas em câmara saturada e na Figura V.16 para as fases analisadas em câmara seca.

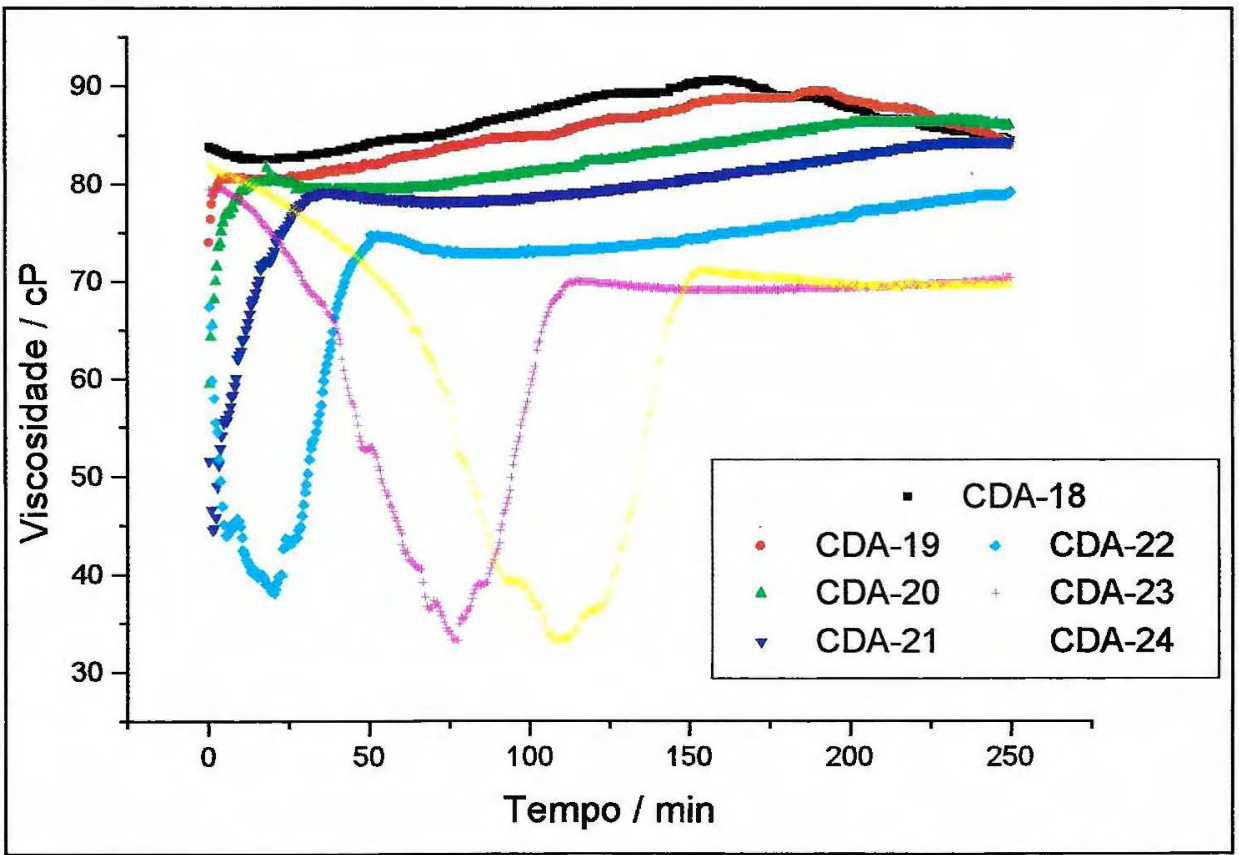

Figura V.15: Reograma das fases CDA-18 a CDA-24 em câmara saturada a $25,0^{\circ} \mathrm{C}$, com taxa de cisalhamento constante de $100 \mathrm{~s}^{-1}$. 


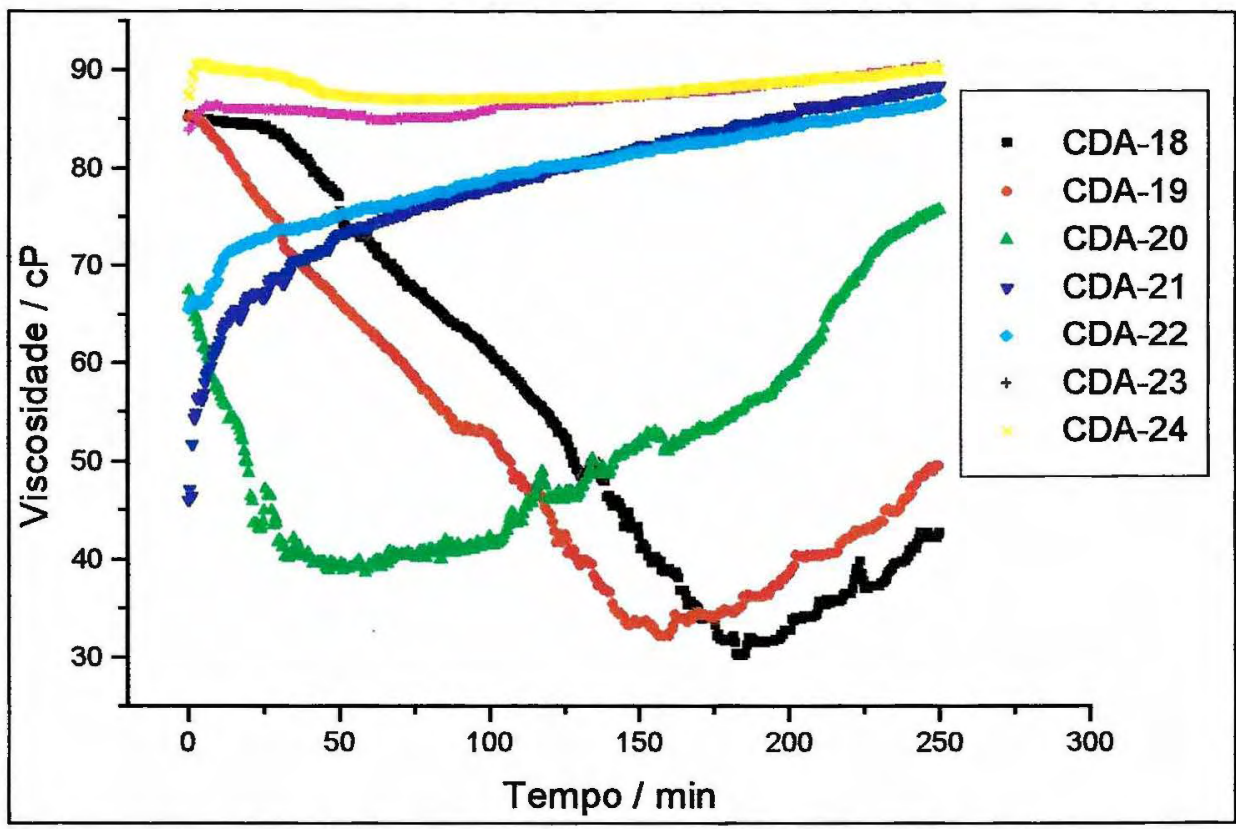

Figura V.16: Reograma das fases CDA-18 a CDA-24 em câmara seca a $25,0^{\circ} \mathrm{C}$, com taxa de cisalhamento constante de $100 s^{-1}$.

Os ensaios realizados em câmara úmida (Figura V.15), mostram que a fase nemática (CDA-18) apresenta um ligeiro aumento na viscosidade durante as primeiras duas horas e meia, começando a diminuir lentamente após este período. Para os sistemas com 0,01\% (CDA-19) e 0,03\% (CDA-20) de colesterol nota-se um aumento acentuado da viscosidade no início do processo de cisalhamento para em seguida manter um comportamento semelhante ao nemático. As fases com 0,06\% (CDA-21), 0,09\% (CDA-22), 0,15\% (CDA23) e $0,21 \%$ (CDA-24) de colesterol apresentam primeiro uma queda da viscosidade até atingir um mínimo, seguido de um aumento acentuado até a estabilização em um valor praticamente constante. Podemos observar que o tempo necessário para se atingir o mínimo é menor quanto menor for a concentração de colesterol. 
A Figura V.16 mostra os resultados obtidos com as fases CDA-18 a CDA-24 em câmara seca. Nota-se que as fases, nemática (CDA-18) e colestéricas com 0,01\% (CDA-19) e 0,03\% (CDA-20) molar de colesterol, apresentam uma queda da viscosidade até atingir um mínimo, seguido de um aumento na viscosidade. O mínimo é atingido em um tempo menor quanto maior for a concentração de colesterol. Para as fases com 0,06\% (CDA-21) e 0,09\% (CDA-22) já não se observa à queda da viscosidade, mas apenas um aumento acentuado desta no início do cisalhamento, seguido por aumento menos intenso da viscosidade. Já as fases com 0,15\% (CDA-23) e 0,21\% (CDA-24) apresentam um valor basicamente constante durante todo o processo de cisalhamento.

Os resultados obtidos para as fases em câmara seca, apresentam um comportamento oposto às fases em câmara saturada. Podemos observar a existência de vales largos que vão desaparecendo quanto maior a concentração de colesterol. Isto pode ser explicado se pensarmos que nas fases com maior quantidade de indutor, a força quiral se torna forte o suficiente para manter a estrutura colestérica estável com os fragmentos se recombinando rapidamente.

A Tabela V.2 mostra os valores de atividade de água $\left(\mathrm{a}_{\mathrm{w}}\right)$ obtidos para amostras CDA-13 a CDA-24 em três diferentes situações. Na primeira situação, o valor de $a_{w}$ é obtido antes das amostras serem cisalhadas. Na segunda, o valor obtido após o cisalhamento da amostra em câmara seca e na terceira, após o cisalhamento em câmara saturada.

De modo geral, os valores obtidos em cada ensaio podem ser considerados constante para todas as fases em que a relação hidrofilico/hidrofóbico é próxima. Porém, podem ser observadas variações de atividade em relação a cada tipo de ensaio. A atividade de água diminui nos 
sistemas que foram cisalhadas em câmara seca, em comparação com os ensaios feitos em câmara saturada, onde ocorre um aumento da atividade.

Tabela V.2: Valores médios de atividade de todas as fases de cristal líquido a base de CDA com colesterol como indutor em diferentes condições.

\begin{tabular}{|l|c|c|c|}
\cline { 3 - 4 } \multicolumn{1}{c|}{} & \multirow{2}{*}{\begin{tabular}{c} 
Sem \\
\multicolumn{1}{c|}{}
\end{tabular}} & \multicolumn{2}{c|}{ Com Cisalhamento } \\
\cline { 3 - 4 } \multicolumn{1}{c|}{} & $\mathbf{a}_{\mathbf{w}}$ & Câmara Seca & $\begin{array}{c}\text { Câmara } \\
\text { Saturada }\end{array}$ \\
\hline Amostra & 0,948 & $\mathbf{a}_{\mathbf{w}}$ & $\mathbf{a}_{\mathbf{w}}$ \\
\hline CDA-13 & 0,948 & 0,943 & 0,959 \\
\hline CDA-14 & 0,948 & 0,943 & 0,960 \\
\hline CDA-15 & 0,948 & 0,945 & 0,962 \\
\hline CDA-16 & 0,948 & 0,942 & 0,961 \\
\hline CDA-17 & 0,942 & 0,944 & 0,962 \\
\hline CDA-18 & 0,941 & 0,930 & 0,952 \\
\hline CDA-19 & 0,942 & 0,932 & 0,953 \\
\hline CDA-20 & 0,941 & 0,935 & 0,952 \\
\hline CDA-21 & 0,943 & 0,938 & 0,951 \\
\hline CDA-22 & 0,941 & 0,936 & 0,956 \\
\hline CDA-23 & 0,939 & 0,932 & 0,951 \\
\hline CDA-24 & & 0,935 & 0,954 \\
\hline
\end{tabular}

Observa-se que para as fases que possuem maior relação hidrofilico/hidrofóbico (CDA-13 a CDA-17), a diferença de atividade das amostras não cisalhadas para as amostras cisalhadas em câmara seca é muito pequena. Enquanto para as amostras com menos água (CDA-18 a CDA-24) essa diferença é mais significativa. 
A análise conjunta destes resultados mostra que o comportamento apresentado na Figura V.15, se deve exclusivamente à quantidade de indutor, visto que não há perda de água durante o processo de cisalhamento e sim uma absorção de água pelo ambiente,' como pode ser visto pelos resultados de atividade apresentados na Tabela V.2. Neste caso, o aumento da quantidade de solvente, aliado ao aumento da concentração do indutor faz com que a estrutura se torne mais estável. Esta estabilidade se reflete em um tempo maior necessário para que ocorra a quebra do edifício colestérico, observada pela diminuição da viscosidade, originando fragmentos de hélice. Estes, por sua vez, seriam estabilizados pela água absorvida da atmosfera saturada, que auxiliaria na hidratação dos fragmentos. Uma vez destruída a estrutura, os fragmentos começam a se rearranjar para formação de uma hélice em uma direção paralela ao fluxo, como proposto por Rey (Rey, 1996 a; Rey, 2000).

Os resultados apresentados para as fases com maior relação hidrofilico/hidrofóbico, mostram um comportamento mais uniforme durante todo o ensaio. Em câmara seca (Figura V.13), o sistema mantém a viscosidade constante ao longo de todo o ensaio, mesmo com uma perda de água, que embora pequena, ainda existe. Tudo indica que neste caso, a quebra e rearranjo da estrutura do cristal líquido ocorra rapidamente, pois como não há falta de água, os fragmentos estão suficientemente hidratados, apesar da perda de solvente ocorrida durante o processo de cisalhamento. Quanto aos resultados em câmara úmida (Figura V.14), observamos que o aumento da viscosidade ao longo do ensaio significa um aumento da tensão de cisalhamento da amostra, que é um indício da deformação na estrutura do cristal líquido. Percebe-se também que essa tensão ocorre por um tempo maior quanto maior a concentração de indutor, o que é natural devido ao aumento da força quiral com a adição do indutor. 
Estes resultados foram comparados com sistemas colesterizados por um indutor hidrofilico.

Os resultados de atividade e dos ensaios reológicos para as fases com indutor hidrofilico (CDA-25 a CDA-34) estão apresentados na Tabela V.3 e Figuras V.17 e V.18 respectivamente.

Tabela V.3: Valores médios de atividade de todas as fases de cristal líquido a base de CDA com D-(+)-Manose como indutor.

\begin{tabular}{|l|c|c|c|}
\cline { 3 - 4 } \multicolumn{1}{c|}{} & \multirow{2}{*}{\begin{tabular}{c} 
Sem \\
\cline { 3 - 4 } \multicolumn{1}{c|}{}
\end{tabular}} & \multicolumn{2}{c|}{ Com Cisalhamento } \\
\cline { 3 - 4 } & & Câmara Seca & $\begin{array}{c}\text { Câmara } \\
\text { Saturada }\end{array}$ \\
\hline Amostra & $\mathbf{a}_{\mathbf{w}}$ & $\mathbf{a}_{\mathbf{w}}$ & $\mathbf{a}_{\mathbf{w}}$ \\
\hline CDA-25 & 0,949 & 0,945 & 0,963 \\
\hline CDA-26 & 0,950 & 0,944 & 0,959 \\
\hline CDA-27 & 0,948 & 0,944 & 0,959 \\
\hline CDA-28 & 0,944 & 0,942 & 0,957 \\
\hline CDA-29 & 0,940 & 0,935 & 0,955 \\
\hline CDA-30 & 0,944 & 0,934 & 0,963 \\
\hline CDA-31 & 0,940 & 0,936 & 0,957 \\
\hline CDA-32 & 0,940 & 0,929 & 0,953 \\
\hline CDA-33 & 0,931 & 0,930 & 0,951 \\
\hline CDA-34 & 0,930 & 0,923 & 0,950 \\
\hline
\end{tabular}

A partir dos resultados apresentados na Tabela V.3 observamos que as fases com indutor hidrofilico apresentam um resultado contrário do obtido nas fases com colesterol, com a queda da atividade de água em função do aumento da concentração de D-(+)-Manose. Este resultado pode estar relacionado ao fato do colesterol estar localizado no interior da micela, enquanto que o açúcar está predominantemente fora da micela. Como a molécula de açúcar apresenta 
grupos $-\mathrm{OH}$, a ocorrência de pontes de hidrogênio com o solvente deve estar diminuindo a presença de água livre no sistema.

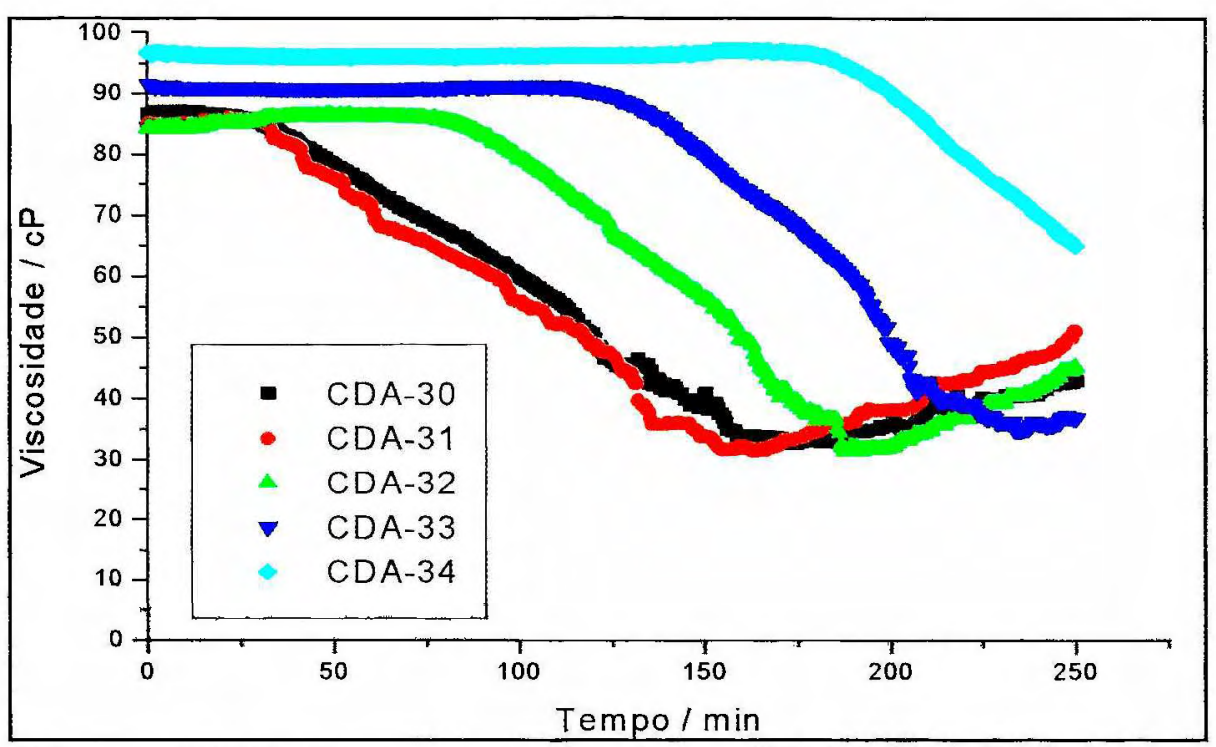

Figura V.17: Reograma das fases CDA-30 a CDA-34 em câmara seca a $25,0^{\circ} \mathrm{C}$, com taxa de cisalhamento constante de $100 \mathrm{~s}^{-1}$.

Os reogramas apresentados na Figura V.17 correspondem às análises em câmara seca dos sistemas com menor concentração de água e com D- $(+)$ Manose como indutor quiral (CDA-30 a CDA-34). Observa-se que todas as curvas mostram inicialmente uma viscosidade constante que, durante o tempo de cisalhamento, tende a diminuir até atingir um mínimo. Aparentemente após o sistema atingir este mínimo, a viscosidade tende a aumentar novamente. Essa tendência deve ser observada com cuidado uma vez que neste mesmo tempo, a integridade da amostra começa a ser comprometida.

Nota-se que quanto maior a concentração de indutor, maior é a viscosidade inicial do sistema e maior também é o tempo para que esta diminua. Uma vez que a taxa de queda da viscosidade é praticamente 
constante, maior também é o tempo necessário para que o sistema atinja o seu mínimo.

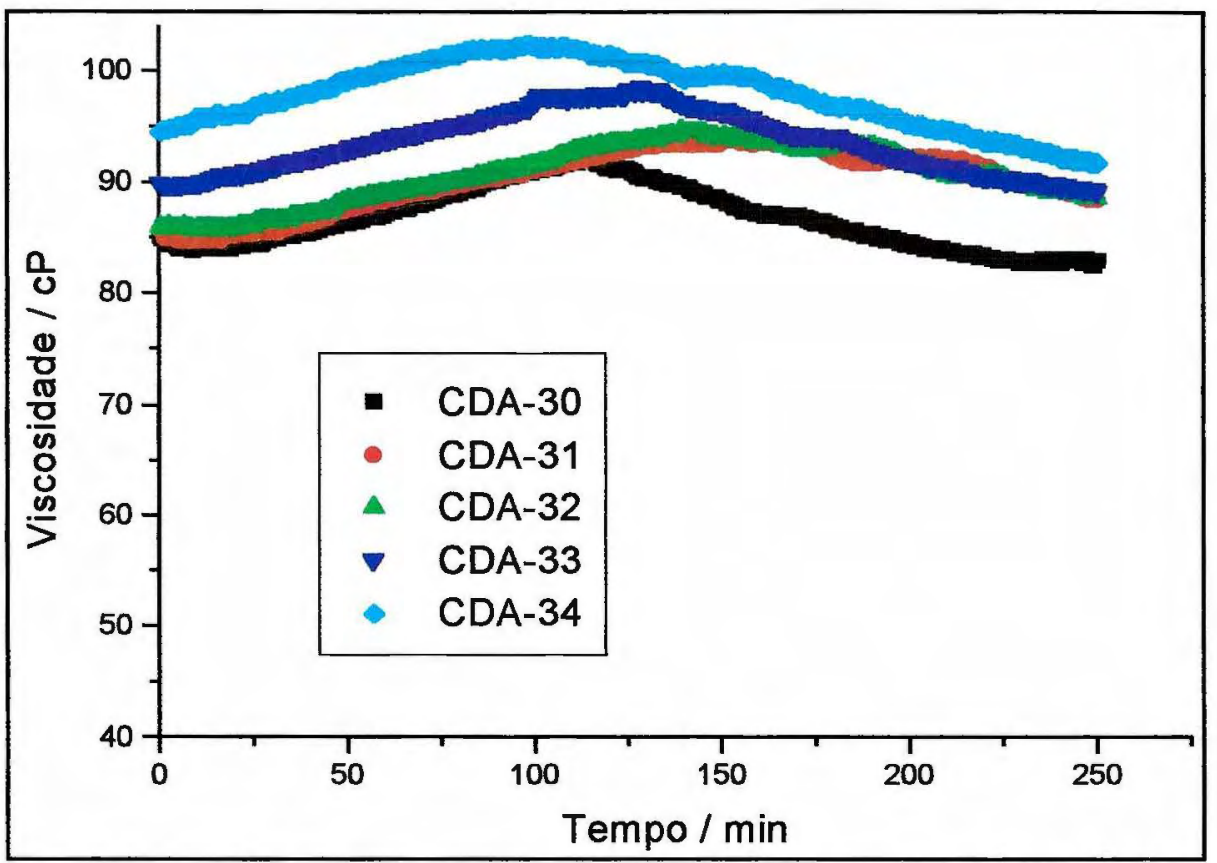

Figura V.18: Reograma das fases CDA-30 a CDA-34 em câmara saturada a $25,0^{\circ} \mathrm{C}$, com taxa de cisalhamento constante de $100 \mathrm{~s}^{-1}$.

Em câmara saturada, as fases com D-(+)-Manose e menor concentração de água apresentam os reogramas mostrados na Figura V.18. Nota-se em todos os sistemas um aumento na viscosidade, até atingir um valor máximo seguido de uma diminuição gradual. Pode-se observar que para as fases colestéricas este máximo é atingido mais cedo quanto maior for a concentração de indutor.

Ao se analisar os dados em câmara seca, nota-se um comportamento que se assemelha a uma mistura dos ensaios com colesterol em câmara seca e úmida. Para a fase nemática e para a fase com menor quantidade de D-(+)Manose o comportamento é parecido com o ensaio em câmara seca dos sistemas com colesterol (Figura V.16), mas para as outras fases colestéricas, o 
comportamento se assemelha ao obtido em câmara úmida (Figura V.15), i.e., quanto maior a concentração de indutor, mais tempo leva para atingir o mínimo no reograma. Este resultado indica que neste caso deve estar havendo uma competição entre a perda de água e a quebra e reorientação da estrutura por fluxo. Possivelmente esse comportamento deve estar relacionado à natureza do indutor, que sendo hidrofilico, tende a manter mais água no sistema, facilitando a estabilização dos fragmentos.

No ensaio em câmara úmida, não se observa a queda da viscosidade como o obtido para as fases com colesterol. $\mathrm{O}$ aumento da viscosidade deve caracterizar uma deformação da estrutura que após atingir uma tensão máxima, começa a se orientar em uma direção preferencial, causando uma diminuição da viscosidade sem quebra do edifício colestérico. Podemos dizer também que, quanto maior é a concentração de D-(+)-Manose, maior é a força quiral do sistema, o que facilita a mudança na orientação da fase, o que pode ser observado pelo menor tempo necessário para se atingir o máximo no reograma.

Os reogramas obtidos em câmara seca para as fases com D-(+)-Manose e com maior concentração de solvente (CDA-25 a CDA-29) estão apresentados na Figura V.19. Pode-se observar que para todas as amostras, a viscosidade também se mantém constante durante todo o ensaio com valores crescentes quanto maior a concentração de D-(+)-Manose. 


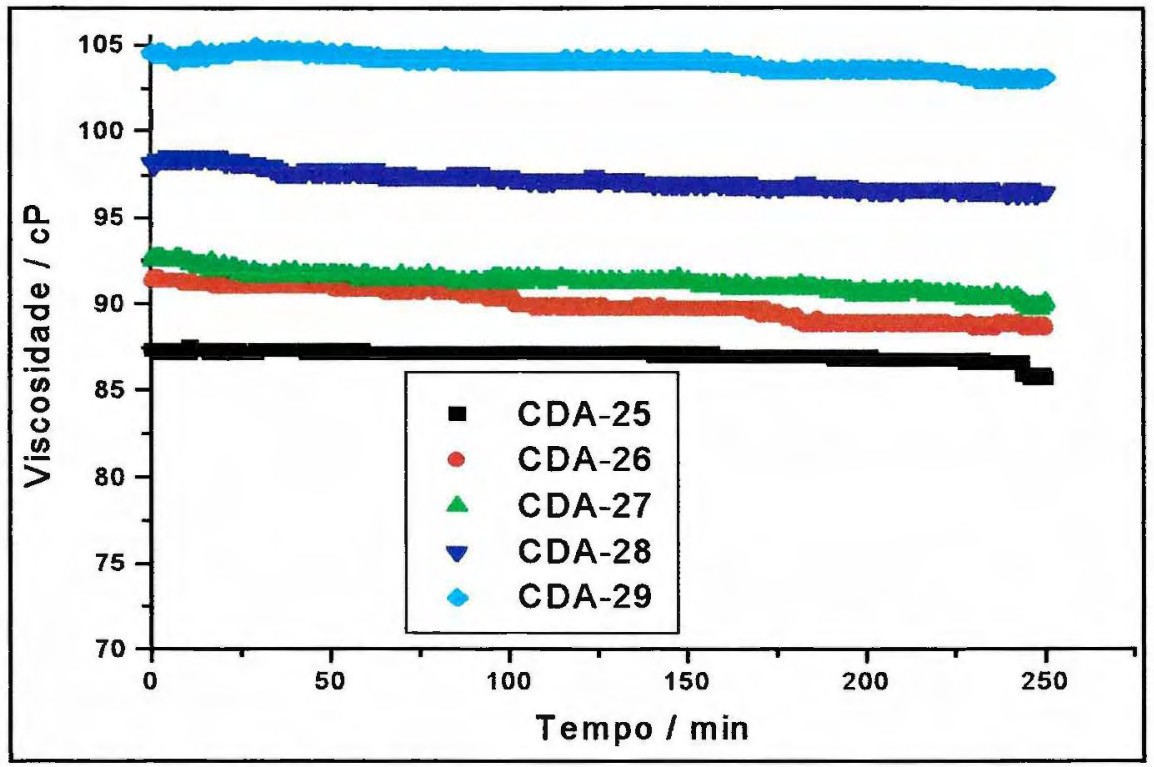

Figura V.19: Reograma das fases CDA-25 a CDA-29 em câmara seca a 25,0C, com taxa de cisalhamento constante de $100 \mathrm{~s}^{-1}$.

Estes resultados são semelhantes aos obtidos para sistemas com maior relação hidrofilico/hidrofóbico e com colesterol como indutor. A maior estabilidade da estrutura liquidocristalina para fases com esta relação é observada mesmo em câmara seca. A diferença observada em relação às fases com colesterol é um aumento da viscosidade com adição de indutor para as fases com D-(+)-Manose. Isto se deve a uma possível interação das micelas com o açúcar, pois o indutor, pode estar agindo como uma barreira dificultando a orientação por fluxo. Este obstáculo contra a orientação por fluxo não é possível com o colesterol localizado no interior da micela. 


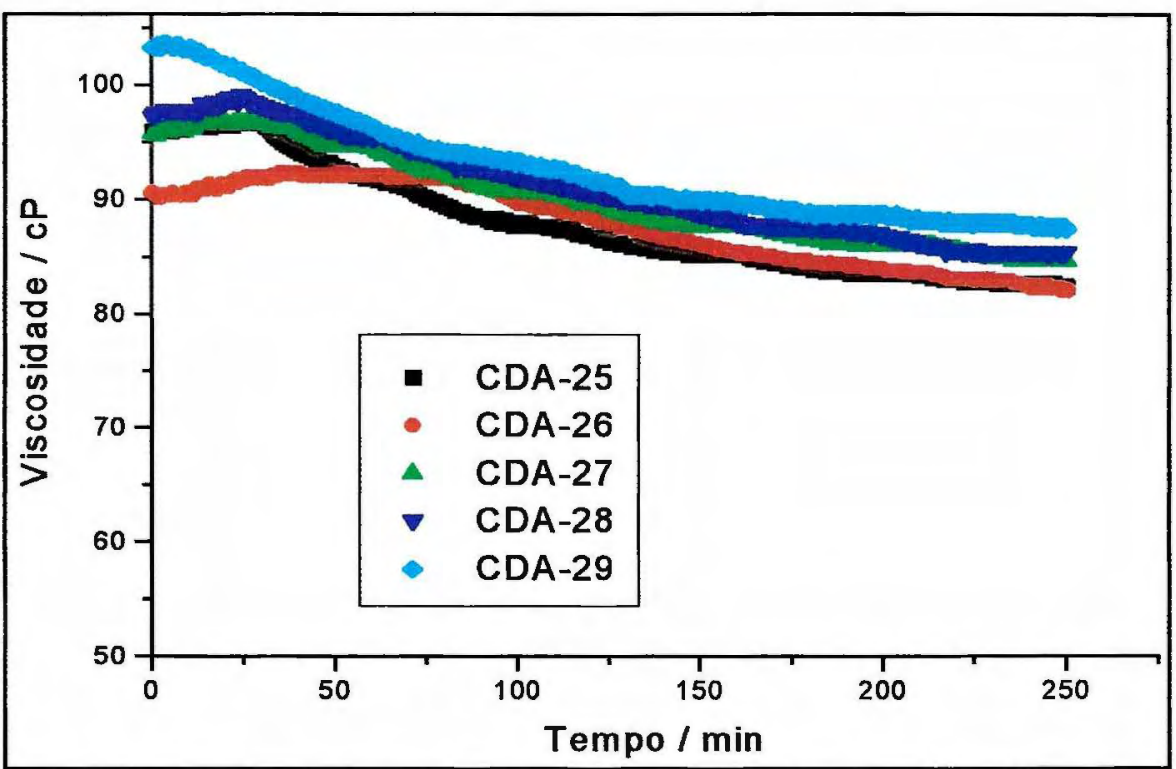

Figura V.20: Reograma das fases CDA-25 a CDA-29 em câmara saturada a $25,0^{\circ} \mathrm{C}$, com taxa de cisalhamento constante de $100 \mathrm{~s}^{-1}$.

A Figura V.20 apresenta o comportamento em câmara saturada das fases com D-(+)-Manose e maior relação hidrofilico/hidrofóbico. O comportamento observado se assemelha à Figura V.18, embora neste caso o máximo seja atingido bem antes. Na fase CDA-29 (fase com 1,00\% molar de D-(+)-Manose), por exemplo, o máximo é atingido nos primeiros minutos do ensaio enquanto para fase CDA-34 (fase com 1,00\% molar de D-(+)-Manose) (Figura V.18), o máximo é atingido após 90 minutos.

O resultado apresentado na Figura V.20 mostra um comportamento semelhante às fases com colesterol e maior relação hidrofilico/hidrofóbico em câmara saturada, ou seja, um aumento gradual da viscosidade até atingir um máximo seguido de sua diminuição. Ao contrário do obtido com o colesterol, neste caso, a viscosidade aumenta com o aumento da concentração de D-(+)Manose.

Esses resultados mostram que ocorre uma mudança no comportamento reológico dependente da natureza do indutor quiral, quando a quantidade de solvente está no limite de existência da fase liquidocristalina. 
Esses resultados mostram que ocorre uma mudança no comportamento reológico dependente da natureza do indutor quiral, quando a quantidade de solvente está no limite de existência da fase liquidocristalina.

As fases com indutor hidrofilico têm sua viscosidade aumentada com a adição do indutor, tanto em câmara úmida como em câmara seca, enquanto que as fases com o indutor hidrofóbico têm a viscosidade diminuída com o aumento da concentração de indutor. Esta inversão do comportamento observado para os sistemas com diferentes tipos de indutor se deve à natureza destes. No caso do açúcar, que está do lado de fora da micela, este acaba interagindo com o solvente como uma barreira que deve ser vencida para que ocorra a orientação por fluxo, tornando o sistema mais viscoso com o aumento da concentração do indutor. Enquanto que o colesterol, por estar no interior da micela, não interferia no processo de orientação por fluxo.

Observa-se também que para os sistemas com maior relação hidrofilico/hidrofóbico, há um aumento da viscosidade ao longo do tempo até atingir um valor máximo, caindo novamente em tempos maiores. Este comportamento deve indicar que nestes sistemas, as estruturas liquidocristalinas devem sofrer algum tipo de acomodação ou rearranjo até atingir um valor máximo de tensão que uma vez atingido, tem a viscosidade diminuída novamente.

\section{V.1.3 Determinação da Energia de Ativação de Fluxo}

Podemos observar que para as fases com colesterol (Figura V.21 e Tabela V.4) a entalpia de ativação de fluxo diminui com o aumento da concentração de indutor. Este resultado mostra que a força quiral age de forma a aumentar a interação entre as micelas, fazendo com que ao se mexer uma micela, esta arraste as demais, diminuindo dessa forma, a energia total necessária para colocar o sistema em movimento. 


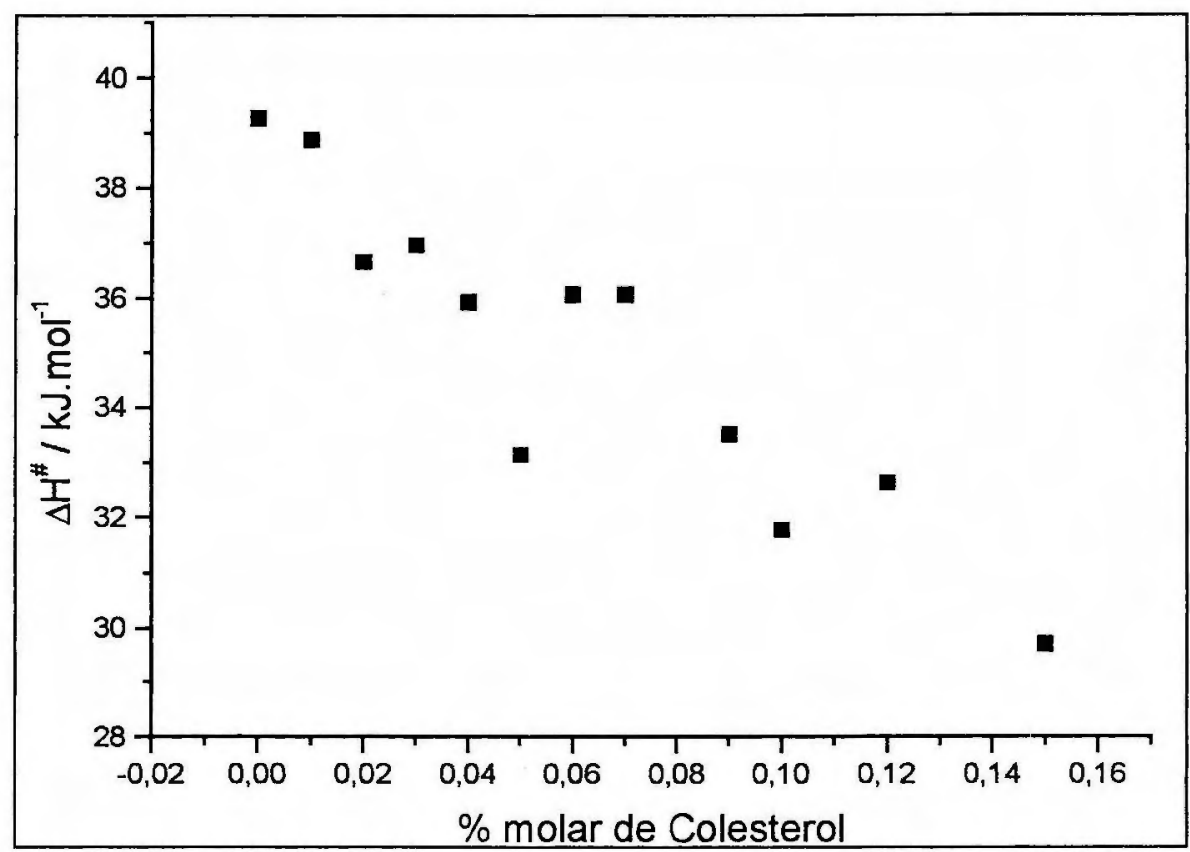

Figura V.21: Variação da Entalpia de Ativação de Fluxo para as fases com indutor hidrofóbico.

Tabela V.4: Valores de $\Delta H^{\#}, \Delta S^{\#}$ e $\Delta G^{\#}$ para fases com Colesterol.

\begin{tabular}{cccc}
\hline Amostra & $\Delta \mathrm{H}^{\#} / \mathrm{kJ} \cdot \mathrm{mol}^{-1}$ & $\Delta \mathrm{S}^{\#} / \mathrm{J} \cdot \mathrm{mol}^{-1} \cdot \mathrm{K}^{-1}$ & $\Delta \mathrm{G}^{\#} / \mathrm{kJ}_{\mathrm{mol}}{ }^{-1}$ \\
\hline CDA-35 & 39,27 & 37,41 & 28,3 \\
CDA-36 & 38,88 & 34,92 & 28,6 \\
CDA-37 & 36,66 & 27,44 & 28,5 \\
CDA-38 & 36,96 & 29,10 & 28,3 \\
CDA-39 & 35,92 & 24,94 & 28,4 \\
CDA-40 & 33,14 & 16,63 & 28,1 \\
CDA-41 & 36,06 & 25,77 & 28,2 \\
CDA-42 & 36,06 & 25,77 & 28,1 \\
CDA-44 & 33,51 & 17,46 & 28,1 \\
CDA-45 & 31,77 & 12,47 & 27,9 \\
CDA-46 & 32,61 & 14,96 & 27,9 \\
\hline
\end{tabular}




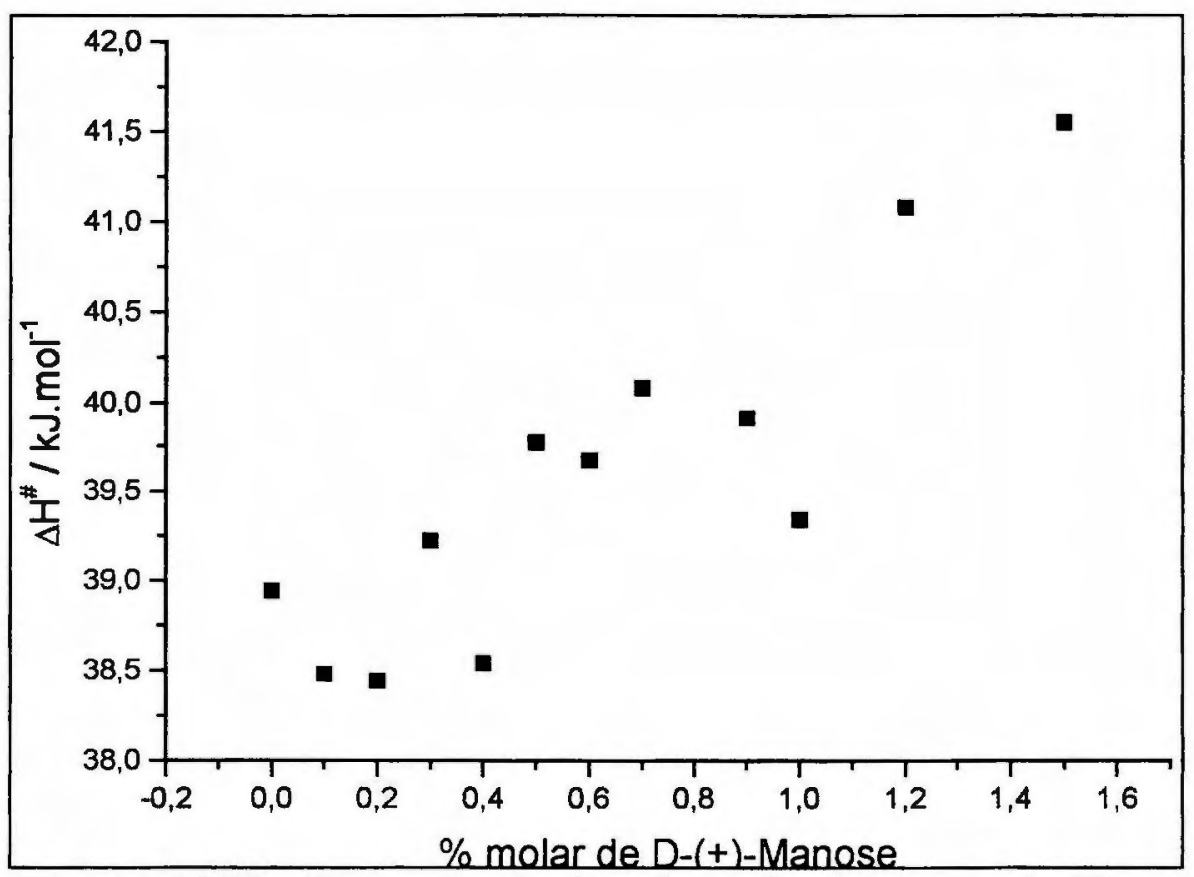

Figura V.22: Variação da Entalpia de Ativação de Fluxo para as fases com indutor hidrofilico.

Para as fases com D-(+)-Manose (Figura V.22 e Tabela V.5), observase um comportamento oposto, com variação da entalpia de ativação de fluxo aumentando com o aumento da concentração de indutor. Este comportamento pode ser explicado pela localização do indutor fora da micela, onde sua presença deve agir como uma barreira para movimentação das micelas.

Estes resultados estão em concordância com os obtidos anteriormente nos ensaios com taxa de cisalhamento constante. 
Tabela V.5: Valores de $\Delta H^{\#}, \Delta S^{\#}$ e $\Delta G^{\#}$ para fases com D-(+)-Manose.

\begin{tabular}{cccc}
\hline Amostra & $\Delta \mathrm{H}^{\#} / \mathrm{kJ} \cdot \mathrm{mol}^{-1}$ & $\Delta \mathrm{S}^{\#} / \mathrm{J} \cdot \mathrm{mol}^{-1} \cdot \mathrm{K}^{-1}$ & $\Delta \mathrm{G}^{\#} / \mathrm{kJ} \cdot \mathrm{mol}^{-1}$ \\
\hline CDA-47 & 29,70 & 5,82 & 27,8 \\
CDA-48 & 38,94 & 34,92 & 44,3 \\
CDA-49 & 38,48 & 33,26 & 43,8 \\
CDA-50 & 38,44 & 33,26 & 43,8 \\
CDA-51 & 39,22 & 35,75 & 44,7 \\
CDA-52 & 38,54 & 33,26 & 44,0 \\
CDA-53 & 39,77 & 37,41 & 45,4 \\
CDA-54 & 39,67 & 36,58 & 45,3 \\
CDA-55 & 40,08 & 38,24 & 45,8 \\
CDA-56 & 39,71 & 36,58 & 45,4 \\
CDA-57 & 39,91 & 37,41 & 45,7 \\
CDA-58 & 39,34 & 37,41 & 45,1 \\
CDA-59 & 41,08 & 40,74 & 47,0 \\
CDA-60 & 41,55 & 42,40 & 47,6 \\
\hline
\end{tabular}

Podemos observar também que em todos os sistemas estudados (Tabelas V.4 e V.5) $\Delta H^{\#}$ e $\Delta S^{\#}$ têm o mesmo comportamento em um mesmo indutor, isto é, se $\Delta H^{\#}$ aumenta com o aumento da concentração de indutor, $\Delta S^{\#}$ também aumenta, ou se $\Delta H^{\#}$ diminui com a adição de indutor, $\Delta S^{\#}$ também diminui. Esse balanço entre eles é também conhecido como efeito de compensação. A existência dessa correlação nos diz que $\Delta G^{\#}$ é basicamente constante durante o processo, significando que a energia total do sistema não muda muito durante o processo de colesterização. Nos sistemas em que o indutor utilizado foi o colesterol, a diminuição de $\Delta S^{\#}$ observada indica que o sistema como um todo se mostra mais organizado, possivelmente devido às restrições de movimento causado pelo edifício colestérico. 


\section{V.2. Ensaios Oscilatórios}

\section{V.2.1. Determinação da Região de Viscoelasticidade Linear}

Os ensaios de determinação de viscoelasticidade linear foram realizados para as fases (CDA-61 a CDA-112). Todos os sistemas apresentaram um perfil semelhante ao exibido na Figura V.23.

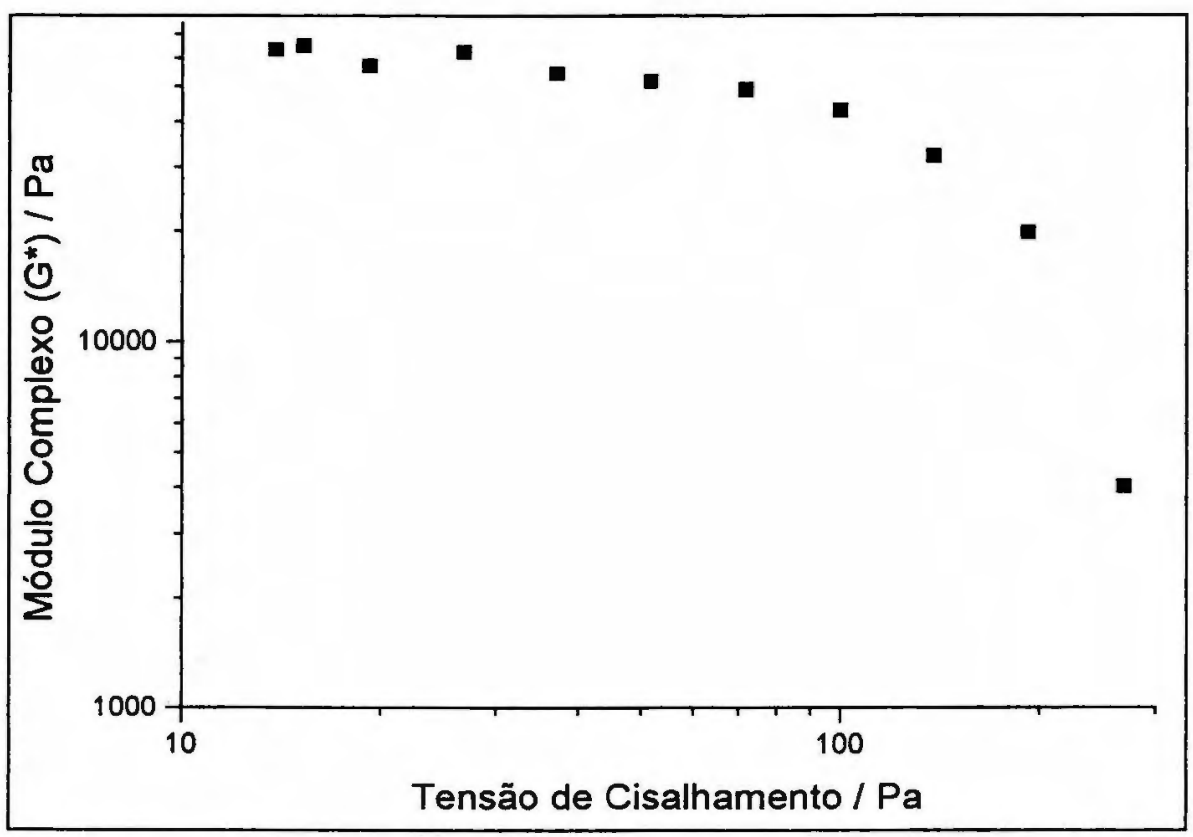

Figura V.23: Curva de determinação da região de viscoelasticidade da amostra CDA-84 com freqüência de oscilação de $1 \mathrm{~Hz}$.

Pode-se observar uma curva que inicialmente mantém o valor do Módulo Complexo $\left(\mathrm{G}^{*}\right)$ constante, até se atingir um valor limite de tensão de cisalhamento, a partir do qual o valor de $\mathrm{G}^{*}$ começa a cair. A região onde o Módulo Complexo se mantém aproximadamente constante, que na Figura V.23 é aproximadamente $100 \mathrm{~Pa}$, é a chamada região de viscoelasticidade linear. 
Os valores de tensão limite da região de viscoelasticidade obtidos para todas as amostras estudadas estão apresentados nas Tabelas V.6 e V.7.

Tabela V.6: Valor de tensão limite no ensaio de determinação da região de viscoelasticidade linear para as fases com colesterol e com maior relação hidrofilico/hidrofóbico.

\begin{tabular}{ccc|ccc}
\hline Fase & $\begin{array}{c}\text { \% molar de } \\
\text { colesterol }\end{array}$ & $\begin{array}{c}\text { Tensão } \\
\text { Limite } / \text { Pa }\end{array}$ & Fase & $\begin{array}{c}\text { \% molar de } \\
\text { colesterol }\end{array}$ & $\begin{array}{c}\text { Tensão } \\
\text { Limite / Pa }\end{array}$ \\
\hline CDA-61 & 0,00 & 300 & CDA87 & 0,00 & 200 \\
CDA-62 & 0,01 & 200 & CDA-88 & 0,01 & 500 \\
CDA-63 & 0,02 & 200 & CDA-89 & 0,02 & 200 \\
CDA-64 & 0,03 & 100 & CDA-90 & 0,03 & 100 \\
CDA-65 & 0,04 & 200 & CDA-91 & 0,04 & 200 \\
CDA-66 & 0,05 & 40 & CDA-92 & 0,05 & 10 \\
CDA-67 & 0,06 & 50 & CDA-93 & 0,06 & 15 \\
CDA-68 & 0,07 & 30 & CDA-94 & 0,07 & 15 \\
CDA-69 & 0,08 & 40 & CDA-95 & 0,08 & 30 \\
CDA-70 & 0,09 & 80 & CDA-96 & 0,09 & 10 \\
CDA-71 & 0,10 & 250 & CDA-97 & 0,10 & 15 \\
CDA-72 & 0,12 & 100 & CDA-98 & 0,12 & 7 \\
CDA-73 & 0,16 & 350 & CDA-99 & 0,15 & 10 \\
\hline
\end{tabular}


Tabela V.7: Valor de tensão limite no ensaio de determinação da região de viscoelasticidade linear para as fases com $\mathrm{D}-(+)-$ Manose e com maior relação hidrofilico/hidrofóbico.

\begin{tabular}{ccc|ccc}
\hline Fase & $\begin{array}{c}\text { \% molar de D- } \\
(+) \text {-Manose }\end{array}$ & $\begin{array}{c}\text { Tensão } \\
\text { Limite } / \text { Pa }\end{array}$ & Fase & $\begin{array}{c}\text { \% molar de } \\
\text { D-(+)-Manose }\end{array}$ & $\begin{array}{c}\text { Tensão } \\
\text { Limite / Pa }\end{array}$ \\
\hline CDA-74 & 0,00 & 200 & CDA-100 & 0,00 & 70 \\
CDA-75 & 0,10 & 200 & CDA-101 & 0,10 & 100 \\
CDA-76 & 0,20 & 100 & CDA-102 & 0,20 & 100 \\
CDA-77 & 0,30 & 200 & CDA-103 & 0,30 & 100 \\
CDA-78 & 0,40 & 200 & CDA-104 & 0,40 & 60 \\
CDA-79 & 0,53 & 60 & CDA-105 & 0,53 & 20 \\
CDA-80 & 0,60 & 300 & CDA-106 & 0,60 & 100 \\
CDA-81 & 0,71 & 100 & CDA-107 & 0,70 & 60 \\
CDA-82 & 0,80 & 200 & CDA-108 & 0,81 & 100 \\
CDA-83 & 0,90 & 70 & CDA-109 & 0,90 & 8 \\
CDA-84 & 1,01 & 100 & CDA-110 & 1,01 & 10 \\
CDA-85 & 1,20 & 100 & CDA-111 & 1,21 & 10 \\
CDA-86 & 1,50 & 100 & CDA-112 & 1,58 & 20 \\
\hline
\end{tabular}

Os dados de tensão limite da região de viscoelasticidade linear obtidos para os sistemas colesterizados por colesterol (Tabela V.6) apresentam uma grande flutuação em seus valores, porém, é possível se observar uma tendência de queda com o aumento da concentração do indutor. Esta tendência é mais definida para os sistemas com menor relação [hidrofilico]/[hidrofóbico], i.e., menor concentração de água. 
Aparentemente esta tendência não é observada nos sistemas colesterizados por D-(+)-Manose (Tabela V.7). É interessante notar uma leve tendência de queda em função da concentração de indutor para os sistemas com menor conteúdo de água, porém, devido à grande flutuação dos valores, esta observação não pode ser confirmada.

De modo geral podemos dizer que o processo de colesterização deve diminuir a região de viscoelasticidade linear dos sistemas liquidocristalinos. Aparentemente, as forças de interação quirais presentes nestes sistemas devem alterar as relações entre tensão e deformação características desta região. De todos os sistemas estudados, os colesterizados por colesterol e com menor teor de água são os que têm forças de interação quirais mais pronunciadas (Alcantara, 1988). Por outro lado, os sistemas colesterizados por D-(+)Manose, com maior relação [hidrofilico]/[hidrofóbico] são os que apresentam menor quiralidade (Aido, 1991).

\section{V.2.2. Creep e Recuperação.}

Neste ensaio a deformação sofrida pelas amostras é medida durante a aplicação de uma tensão (dentro da região de viscoelasticidade linear) e durante um intervalo de tempo após a sua retirada.

Dependendo da tensão de cisalhamento imposta ao sistema, este pode apresentar desde um comportamento de um sólido viscoelástico, quando a tensão aplicada é bem menor que a tensão limite da região de viscoelasticidade linear (Figura V.24), até um líquido newtoniano ideal (Figura V.25). 


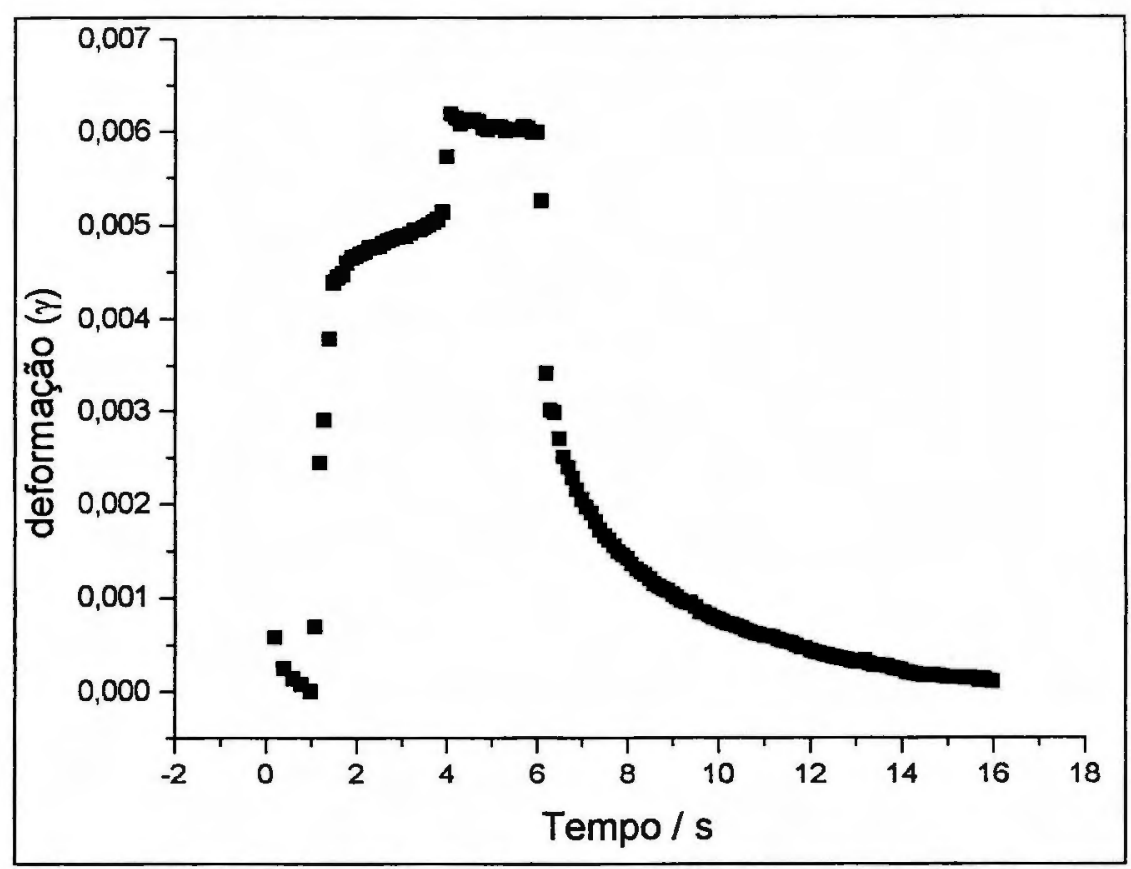

Figura V.24: Amostra CDA-100 quando a tensão de cisalhamento é bem menor do que a tensão limite da região de viscoelasticidade linear.

Na Figura V.24 observa-se um comportamento de um sólido KelvinVoigt, pois a deformação imposta pela tensão ao material é recuperada, fazendo com que o fluido volte ao seu estado original, $\gamma=0$. Nota-se também, um degrau na curva por volta de 4 segundos, devido possivelmente a diferentes processos de orientação associados às contribuições elásticas e viscosas do sistema quando submetido à tensão. $\mathrm{O}$ aparecimento de degraus também foi observado em outras amostras embora às vezes não tão bem definidos como este. 


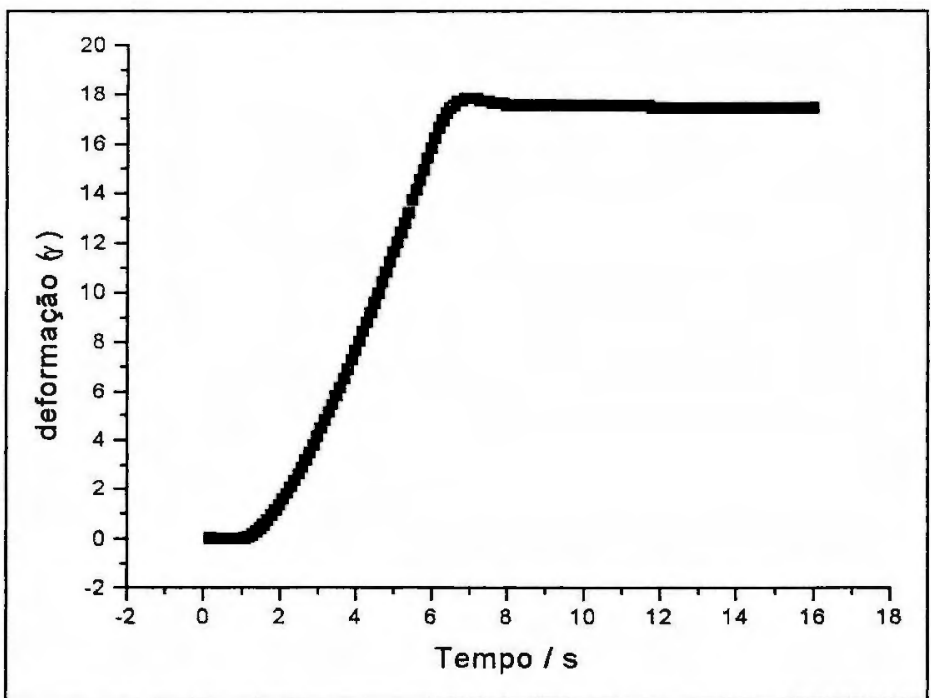

Figura V.25: Amostra CDA-100 quando a tensão de cisalhamento aplica é bem superior à tensão limite da região de viscoelasticidade linear.

$\mathrm{Na}$ Figura V.25 observa-se um comportamento de um líquido newtoniano, pois a deformação imposta pela tensão ao material é mantida, ou seja, toda a energia fornecida ao fluído foi gasta na difusão das micelas.

Em particular para este ensaio deve-se escolher uma tensão de cisalhamento abaixo da tensão limite de escoamento do material.

Todas as amostras estudadas apresentaram um comportamento semelhante ao comportamento descrito pelo modelo de Burger (associação em série dos modelos de Maxwell e Kelvin-Voigt), como pode ser visto na Figura V.26. 


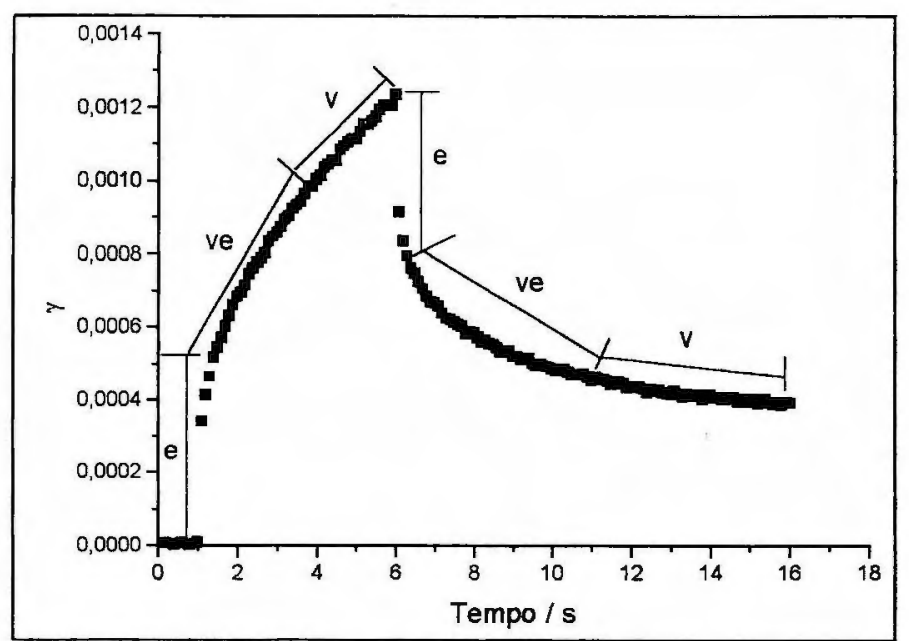

Figura V.26: Perfil da curva de creep e recuperação da Amostra $C D A-86$, onde " $e$ " representa a parte elástica $e$ " $v$ " a viscosa do modelo de Maxwell e "ve" o modelo de Kelvin-Voigt.

Pode-se observar que a resposta da componente elástica de Maxwell não é imediata, ao contrário do esperado teoricamente. O modelo foi então modificado, colocando-se o termo elástico dependente do tempo para melhorar a sua adaptabilidade aos resultados experimentais.

A modificação da equação do modelo de Burger proposta pelo nosso grupo está apresentada abaixo (Equação V.1)

$$
\gamma(t)=\frac{\tau_{0}}{G_{0}}\left(t-t_{1}\right)+\frac{\tau_{0}}{\eta_{0}} t+\frac{\tau_{0}}{G_{1}}\left[e^{\left(-t / s_{1}\right)}\right] \quad \text { Equação V.1. }
$$

Onde $\lambda_{1}=\frac{\eta_{1}}{G_{1}}$ e $\mathrm{t}_{1}$ é o tempo no inicio da na fase de creep e no início da fase de recuperação.

Os resultados obtidos para os valores das constantes elásticas $\left(\mathrm{G}_{0}\right.$ e $\left.\mathrm{G}_{1}\right)$ e viscosas $\left(\eta_{0}\right.$ e $\left.\eta_{1}\right)$ do modelo modificado de Burger foram correlacionados com a concentração de indutor, estando representados nas Figuras V.27 a V.34. 


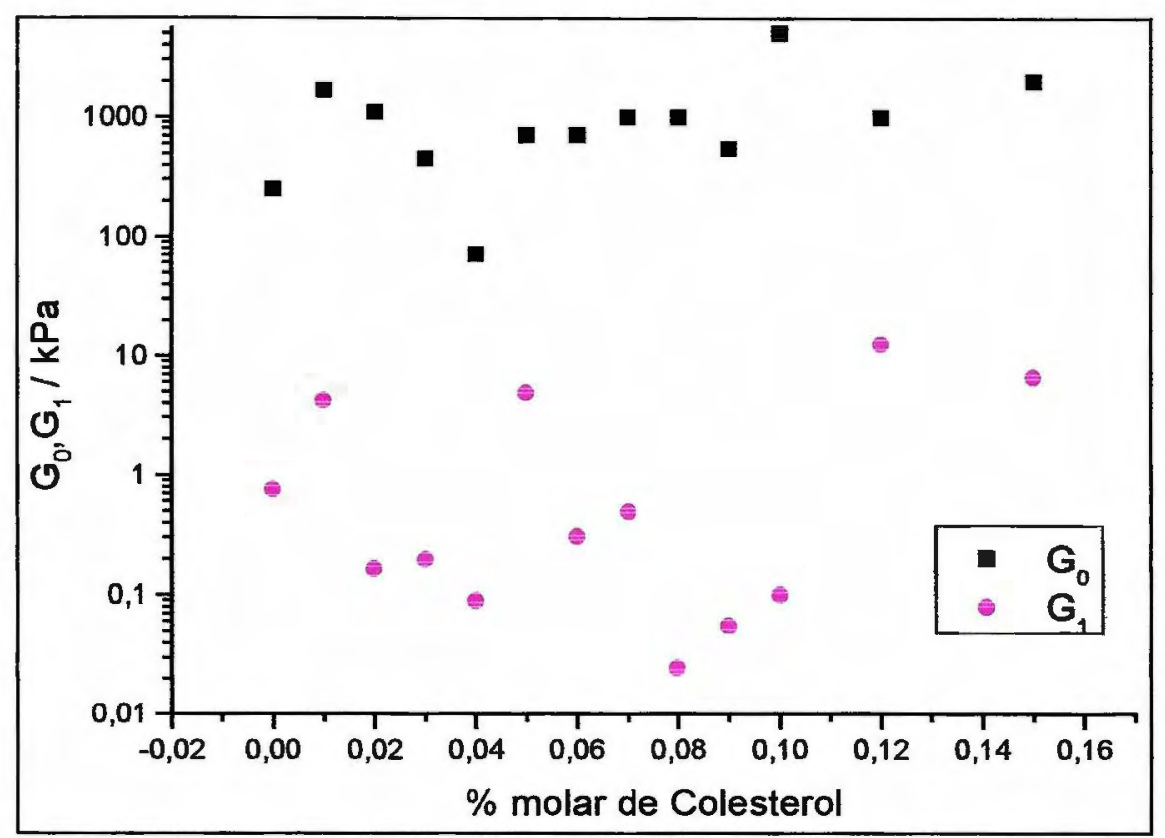

Figura V.27: Constantes elásticas do modelo de Burger para as fases $C D A-61$ a $C D A-73$.

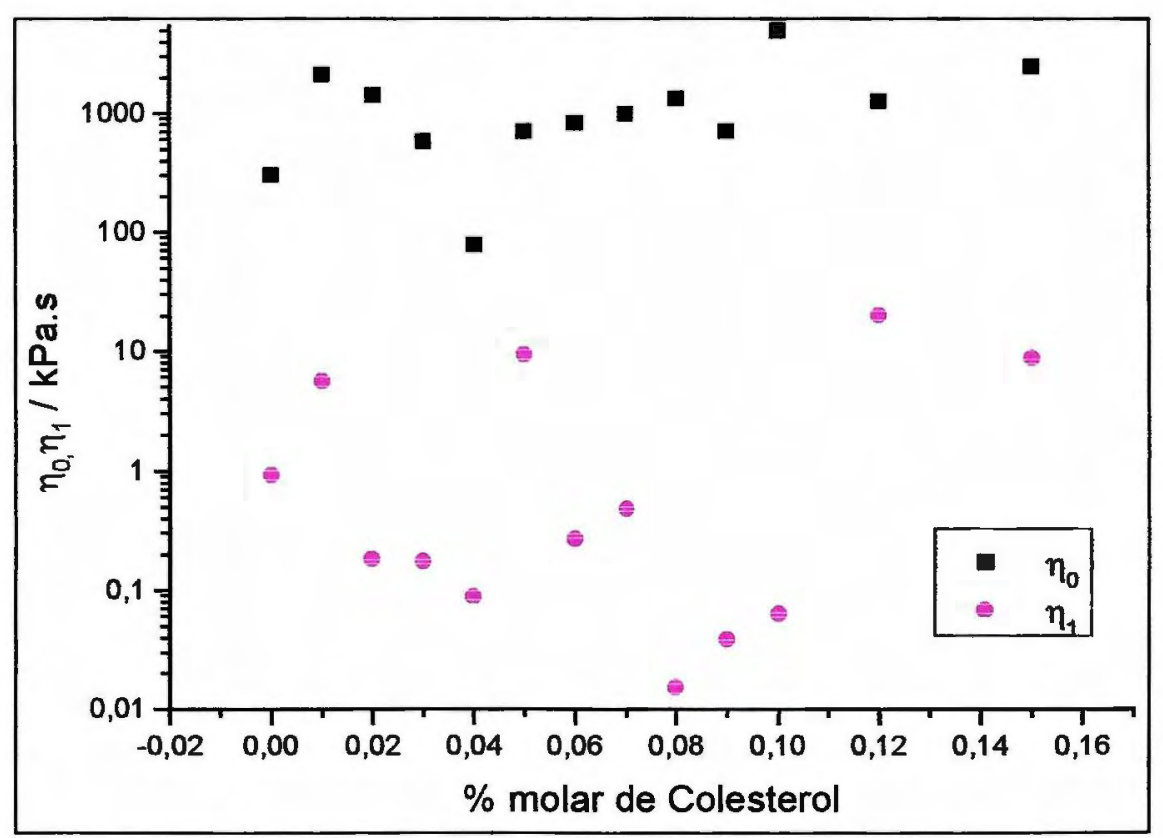

Figura V.28: Constantes viscosas do modelo de Burger para as fases CDA-61 a CDA-73. 
As fases com colesterol como indutor e maior relação hidrofilico/hidrofóbico (CDA-61 a CDA-73) apresentaram valores para as constantes elásticas e viscosas de Maxwell $\left(\mathrm{G}_{0}\right.$ e $\left.\eta_{0}\right)$ maiores do que paras as constantes elásticas e viscosas de Kelvin-Voigt $\left(G_{1}\right.$ e $\left.\eta_{1}\right)$ respectivamente (Figuras V.27 e V.28). Isto significa que estes sistemas liquidocristalinos apresentam características reológicas mais próximas de um fluido de Maxwell (líquido viscoelástico) do que de um sólido de Kelvin-Voigt (sólido viscoelástico). Observamos também que todas estas constantes praticamente não variam com o aumento da concentração de indutor.

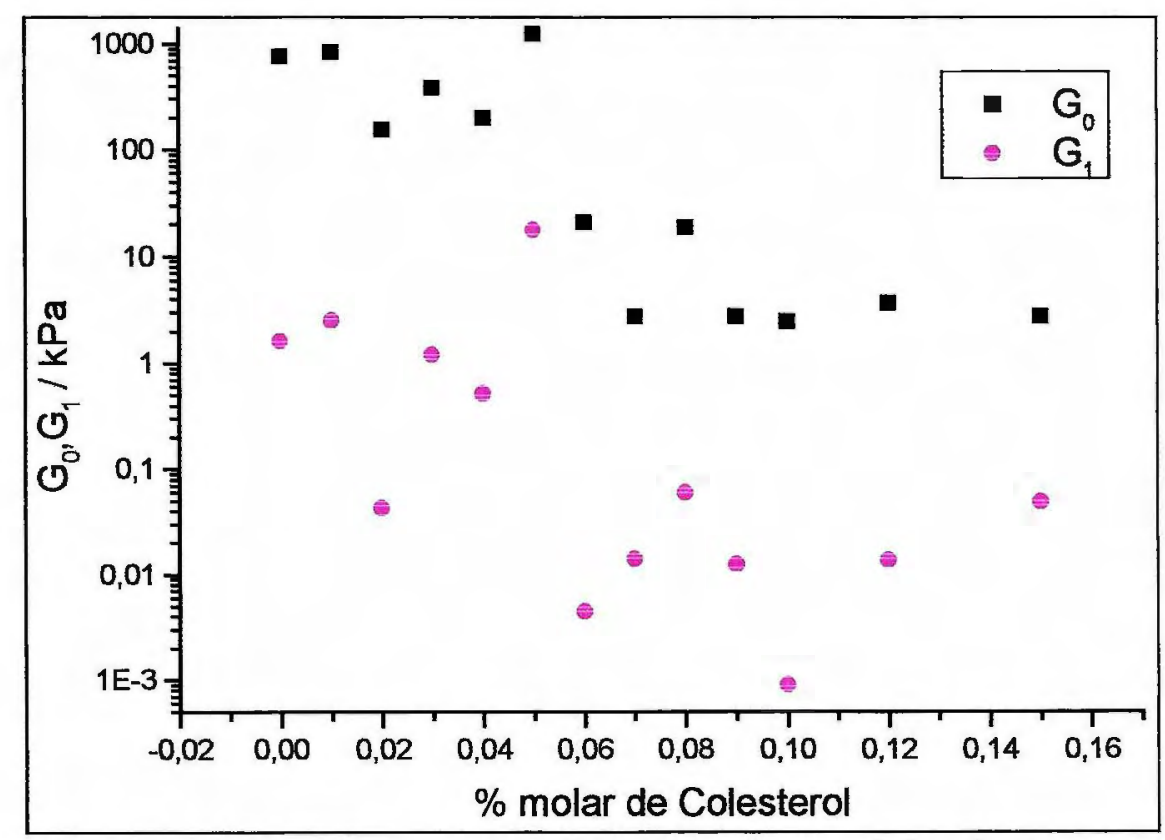

Figura V.29: Constantes elásticas do modelo de Burger para as fases $C D A-87$ a $C D A-99$ 


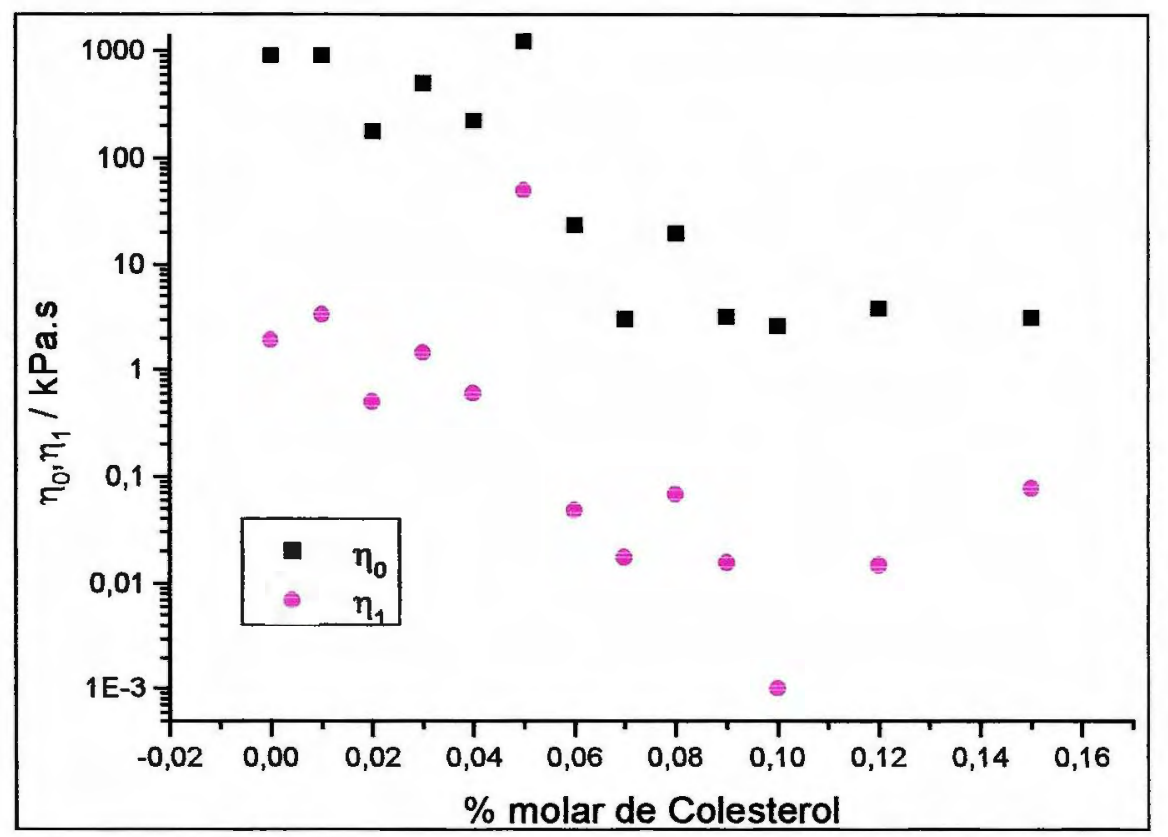

Figura V.30: Constantes viscosas do modelo de Burger para as fases $C D A-87$ a $C D A-99$.

Os mesmos resultados obtidos para os sistemas com colesterol como indutor e menor relação hidrofilico/hidrofóbico (CDA-87 a CDA-99) também apresentaram valores maiores para as constantes de Maxwell $\left(G_{0}\right.$ e $\left.\eta_{0}\right)$ do que para as constantes de Kelvin-Voigt $\left(\mathrm{G}_{1}\right.$ e $\left.\eta_{1}\right)$ (Figuras V.29 e V.30), porém, mostraram uma nítida tendência em função da concentração de indutor.

As fases com indutor D-(+)-Manose (CDA-74 a CDA-86) e maior relação hidrofilico/hidrofóbico também apresentaram valores maiores para as constantes de Maxwell $\left(\mathrm{G}_{0}\right.$ e $\left.\eta_{0}\right)$ do que para as constantes de Kelvin-Voigt $\left(G_{1}\right.$ e $\left.\eta_{1}\right)$ (Figuras V.31 e V.32), ou seja, as fases apresentam um comportamento mais semelhante ao de um fluido viscoelástico do que de um sólido viscoelástico. Novamente é possível se observar uma dependência com a concentração de indutor, isto é, os valores das constantes elásticas e viscosas diminuem com o aumento da concentração de D-(+)-Manose. 


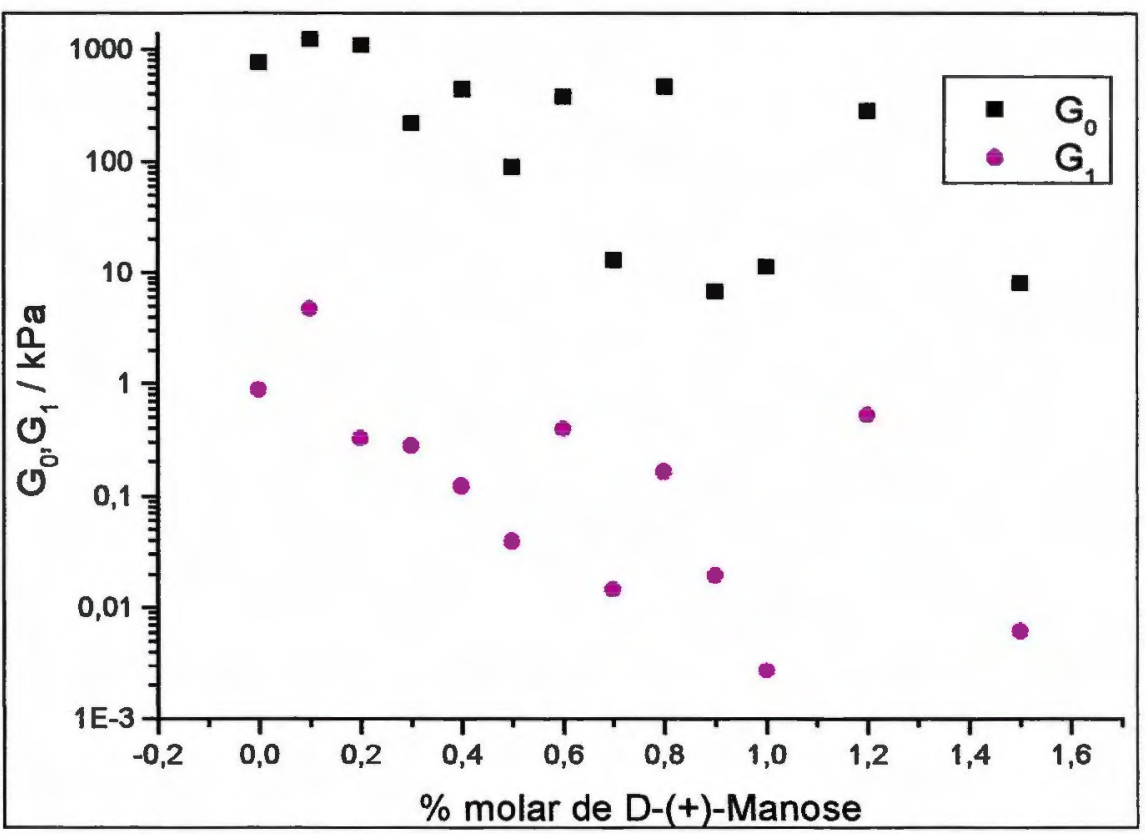

Figura V.31: Constantes elásticas do modelo de Burger para as fases $C D A-74$ a $C D A-86$.

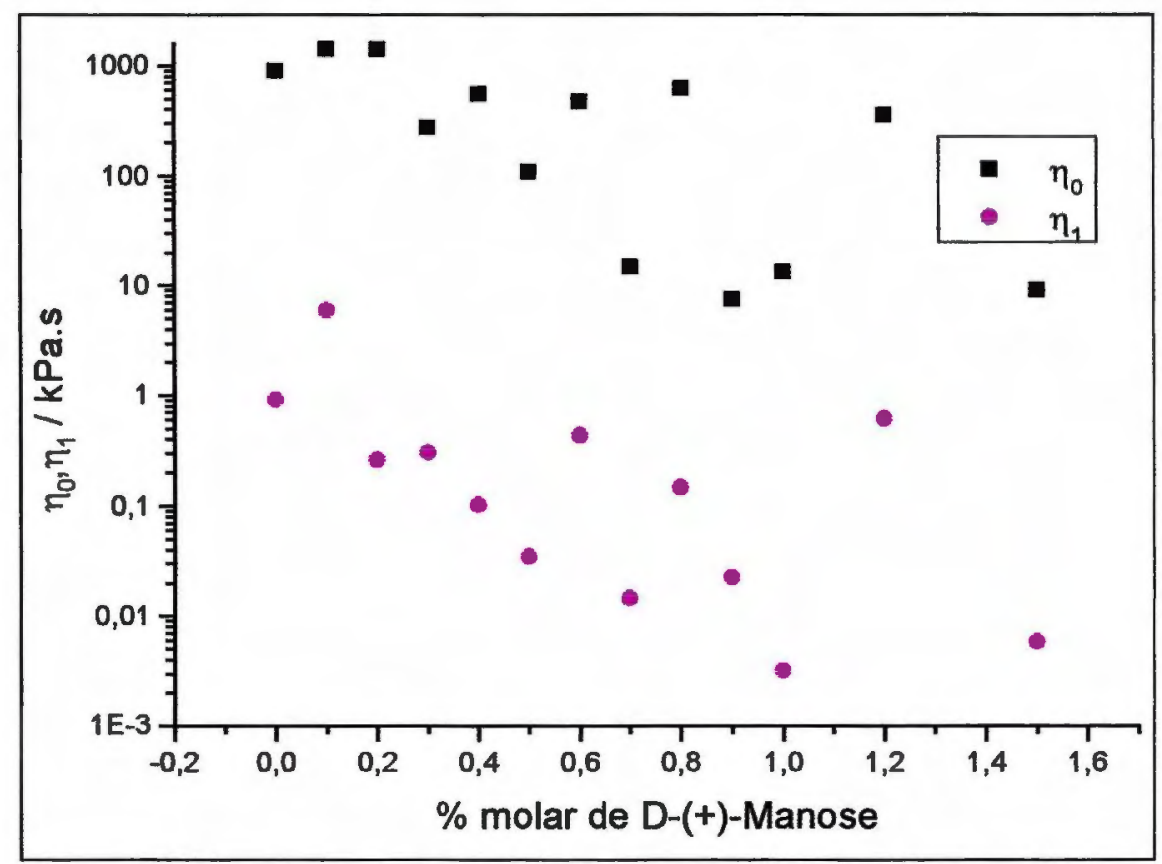

Figura V.32: Constantes viscosas do modelo de Burger para as fases CDA-74 a CDA-86.

BIBLIOTECA INSTITUTO DE QUIMICA 
Os resultados obtidos para as fases com D-(+)-Manose como indutor e menor relação hidrofilico/hidrofóbico (CDA-100 a CDA-112) também mostraram valores para as constantes elásticas e viscosas de Maxwell $\left(\mathrm{G}_{0}\right.$ e $\eta_{0}$ ) maiores do que paras as constantes elásticas e viscosas de Kelvin-Voigt $\left(\mathrm{G}_{1}\right.$ e $\left.\eta_{1}\right)$ respectivamente (Figuras V.33 e V.34). Observamos também que todas estas constantes praticamente não variam com o aumento da concentração de indutor.

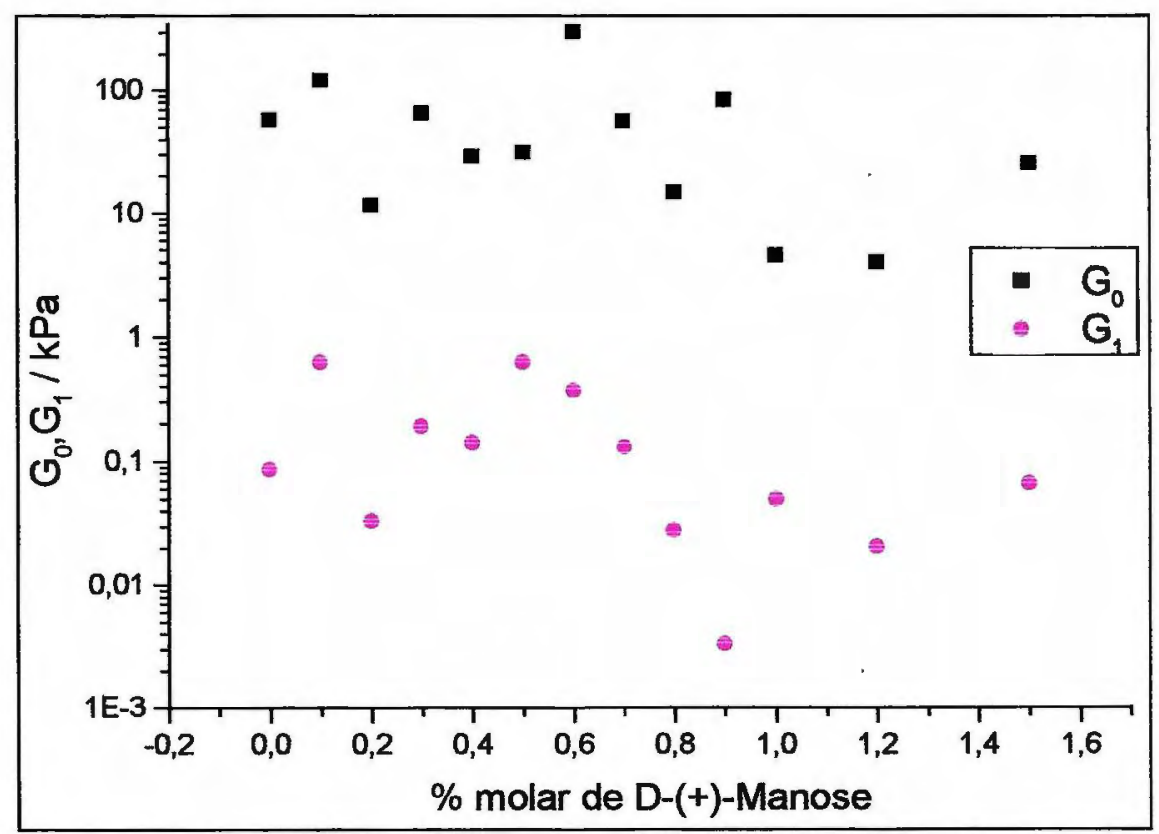

Figura V.33: Constantes elásticas do modelo de Burger para as fases CDA-100 a CDA-112. 


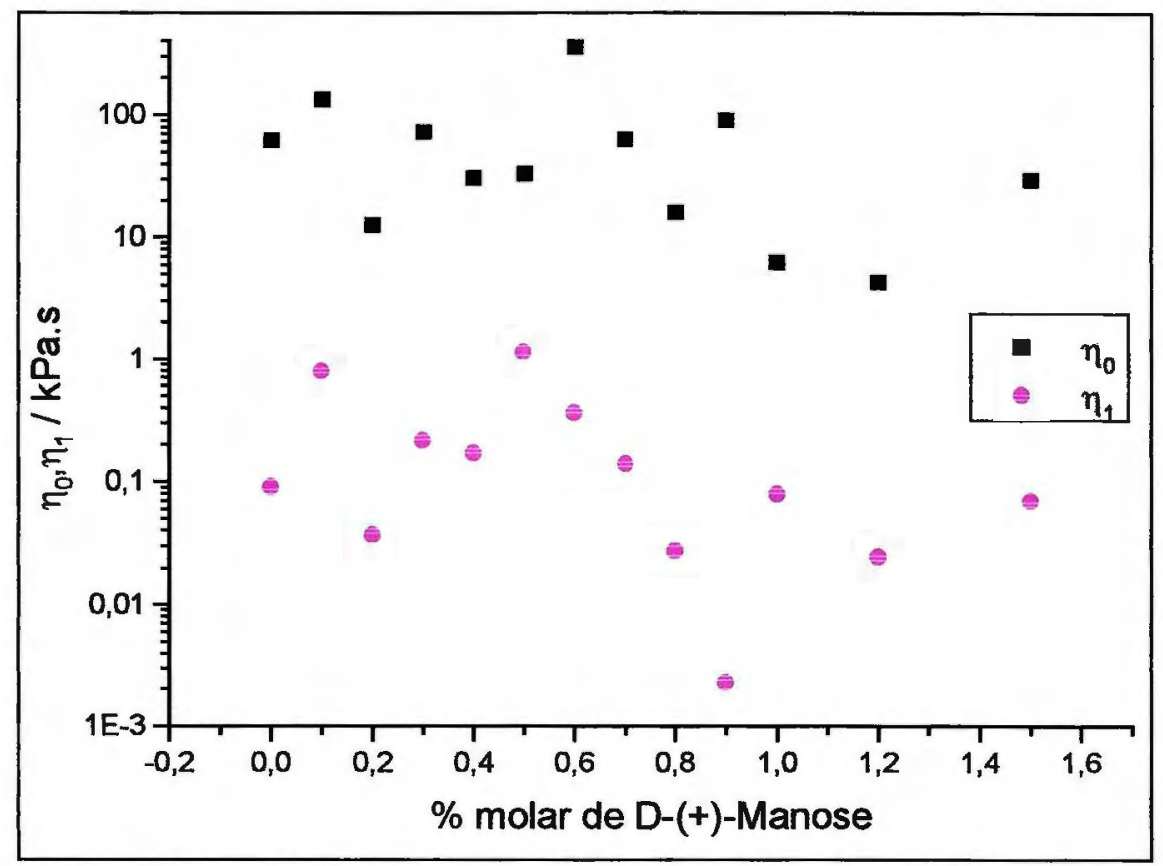

Figura V.34: Constantes viscosas do modelo de Burger para as fases CDA-100 a CDA-112.

De modo geral, pode-se notar que tanto o tipo de indutor quanto à concentração de solvente presente, devem estar influenciando nos valores das constantes obtidas, embora não se possa obter uma correlação direta sobre estes efeitos. Se analisarmos os sistemas segundo a sua quiralidade, estaríamos observando uma tendência de decréscimo destes valores, porém, os resultados obtidos para o colesterol com maior concentração de água e D-(+)-Manose com menor concentração de água não corroboram esta suposição. Do mesmo modo, se observarmos os sistemas em função do indutor utilizado, a análise também não é tão simples uma vez que com o mesmo indutor de quiralidade podemos ter ambos os comportamentos obtidos. As flutuações obtidas para todos os valores também não ajudam para se definir uma tendência de comportamento para os sistemas estudados. A partir dos resultados obtidos no presente trabalho, só podemos dizer que os fatores que influenciam os valores 
das constantes elásticas e viscosas são mais complexos do que o esperado e que muito trabalho ainda deve ser feito para se conseguir obter um perfil mais completo sobre estes sistemas.

\section{V.2.3. Determinação dos Módulos G' e G” em Função da} Freqüência.

Em todas os sistemas estudados tanto aqueles colesterizados por colesterol quanto aqueles onde se utilizou -(+)-Manose (CDA-61 a CDA-112), o perfil obtido para os módulos de armazenamento (G') e módulo de perda (G”) se mostraram semelhantes (Figura V.35). Pode-ser observar que o módulo de armazenamento é sempre superior ao módulo de perda e ambos tendem a aumentar com o aumento da freqüência de oscilação. Este comportamento indica que esses sistemas liquidocristalinos, quando em repouso, têm um comportamento mais próximo de um sólido do que de um líquido, apresentando uma tensão de escoamento limite.

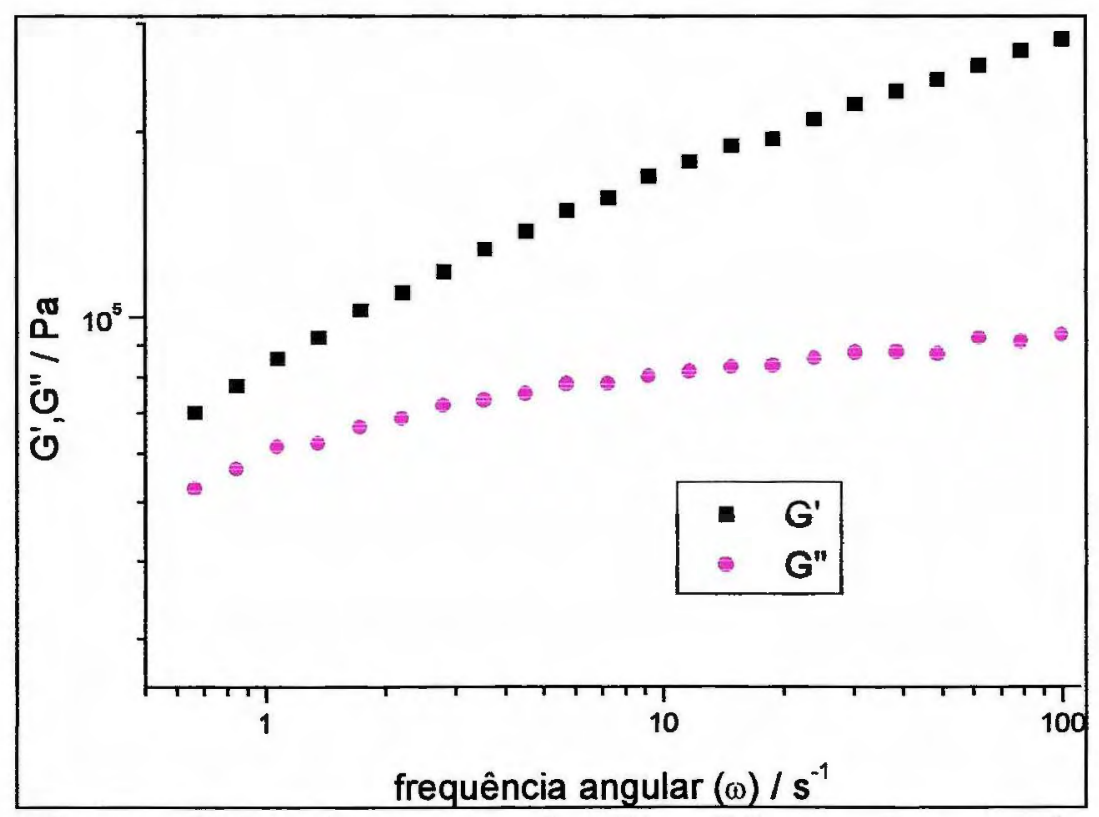

Figura V.35: Variação de G'e G" em função da freqüência angular para a amostra $C D A-73$. 
Os resultados obtidos para as fases com indutor hidrofóbico e maior relação hidrofilico/hidrofóbico mostraram que tanto $o$ módulo de armazenamento quanto o de perda tendem a aumentar com o aumento da concentração de indutor (Figuras V.36 e V.37). É interessante notar o desvio de comportamento para as fases nemáticas e com baixa concentração de indutor.

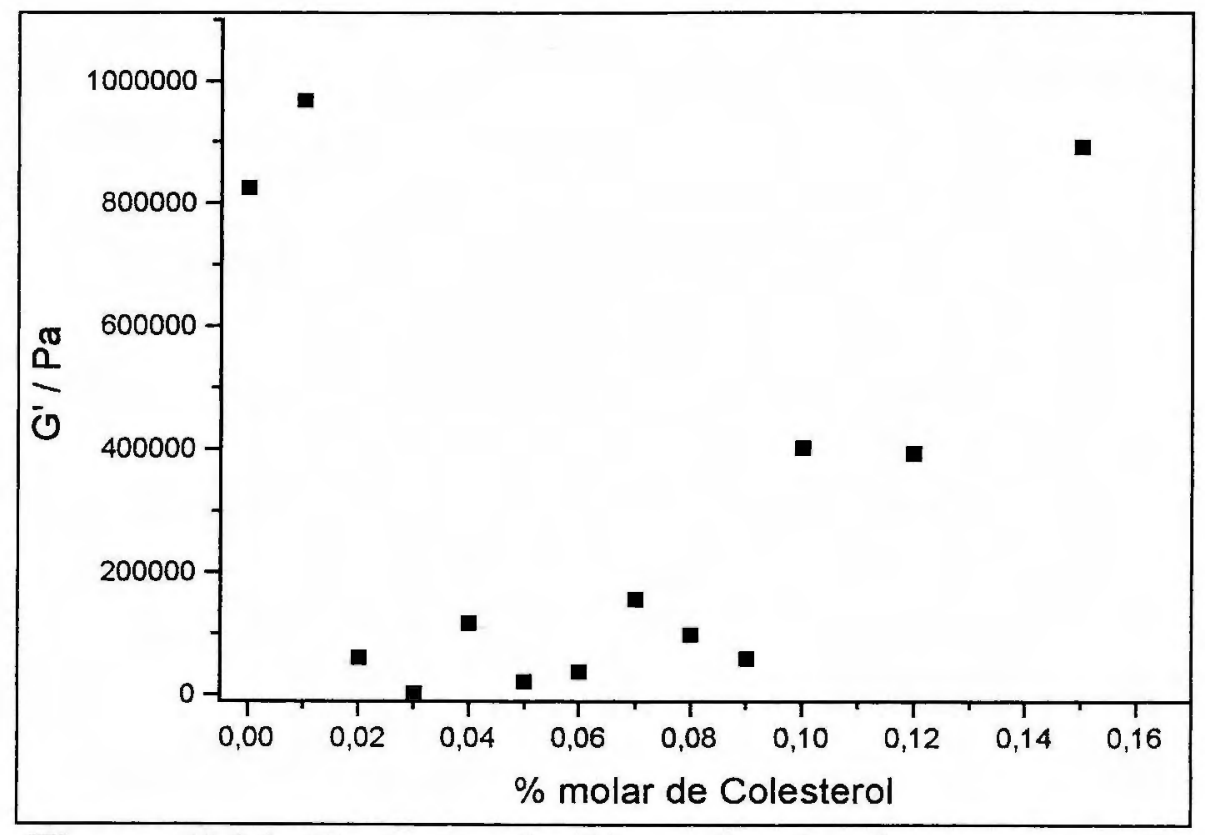

Figura V.36: Variação de $G^{\prime}$ em função da concentração de indutor para sistemas com colesterol e com maior relação hidrofillico/hidrofóbico. 


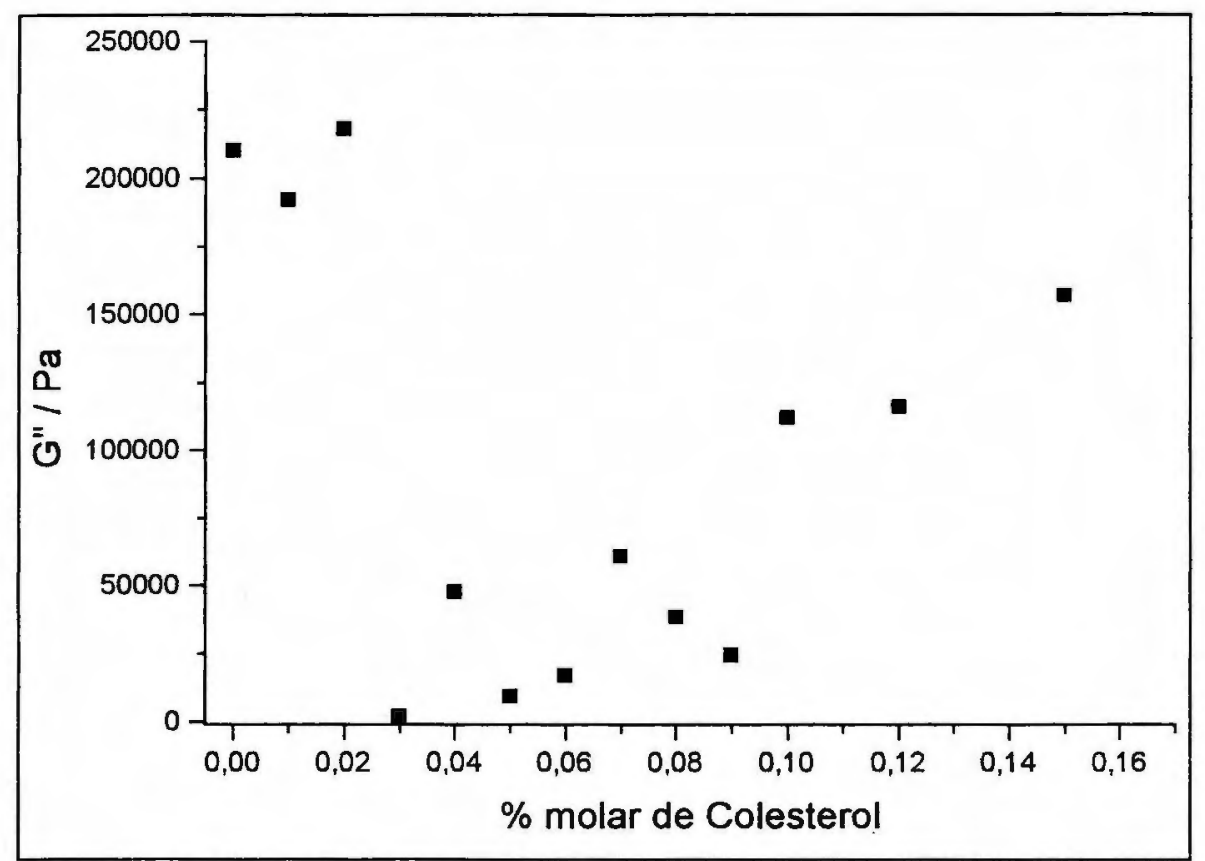

Figura V.37: Variação de G" em função da concentração de indutor para sistemas com colesterol e com maior relação hidrofilico/hidrofóbico.

Nas Figuras V.38 e V.39 estão apresentados os módulos de armazenamento (G') e de perda (G") em função da concentração de colesterol para as fases com menor relação hidrofilico/hidrofóbico (CDA-87 a CDA-99). Ao contrário dos resultados obtidos para os sistemas com maior relação hidrofilica/hidrofóbica, estas mesofases apresentam uma nítida tendência de queda dos valores de G' e G” em função do aumento da concentração de indutor. 


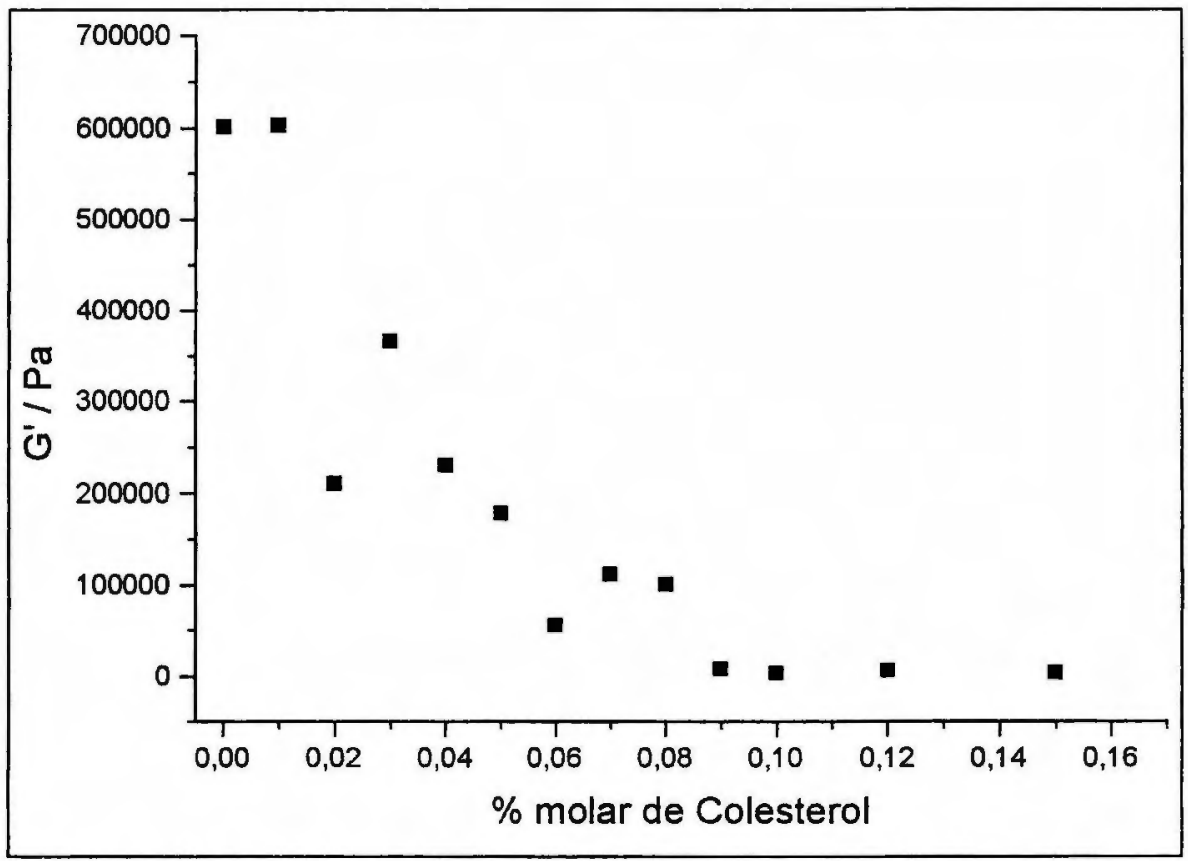

Figura V.38: Variação de G' em função da concentração de indutor para sistemas com colesterol e com menor relação hidrofilico/hidrofóbico.

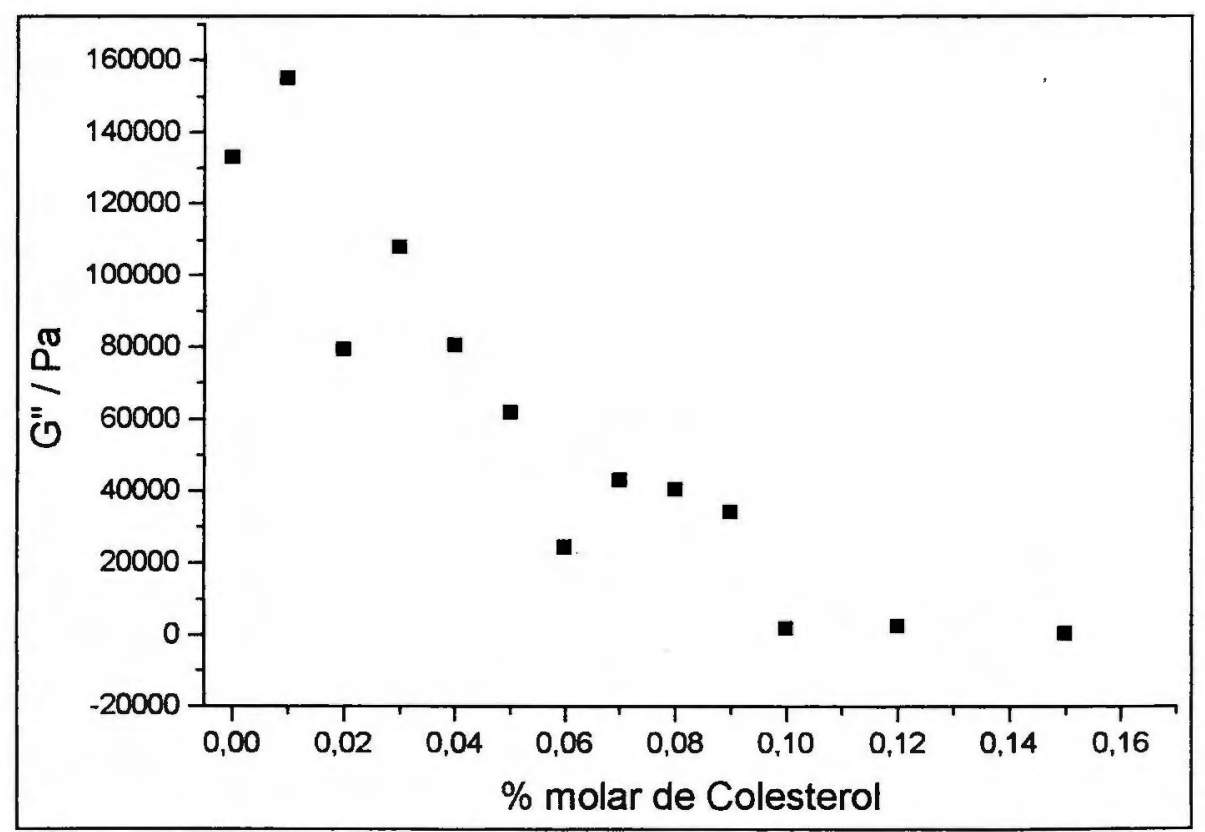

Figura V.39: Variação de G" em função da concentração de indutor para sistemas com colesterol e com menor relação hidrofilico/hidrofóbico. 
Nas Figuras V.40 e V.41 estão apresentados os módulos $\cdot$ de armazenamento $\left(G^{\prime}\right)$ e de perda $\left(G^{\prime \prime}\right)$ em função da concentração de $D-(+)-$ Manose das fases com maior relação hidrofilico/hidrofóbico (CDA-74 a CDA-86). Podemos observar uma leve tendência de queda dos valores de G' e G" em função do aumento da concentração de indutor. Esta tendência também é observada para os sistemas com menor relação hidrofilico/hidrofóbico (CDA-100 a CDA-112) (Figuras V.42 e V.43).

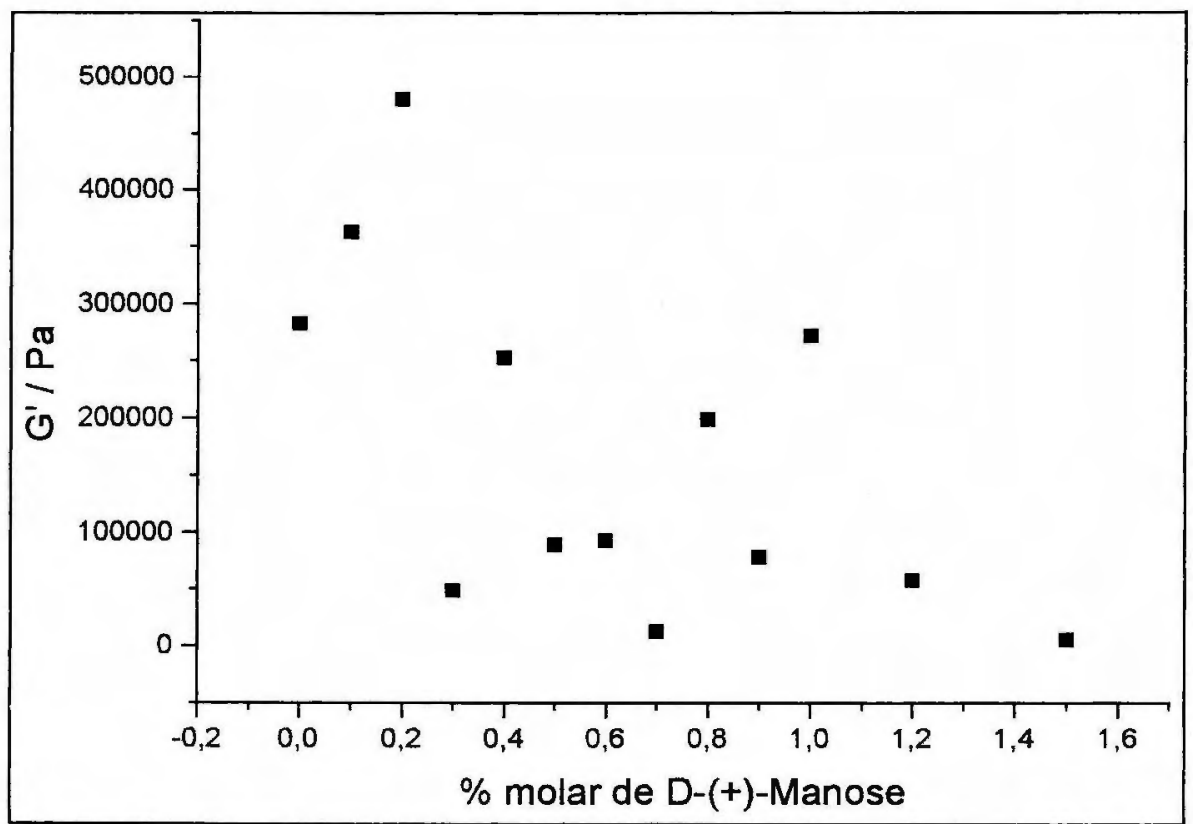

Figura V.40: Variação de G' em função da concentração de indutor para sistemas com D-(+)-Manose e com maior relação hidrofilico/hidrofóbico. 


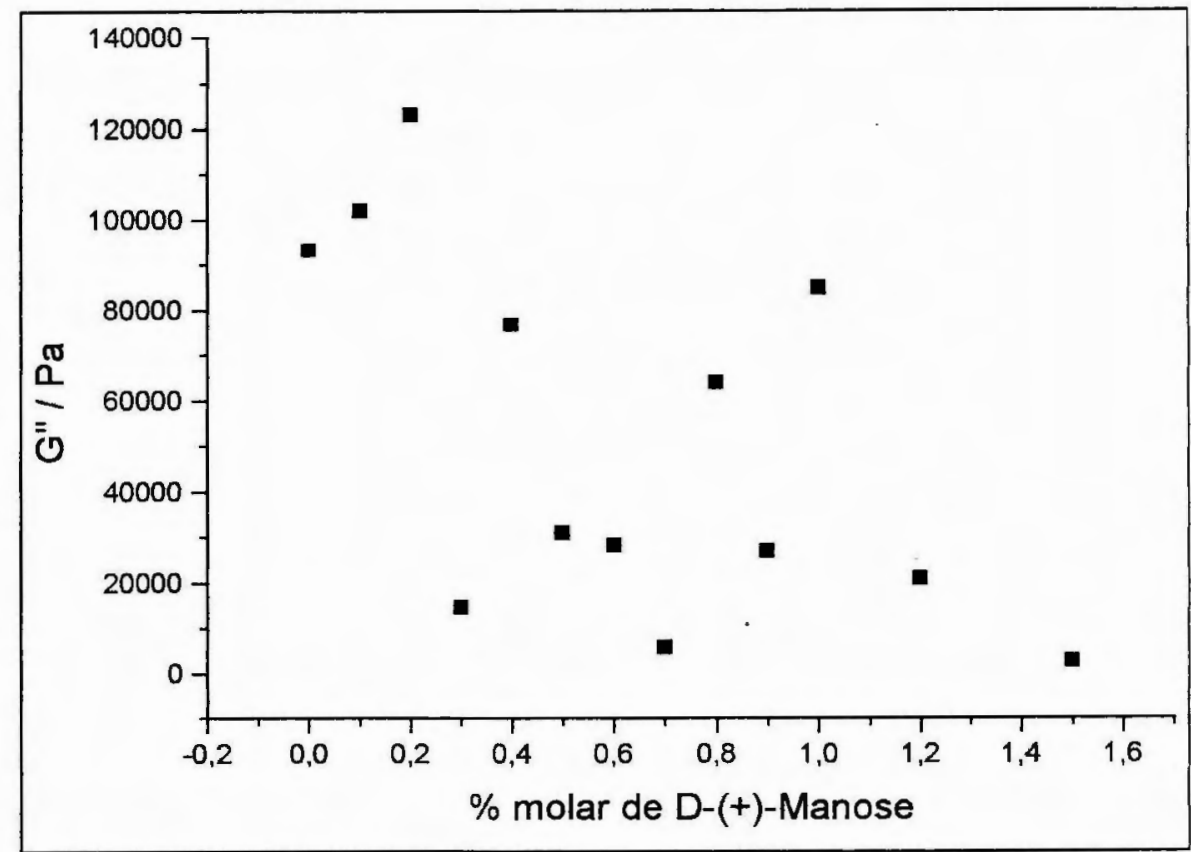

Figura V.41: Variação de G" em função da concentração de indutor para sistemas com D-(+)-Manose e com maior relação hidrofilico/hidrofóbico.

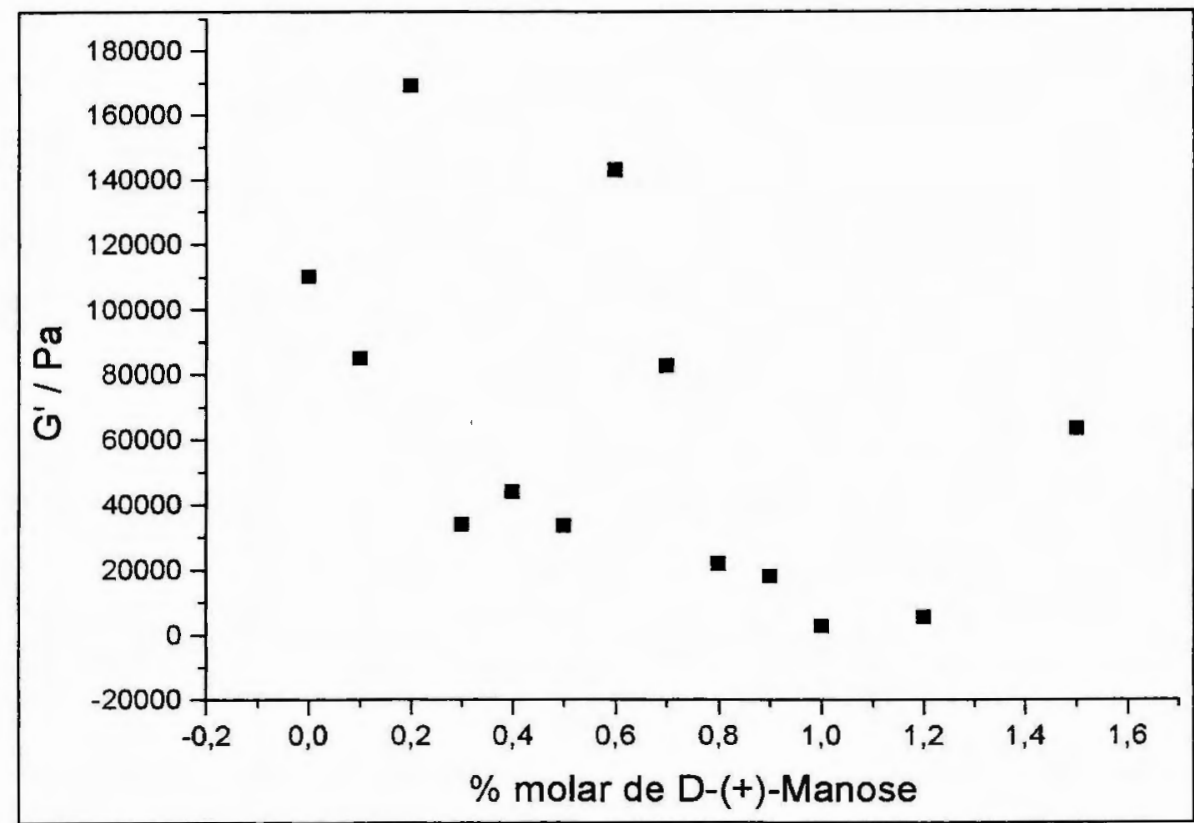

Figura V.42: Variação de $G$ ' em função da concentração de indutor para sistemas com D-(+)-Manose e com menor relação hidrofilico/hidrofóbico. 


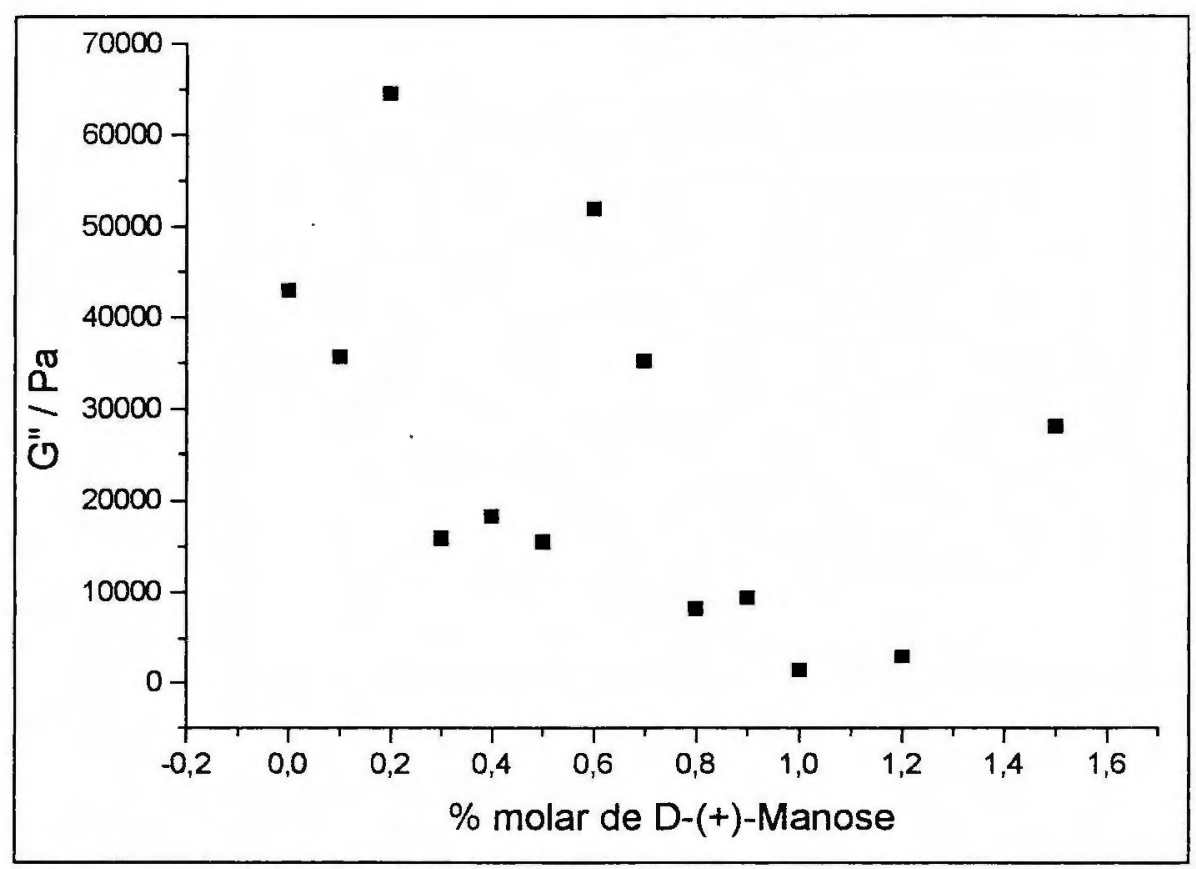

Figura V.43: Variação de $G$ " em função da concentração de indutor para sistemas com D-(+)-Manose e com menor relação hidrofilico/hidrofóbico.

Uma análise total destes resultados deve principalmente considerar três fatores fundamentais: o aumento da quiralidade do sistema obtida pelo aumento da concentração de indutor, que leva a um fortalecimento da estrutura como um todo; a variação do balanço hidrofilico/hidrofóbico de cada sistema, que por sua vez toma o sistema mais ou menos coeso e as alterações dos valores de G' e G" que estão diretamente relacionadas com o valor do módulo complexo $\left(\mathrm{G}^{*}\right)$, principal constante elástica do material.

Novamente os resultados experimentais obtidos não são suficientes para se determinar um comportamento definido para os sistemas estudados. De modo geral poderíamos dizer que a diminuição dos valores de $G^{\prime}$ e $G^{\prime \prime}$ conduziriam à diminuição dos valores de $G^{*}$ e conseqüentemente a diminuição do caráter elástico do sistema durante o processo de colesterização. Porém, os resultados obtidos para os sistemas colesterizados 
com colesterol e com balanço hidrofilico/hidrofóbico por volta de 15 são contrários a esta observação. Novamente as flutuações obtidas para os valores estão longe de poderem ajudar no entendimento das relações envolvidas neste processo.

Finalmente podemos dizer que o caminho para o completo entendimento do comportamento elástico de sistemas liquidocristalinos colestéricos, assim como os fatores que o influenciam, apenas começa a ser conhecido. Muita coisa ainda resta a ser feita até que se consiga atingir um nível de compreensão adequado para a sua completa manipulação. 


\section{Conclusão}

O estudo reológico das fases de cristal líquido liotrópico a base de cloreto de decilamônio (CDA) nos leva a concluir que nos sistemas com maior concentração de água, o comportamento reológico é newtoniano, enquanto que nos sistemas em que a concentração de água é menor, o comportamento reológico é inicialmente pseudoplástico, mudando para newtoniano após cisalhamentos sucessivos. Isto pode ser explicado por um processo de orientação por fluxo ocorrendo em três etapas: a primeira é uma quebra de estrutura formando microdomínios; a segunda, o rearranjo dos fragmentos da estrutura na direção de fluxo e a terceira etapa é a acomodação dos fragmentos formando uma nova estrutura na direção do cisalhamento.

As amostras de cristal líquido a base de CDA tende a perder ou ganhar água por cisalhamento dependendo das condições experimentais (amostras cisalhadas em ambiente seco ou saturado de água). No caso da absorção de água, é possível se observar à existência de um limite de absorção, independente da quantidade e da natureza do indutor.

Outro fato observado é que a natureza do indutor também influi no comportamento das fases. Para os sistemas com indutor hidrofóbico (colesterol) a viscosidade é menor com o aumento da concentração do indutor. Provavelmente neste caso, a interação quiral ajuda no processo de movimentação das micelas. No processo de cisalhamento, a movimentação de uma micela auxiliaria no arraste das outras devido às forças de interação do edifício colestérico, orientando o sistema como um todo, isso também é refletido pela diminuição da entalpia de ativação de fluxo.

Quando D-(+)-Manose é adicionado ao sistema, o comportamento observado é o oposto, pois devido a sua natureza hidrofilica do indutor, a 
interação com a água é maior, formando uma barreira que dificulta a movimentação das micelas, aumentando a energia de ativação de fluxo.

Os ensaios oscilatórios mostram que a capacidade de armazenamento e devolução de energia, determinada pelo valor do módulo de armazenamento $\left(G^{\prime}\right)$ é maior que a capacidade de dissipação desta por calor ou difusão das partículas, obtida pelo módulo de perda (G”). Os ensaios mostraram para os sistemas de menor balanço hidrofilico/hidrofóbico, a diminuição dos módulos com o aumento da concentração de indutor.

Os ensaios oscilatórios também mostram que nos sistemas em que a relação hidrofilico/hidrofóbico é maior, há um aumento nos valores dos módulos. A existência de uma maior concentração de solvente, provocaria uma deformação do sistema em vez de sua quebra, porém isso só é observado para as fases indutor hidrofóbico. Para as fases com indutor hidrofilico foi observado uma queda do valores de módulos. Este comportamento talvez possa ser explicado pela localização do indutor fora da micela, pois a água se "ligaria" no açúcar através de interações por ponte de hidrogênio, o que diminuiria a quantidade de água disponível para auxiliar na deformação da estrutura colestérica, impedindo a sua quebra. Com isso a tensão aplicada tenderia também a diminuir.

O sistema liotrópico estudado pode ser descrito por um modelo de Burger modificado, no qual a componente elástica do elemento de Maxwell apresenta uma dependência temporal, provavelmente devido à inércia do sistema.

As constantes referentes aos elementos de Maxwell são maiores do que as constantes dos elementos de Kelvin-Voigt, o que torna o sistema mais semelhante a um fluido com característica do modelo maxwelliano. Todas elas também apresentam uma dependência da quantidade de água disponível e da concentração de indutor, ou seja, para as fases com maior quantidade de água 
disponivel as constantes tendem a não variar com adição do indutor. Para as fases em que a quantidade de água disponível é menor as constantes tendem a diminuir com relação à adição de indutor. 


\section{Bibliografia}

Aido, T.M.H., tese de doutorado, IQUSP, 1991.

Alcantara, M.R., Dissertação de Mestrado, IQUSP, 1982.

Alcantara, M.R., Tese de Doutorado, IQUSP, 1988.

Andrade, E.N.da C., Phil. Mag., 17, 497, 1934.

Arrhenius, S., Meddel. Velenskapsakad. Nobelinst, 3, 20, 1916.

Acimis, M. Reevers, L.W., Can. J. Chem., 58, 1533, 1980.

Alcantara, M.R., Dias, L.C.F., Colloids Surf. A, 136, 155-158, 1998.

Alcantara, M.R., Fernandes Jr., E.G., Colloids Surf. A, 177, 75, 2001.

Alcantara, M.R., Moura, A.F., Colloids Surf. A, 175, 303, 2000.

Alcantara, M.R., Moura, A.F., Fernandes Jr., E.G., Liq. Cryst., 2, 191, 2002.

Alcantara, M.R., Vanin, J.A., Colloids Surf. A, 97, 151, 1995.

Alcantara, M.R., Vanin, J.A., Mol. Cryst. Liq. Cryst., 107, 333 (1984a).

Alcantara, M.R., Vanin, J.A., Mol. Cryst. Liq. Cryst. Lett., 102, 2 (1984b).

Akutagawa, T., Matsunaga, Y., Yashahura, K., Liq. Cryst., 17, 659, 1994.

Asada, T., Muramatsu, H., Watanabe, R., Onogi, S., Macromolecules, 13, $867,1980$.

Aido, T.M.H., Alcantara, M.R., Felippe Jr., O., Pereira, A.M.G., Vanin, J.A., Mol. Cryst. Liq. Cryst., 185, 61 (1990).

Aido, T.M.H., Alcantara, M.R., Felippe Jr., O., Pereira, A.M.G., Vanin, J.A., Mol. Cryst. Liq. Cryst., 195, 45 (1991).

Aphonin, O.A., Panina, Yu.V., Pravdin, A.B., Yakovlev, D.A., Liq. Cryst., $15,395,1993$.

Blinc, R., Ber. Bunsenges Phys. Chem., 87, 271, 1983.

Bird, R.B., Stuart, W.E., Transport Phenomena, Ed. John Wiley \& Sons, 
New York, 1960.

Bretas, R.E.S., D’Ávila, M.A., Reologia de Polímeros Fundidos, Editora UFSCar, 2000.

Barnes, H.A., Hutton, J.F., Walters, K., An Introduction to Rheology, vol. 3, Elsevier Science Publishers, 1993.

Berjano, M., Guerrero, A, Muñoz, J., Gallegos, C., Coll. Polym., Sci., 271, 600-606, 1993.

Chandrasekhar, S., Liquid Crystals, $2^{\text {nd }}$ Ed., Cambridge University Press, 1994.

Cano, R., Chatelain, P., C.R. hebd. Séances Acad. Sci., 251, 1139, 1960.

Cano, R., Chatelain, P., C.R. hebd. Séances Acad. Sci., 253, 1815, 1961.

Cano, R., Chatelain, P., C.R. hebd. Séances Acad. Sci., 259, 352, 1964.

Chandrasekhar, S., Ranganath, G.S., Rep. Prog. Phys., 53, 59, 1990.

Chen, S.B., Koch, D.L., J. Non-Newtonian Fluid Mech., 69, 273, 1997.

Clark, N.A., Largewall, S.T., Appl. Phys. Lett., 31, 899, 1980.

Chandrasekhar, S., Sadashiva, B.K., Suresh, K.A., Pramana, 9, 471, 1977.

Charvolin, J., Levelut, A.M., Samulski, E.T., J. Phisique Lett., 40, L-587, 1979.

Chénard, Y., Paiement, N., Zhao, Y., Liq. Cryst., 27, 459, 2000.

Craighead, H.G., Cheng, J., Hackwood, S., Appl. Phys. Lett., 40, 22, 1982.

Chidichimo, G., Arabia, G., Golemme, A., Doane, J.W., Liquid Crystals, 5, $1443,1989$.

Chandani, A.D.L., Gorecka, E., Ouchi, Y., Takezoe, H., Fukuda, A., Jpn. J. Appl. Phys., 28, L1265, 1989.

Drzaic, P.S., J. Appl. Phys., 60, 2142, 1986.

DeGennes, P.G., Prost, J., "The Physics of Liquid Crystals", $2^{\text {nd }}$ Edition, Oxford University Press, Claredon, 1993. 
Diehl, P., Tracey, A.S., FEBS. Lett., 59, 131, 1975.

Doane, J.W., Golemme, A., West, J.L. Whitehead, J.B., Wu, B.-G, Mol. Cryst. Liq. Cryst., 165, 511, 1988.

Destrade, C., Tinh, N.H., Gasparoux, H., Malthete, J., Levelut, A. M., Molec. Crystals Liq. Crystals, 71, 111, 1981.

Doane, J.W., Vaz, N.A., Wu, B.-G., Zumer, S., Appl. Phys. Lett., 48, 269, 1986.

Ericksen, J.L., Appl. Mech Ver., 20, 1029 (1968).

Elliot, A., Ambrose, A.J., Disc. Far. Soc., 9, 246, 1950.

Friedel, G., Ann. Phys., 18, 273, 1922.

Friedel, G., Colloid Chemistry, vol.1, Alexander, J., Ed., The Chemical Catalog Co. Inc., N. York, 1926.

Forrest, B.J., Reeves, L.W., Chem. Rev., 81, 1, 1981.

Franco, J.M., Muñoz, J., Gallegos, C., Langmuir, 11, 669-673, 1995.

Guzmán, J., Anales Soc. Españ. Fis. Quim., 11, 353, 1913.

Glasstone, S., Laider, K.J., Eyring, H., Theory of Rate Process, Ed. McGraw-Hill., New York, 1941.

Gallegos, C., Nieto, M., Nieto, C., Muñoz, J., Progr Colloid Polym Sci., 84, 236-240, 1991.

Han, W.H., Rey, A.D., Phys., Rev. E., 49, 597, 1994, a.

Han, W.H., Rey, A.D., Phys., Rev. E., 50, 1688, 1994, b.

Hunter, R.J., "Introduction to Modern Colloid Science", Oxford University. Oxford, 1993.

Hendrikx, Y., Charvolin, J., J. Phisique, 42, 1427, 1981

Heppke, G., Parghi, D.D., Sawade, H., Liq. Cryst., 27, 313, 2000.

Hantzschel, D., Schulte, J., Enders, S., Quitzsch, K., PCCP Physical Chemistry Chemical Physics, 5, 895-904, 1999. 
Israelachvilli, J.N., Intermolecular and Surface Forces, $2^{\text {nd }}$ Ed., Academic Press, London, 1992.

Kentischer, F., Rainer, M., Warnick, P., Heppke, G., Liq. Cryst., 25, 341, 1998.

Kern, F., Lequeux, F., Zana, R., Candau, S.J., Langmuir, 10, 1714-1723, 1994.

Kruk, G., Kocot, A., Wrzalik, R., Vij, J.K., Karthaus, O., Ringsdorf, H., Liq. Crystals, 14, 807, 1993.

Laschevsky, A., Angew. Chem. Int. Ed. Engl. Adv. Mater., 28, 1574, 1989.

Leslie, F.M., Proc. R. Soc. London, Ser. A, 307, 359 (1968).

Leslie, F.M., Adv. Liq. Cryst., 4, 1 (1979).

Leong, Y.K., Boger, D.V., J. Coll. Int. Sci., 136, 249 (1990).

Lyou, D.J., Kim, S.C., Polymer Journal, 3, 279-285, 1997.

Laüger, J., Weigel, R., Berger, K., Hiltrop, K., Richtering, W., J. Colloid Interface Sci., 181, 521-529, 1996.

Linemann, R., Läuger, J., Schmidt, G., Kratzat, K., Richtering, W., Rheological Acta, 5, 440-449, 1995.

Link, D.R., Natale, G., Shao, R., Maclennan, J.E., Clark, N.A., Körblova, E., Walba, D.M., Science, 278, 1924, 1997.

Macosko, C.W., Rheology - Principles, Measurements, and Applications, VCH Publishers Inc., 1994.

Markovitz, H., Physics Today, 21, 23, 1968.

Matsunaga, Y., Miyamoto, S., Mol. Cryst. Liq. Cryst., 237, 311, 1993.

Maffettone, P.L., Sonnet, A.M., Vigra, E.G., J. Non-Newtonian Fluid Mech., 90, 283, 2000.

Mertesdorf, C., Ringsdorf, H., Stumpe, J., Liq.Cryst., 9, 337, 1991.

Moltalvo, G., Rodenas, E., Valiente, M., J. Coll. Int. Sci., 2, 232-237, 1998. 
Mukherjee, B., Mazumder, S., Calderer, M.C., J. Non-Newtonian Fluid Mech., 99, 37, 2001.

Meyer, R.B., Liebert, L., Strzelecki, L., Keller, P., J. Phys. Lett., 36, L69, 1975.

Markovitsi, D., Lecuyer, I., Clergeot, B., Jallabert, C., Strzelecka, Verber, M., Liq. Cryst., 6, 83, 1989.

Nettesheim, F., Zipfel, J., Lindner, P., Richtering, W., Colloids Surf. A, $183,563,2001$.

Németh, Zs., Halász, L., Pálinkás, J., Bóta, A., Horányi, T., Colloids Surf. A, 145, 107-119, 1998.

Niori, T., Sekine, T., Watanabe, J., Furukawa, T., Takezoe, H., J. Mater. Chem., 6, 1231, 1996.

Ohta, K., Ema, H., Yamamoto, I., Matsuzaki, K., Liq. Cryst., 3, 1671, 1988.

Ohta, K., Hasebe, H., Ema, H., Fujimoto, T., Yamamoto, I., J. Chem. Soc. Chem. Commun., p. 1610, 1989.

Ohta, K., Takenaka, O., Hasebe, H., Morizumi, Y., Fujimoto, T., Yamamoto, I., Mol. Cryst. Liq. Cryst., 195, 123, 1991 a.

Ohta, K., Watanabe, H., Hasebe, H., Morizumi, Y., Fujimoto, T., Yamamoto, I., Mol. Cryst. Liq. Cryst., 196, 13, 1991 b.

Paoli, V.R., Tese de Doutorado, IQUSP, 1981.

Patakali, R., Dékány, I., Colloids Surf. A, 183, 715, 2001.

Peuvrel, E., Navard, P., Liq. Cryst., 7, 95, 1990.

Porter, R.S., Barral, E.M., Johnson, J.F., J. Chem. Phys., 45, 1452, 1966.

Prevysh, V.A., Wang, S.A., Khan, Spontak, R.J., Coll. And Polymer Sci., 3, 284-287, 1997.

Penfold, J., Staples, E., Khan Lodhi, A., Tucker, I., Tiddy, G.J.T., J. Phys. Chem. B, 101, 66-72, 1994. 
Pelzl, G., Diele, S., Jákli, A., Lischka, Ch., Wirth, I., Weissflog, W., Liq. Cryst., 26, 135, 1999.

Rey, A.D., J. Chem. Phys., 104, 4343, 1996 a.

Rey, A.D., J. Non-Newtonian Fluid Mech., 64, 207, 1996 b.

Rey, A.D., J. Rheol., 44, 855, 2000.

Robinson, C., Trans. Far. Soc., 52, 571, 1956.

Robinson, C., Tetrahedron, 13, 219, 1961.

Robinson, C., Molec. Cryst., 1, 467, 1966

Radley, K., Saupe, A., Mol. Phys., 35, 1405, 1978.

Robinson, C., Ward, J.C., Nature, 180, 1183, 1957.

Radley, K.,Reeves, L.W.,Tracey, A.S., J. Phys. Chem., 80, 174, 1976.

Richetering, W., Laüger, J., Linemann, R., Langmuir, 10, 4374-4379, 1994.

Robinson, C., Ward, J.C., Beevers, R.B., Disc. Far. Soc., 25, 29, 1958.

Robinson, W.K., Kloess, P.S., Carboni, C., Coles, H.J., Liq. Cryst., 23, 309 , 1997.

Ringsdorf, H., Wustfeld, Zerta, E., Ebert, M., Wendorff, J.H., Angew. Chem. Int. Ed. Engl. Adv. Mater., 28, 914, 1989.

Scharamm, G., "A Pratical Approach to Rheology and Rheometry", Gebrueder HAAKE GmbH, Karlsruhe, 1994.

Shaw, D.J., Introduction to Colloid \& Surface Chemistry, $4^{\text {th }}$ Ed., 1997

Site 1: http://plc.cwru.edu

Site 2: www.iq.usp.br/dqf/mralcant.htm

Suzuki, M., Dissertação de Mestrado, IQUSP, 1974.

Suzuki, M., Tese de Doutorado, IQUSP, 1979.

Shikata, T., Hirata, H., Kotaka, T., Langmuir, 3, 1081-1086, 1987.

Shikata, T., Hirata, H., Kotaka, T., Langmuir, 4, 354-359, 1988.

Shikata, T., Hirata, H., Kotaka, T., Langmuir, 5, 398-405, 1989. 
Smyth, C., Kudryashov, E.D., Buckin, V., Colloids Surf. A, 183, 517, 2001.

Soltero, J.F.A., Puig, F.E., Manero, O., Langmuir, 12, 2654, 1996.

Soltero, J.F.A., Puig, J.E., Manero, O., Schulz, P.C., Langmuir, 11, 3337$3346,1995$.

Thurn, H., Löbl, M., Hoffmann, H., J. Phys. Chem., 89, 517, 1985.

Takabe, T., Hashimoto, T., Ernst, B., Navard, P., Stein, R.S., J. Chem. Phys., 92, 1386-1396, 1990.

Trukhin,, D.V., Sinyachenko, O.V., Kazakov, V.N., Lylyk, S.V., Belokon, A.M., Pison, U., Colloids Surf. B, 21, 231, 2001

Vanin, J.A., Tese de Doutorado, IQUSP, 1974.

Vries, Hl., Acta Cryst., 4, 219, 1951.

Vinogradov, G.V., Malkin, A.Ya., "Rheology of Polymers", MIR Publishers, Moscou, 1980.

Vaz, N.A., Smith, G.W., Montegomery, G.P., Mol. Cryst. Liq. Cryst., 146, $1,1987$.

Walter, L., Wagner, N., J. Rheology, 5, 1525-1547, 1994.

Weber, P., Guillon, D., Skoulios, A., Liq. Cryst., 9, 369, 1991. 